\title{
Development and Testing of a High-Pressure Downhole Pump for Jet-Assist Drilling
}

RECEIVED

AUIG 211997

OSTI

\section{Final Report \\ July 1996}

Work Performed Under Contract No.: DE-AC21-94MC31198

For

U.S. Department of Energy

Office of Fossil Energy

Federal Energy Technology Center

Morgantown Site

P.O. Box 880

Morgantown, West Virginia 26507-0880

By

FlowDril Corporation

21414 68th Avenue South

Kent, Washington 98032 


\section{DISCLAIMER}

This report was prepared as an account of work sponsored by an agency of the United States Government. Neither the United States Government nor any agency thereof, nor any of their employees, makes any warranty, express or implied, or assumes any legal liability or responsibility for the accuracy, completeness, or usefulness of any information, apparatus, product, or process disclosed, or represents that its use would not infringe privately owned rights. Reference herein to any specific commercial product, process, or service by trade name, trademark, manufacturer, or otherwise does not necessarily constitute or imply its endorsement, recommendation, or favoring by the United States Government or any agency thereof. The views and opinions of authors expressed herein do not necessarily state or reflect those of the United States Government or any agency thereof. 


\section{DISCLAIMER}

Portions of this document may be illegible electronic image products. Images are produced from the best available original document. 


\section{TABLE OF CONTENTS}

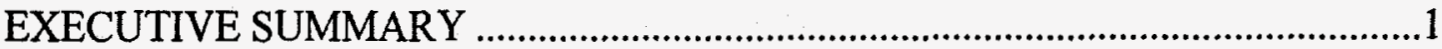

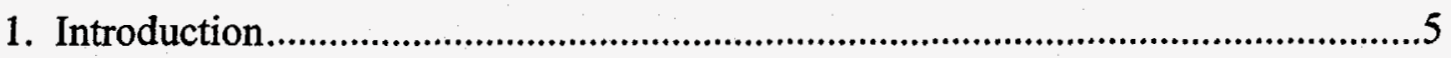

1.1 Jet-Assist Drilling Background.........................................................................

1.2 The Down Hole Pump Approach....................................................................6

1.3 Intensifier Type Pump....................................................................................

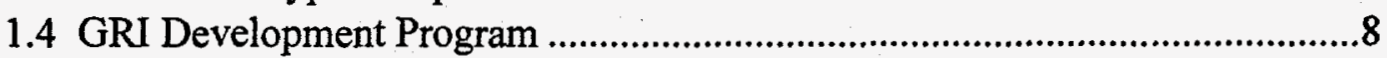

2. DHP Market Analysis Summary …………………...........................................13

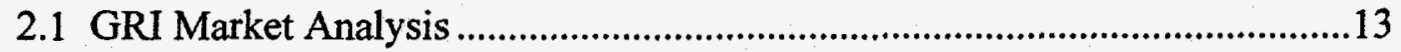

2.2 Slimhole Market Analysis....................................................................18

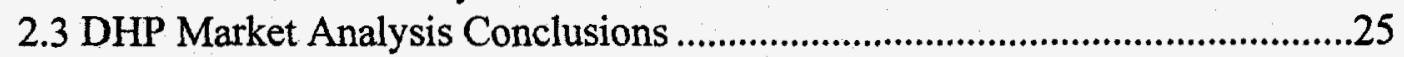

3. Specifications for Down Hole Pump ...................................................................2

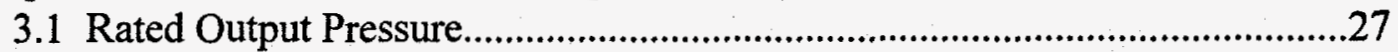

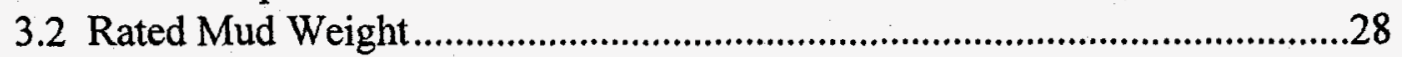

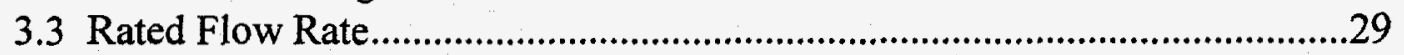

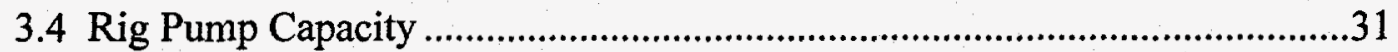

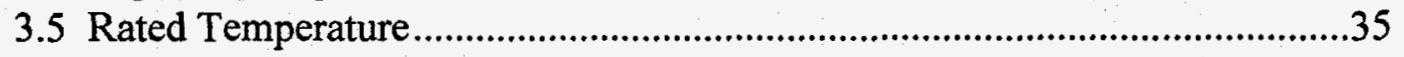

3.6 Performance and Design Specifications .........................................................36

4. DHP Design Description......................................................................................38

4.1 DOE/FlowDril DHP Basic Arrangement..................................................38

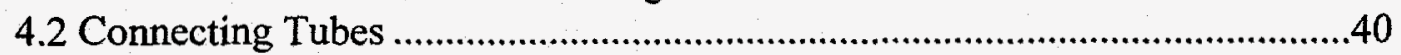

4.3 Low pressure Drive Cylinders/Pistons/Seals ......................................................41

4.4 UHP Cylinders/Plunger/Seals....................................................................42

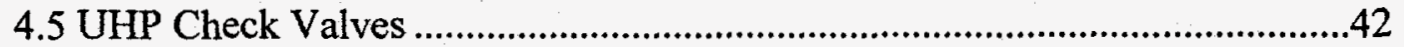

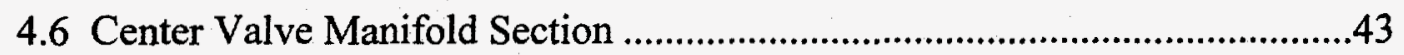

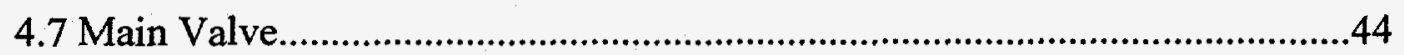

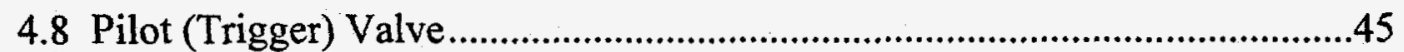

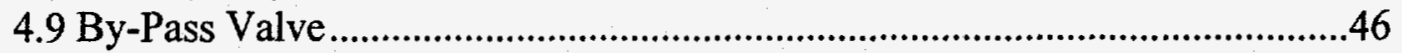

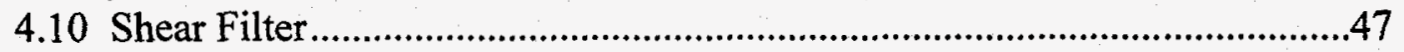

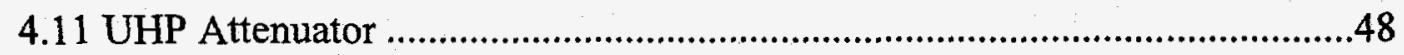

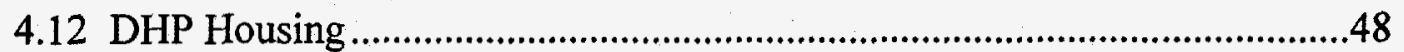

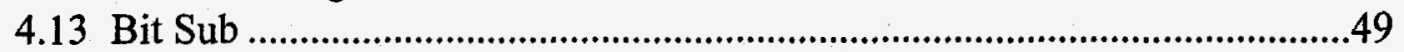

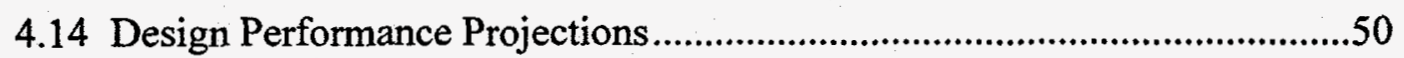

5. DHP Initial Laboratory Test ...............................................................................52

5.1 Laboratory Test Arrangement........................................................................52

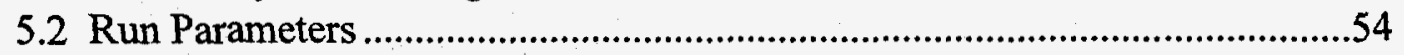

5.3 Character of Input and Output Pressures ......................................................5

5.4 Stroke Rate and UHP Output Flow Rate …...................................................

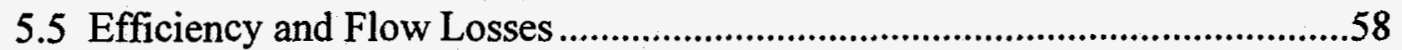

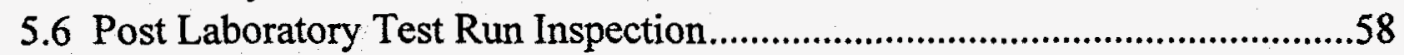

5.7 Conclusions after First Laboratory Test Run................................................60

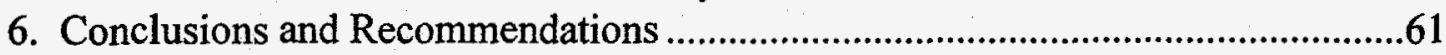

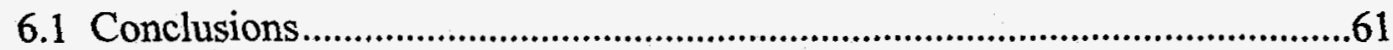

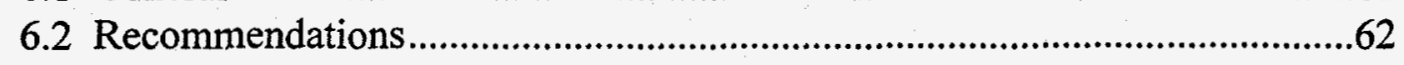




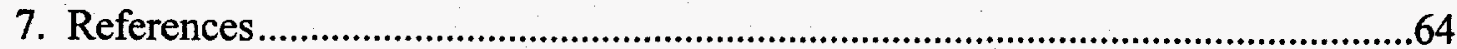




\section{LIST OF TABLES AND FIGURES}

TABLE 1. TEN REGIONS INCLUDED IN MARKET ANALYSIS......................................................14

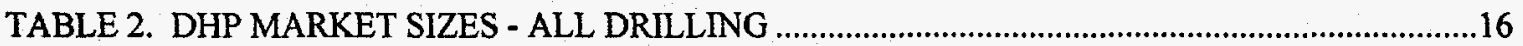

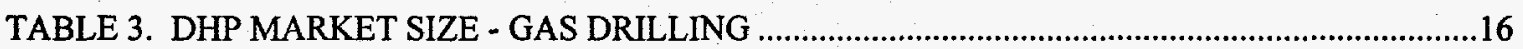

TABLE 4. INDUSTRY SAVINGS FROM DHP USE - ALL DRILLING ..............................................17

TABLE 5. INDUSTRY SAVINGS FROM DHP USE - GAS DRILLING ..............................................18

TABLE 6. MAXIMUM PROJECTED DHP MARKET SIZE (REVENUE) FOR SLIM-HOLE OPERATION.

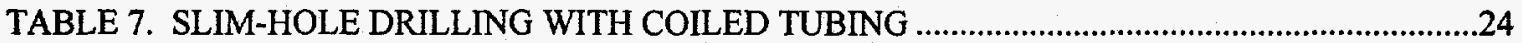

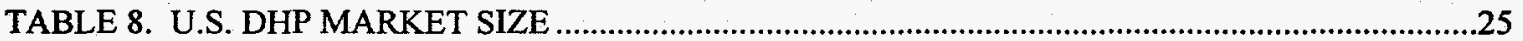

TABLE 9. MEASURED THRESHOLD PRESSURE FOR SEVERAL ROCKS .....................................28

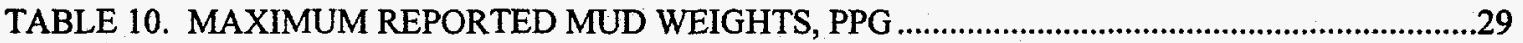

TABLE 11. DRILL RIGS WITH SUFFICIENT PUMPING HORSEPOWER TO OPERATE DHP .........33

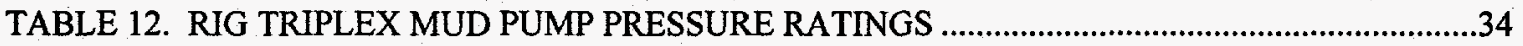

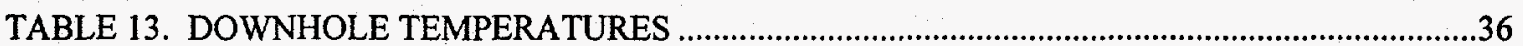

TABLE 14. DHP DESIGN POINT PERFORMANCE SPECIFICATIONS …..........................................36

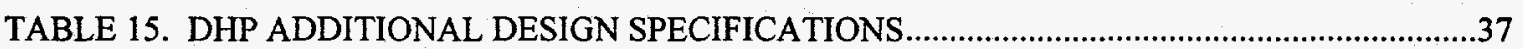

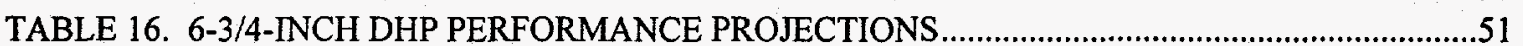

TABLE 17. LABORATORY FIRST TEST RUN PARAMETERS .......................................................54

FIGURE 1. DOWN HOLE PUMP APPROACH TO JET-ASSIST DRILLING ........................................6

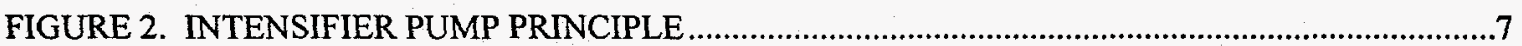

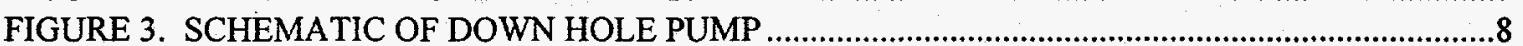

FIGURE 4. GRI 7-5/8 INCH DHP FIELD EXPERIMENT CONFIGURATION ........................................9

FIGURE 5. PHOTOGRAPH OF FIRST PROTOTYPE, 7-5/8 INCH, HIGH PRESSURE DOWN HOLE PUMP DURING FIRST FIELD EXPERIMENT UNDER GRI PROGRAM ...................................11

FIGURE 6. SMITH F2 8-3/4 INCH DRILL BIT WITH EXTENDED UHP NOZZLE USED DURING

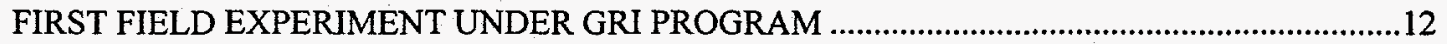

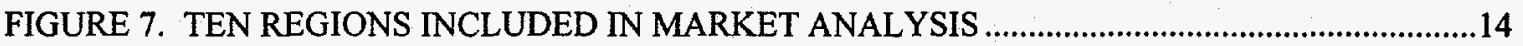

FIGURE 8. BIT HOURS BY BIT SIZE: 3-3/4"(3.6) THROUGH 6-3/4"(6.6)...........................................19

FIGURE 9. RMI PROJECTIONS OF NUMBER OF "SLIM-HOLES" DRILLED WORLD-WIDE.

FLOWDRIL'S ESTIMATE FOR NUMBER OF "SLIM-HOLES" IN US BASED ON RMI

PROJECTIONS AND BIT HOURS FROM SMITH AND HUGHES CHRISTENSEN BIT RECORD

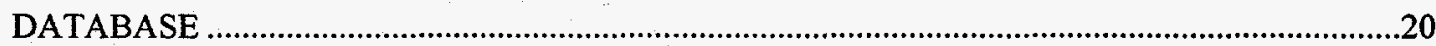

FIGURE 10. PROJECTED NUMBER OF "SLIM-HOLE" COMPLETIONS, BASED ON SHOOK, ET

AL

FIGURE 11. PROJECTIONS OF NUMBER OF HOLES DRILLED AS SLIM-HOLES ..........................22

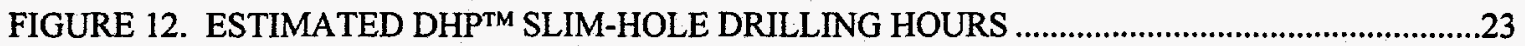

FIGURE 13. PRESSURE, HORSEPOWER VERSUS FLOW RATE RELATIONSHIP DOWNHOLE ...30

FIGURE 14. FULLERTON RELATIONSHIP FOR 7-7/8 INCH HOLE SIZE USING 4.5 INCH DRILL PIPE.

FIGURE 15. SURFACE MUD PUMP COSTS VERSUS OPERATING PRESSURE

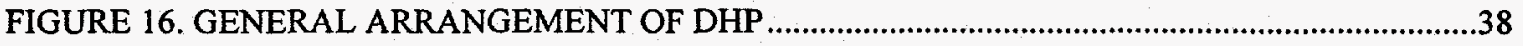

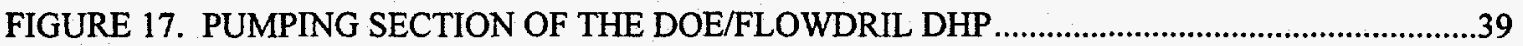

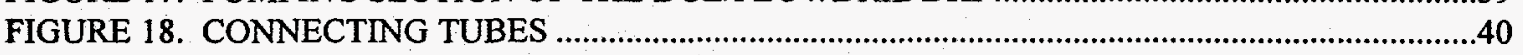

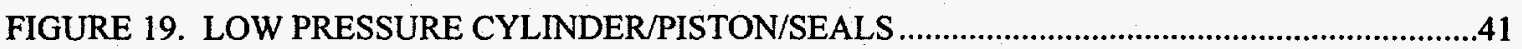

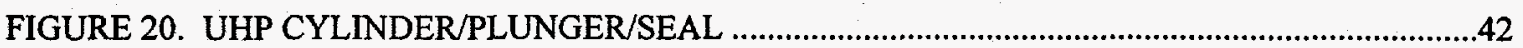

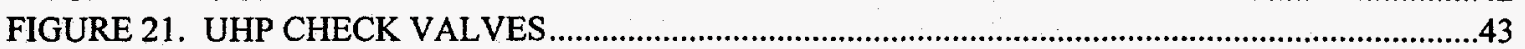

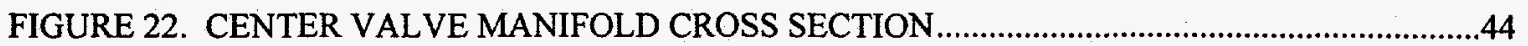

FIGURE 23. FOUR-WAY DIRECTIONAL MAIN CONTROL VALVE ……...........................................45

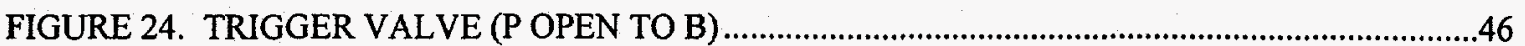

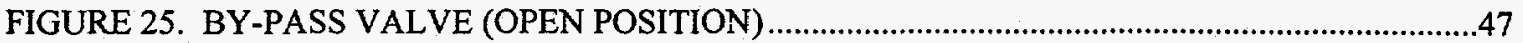


FIGURE 26. SHEAR FILTER

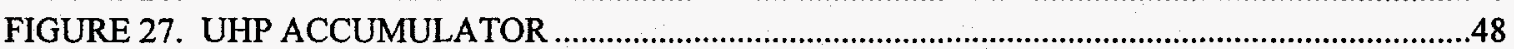

FIGURE 28. FIELD EXPERIMENT CONFIGURATION OF 6-3/4" DHP ASSEMBLY ..........................49

FIGURE 29. LABORATORY TEST ARRANGEMENT FOR TESTING DHP ........................................53

FIGURE 30. INLET LOW PRESSURE FLOW PRESSURE SIGNAL ….............................................54

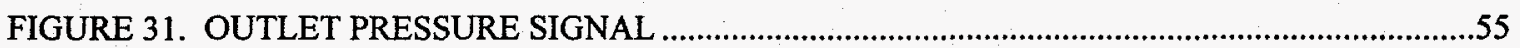

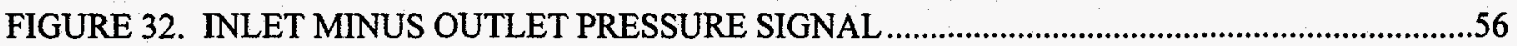

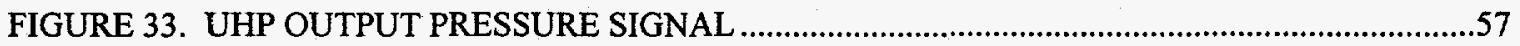




\section{EXECUTIVE SUMMARY}

The goal of jet-assist drilling is to increase the rate of penetration (ROP) in deeper gas and oil wells, where the rocks become harder and more difficult to drill. Increasing the ROP can result in fewer drilling days, and therefore, less drilling cost.

In late 1993, FlowDril and the Gas Research Institute (GRI) began a three-year development of a down hole pump (DHP ${ }^{\mathrm{TM}}$ ) capable of producing 30,000 psi out pressure to provide the high-pressure flow for high-pressure jet-assist of the drill bit. The U.S. Department of Energy (DOE) through its Morgantown, WV (DOE-Morgantown) field office, joined with GRI and FlowDril to develop and test a second prototype designed for drilling in 7-7/8 inch holes. This project, "Development and Testing of a High-Pressure Down Hole Pump for Jet-Assist Drilling," is for the development and testing of the second prototype. It was planned in two phases. Phase I included an update of a market analysis, a design, fabrication, and an initial laboratory test of the second prototype. Phase II is continued iterative laboratory and field developmental testing. This report summarizes the results of Phase I.

The project was originally proposed to extend the DHP and jet-assist drilling technology to drilling slimholes. Results of the market analysis for DHP jet-assisted slimhole drilling indicated that the slimhole market would be small (about 1/20th) compared to 7-7/8 inch hole size. The DHP market size for 7-7/8 inch hole size was estimated to be \$76.6 million annually for gas and oil drilling out of a total potential DHP market of \$207 million annually including hole size 6 inch through 12-1/4 inch. Potential oil and gas industry savings from use of the DHP for drilling are proportional to market size, and were estimated to be $\$ 63$ million annually for $7-7 / 8$ inch hole size, compared to savings of $\$ 173$ million annually across all hole sizes to which the DHP would be appropriate. The best U.S. land market locations for use of the DHP were identified as East Texas RR District 3, Oklahoma, and East Texas RR District 6. For gas drilling alone, areas with the largest market potential were East Texas RR District 6, Oklahoma and Wyoming. As a consequence of the market size for 7-7/8 inch holes, associated savings to the industry, and a desire to promote earlier commercialization of the DHP jet-assisted drilling technology, this project was re-directed from slimhole applications to development of a second prototype DHP for 7-7/8 inch hole size.

In the downhole pump approach shown in the first of the following figures, conventional drill pipe and drill collars are used, with the DHP as the last component of the bottom hole assembly next to the bit. Both the first prototype, and the second prototype described in this report, are reciprocating double ended, intensifier style positive displacement, high-pressure pumps. In the case of the down hole intensifier pump, the drive fluid and the high-pressure output fluid are both derived from the same source, the abrasive drilling mud pumped down hole through the drill string. Approximately seven percent of the stream is pressurized to $30,000 \mathrm{psi}$ and directed through a high-pressure nozzle on the drill bit to produce the high speed jet and assist the mechanical action of the 
bit to make it drill faster. The remainder of the fluid stream passes through the bit nozzles at conventional bit nozzle pressures. The DHP is about the same size as and is handled like a conventional drill collar. The power required to drive the DHP is obtained from increasing the operating pressure of the surface pumps and delivered downhole via the conventional mud stream. It is expected that surface pump pressures necessary to drive the DHP will be approximately 3,500 to 3,700 psi. Rigs, rig mud pumps, and rig equipment have sufficient capacity and capability, without any changes other than a change in pump liners to higher rated pressure, to economically operate the DHP with surface pressures in this range.

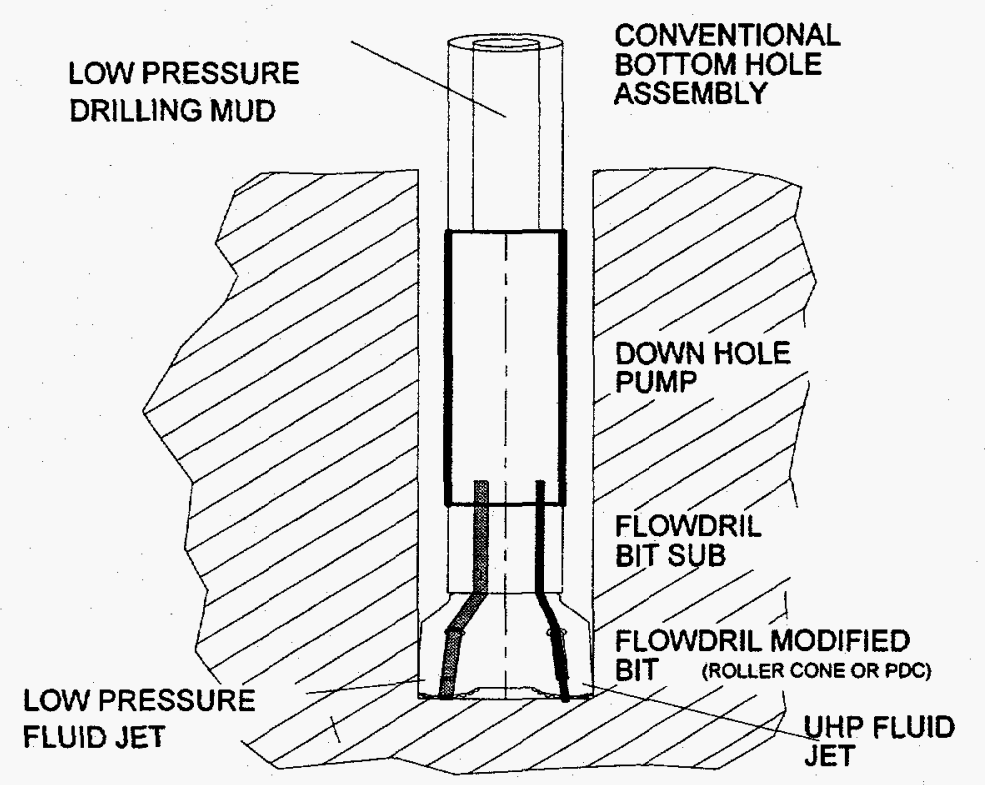

Down Hole Pump Approach to Jet-Assist Drilling

Because of space limitations within the envelope of a drill collar, the down hole intensifier employs multiple low pressure drive pistons and fluid porting through the shaft connecting the drive pistons. Other elements required for a practical down hole pump are a by-pass valve, an ultra-high pressure (UHP) accumulator and a filter on the inlet to the UHP portion of the fluid circuit. The by-pass valve allows for circulation in the hole without the DHP operating, particularly in the event the DHP stalls. The attenuator maintains UHP flow during the non pumping period at the end of stroke when the intensifier style pump shifts direction. The filter reduces the size of particles allowed through the components in the UHP portion of the fluid circuit, minimizing the opportunity for plugging and reducing wear.

The basic arrangement of the components are shown in the following figure as they occur in the 6-3/4 inch DHP design. At the lower end of the DHP, the fluid outlet end, is the bit sub (to which the drill bit is attached). In the bit sub and extending into the DHP is the UHP inner conduit (IC) that carries UHP fluid from the DHP to the drill bit. Above the 
bit sub is the pumping section of the DHP within the DHP housing. The pumping section consists of a lower and an upper end. The lower end of the pump, generally consists of the lower UHP cylinder and two lower end low pressure drive chambers. Between the lower and upper drive chambers is the center valve (manifold) section where the by-pass valve and the DHP shifting control valves (pilot valve and main valve) are located. The upper end of the pump, as does the lower end, generally consists of the two upper drive chambers and the upper UHP cylinder. Above the pumping section and still within the housing are the shear filter, the UHP accumulator (also called an attenuator, and a coarse inlet screen.

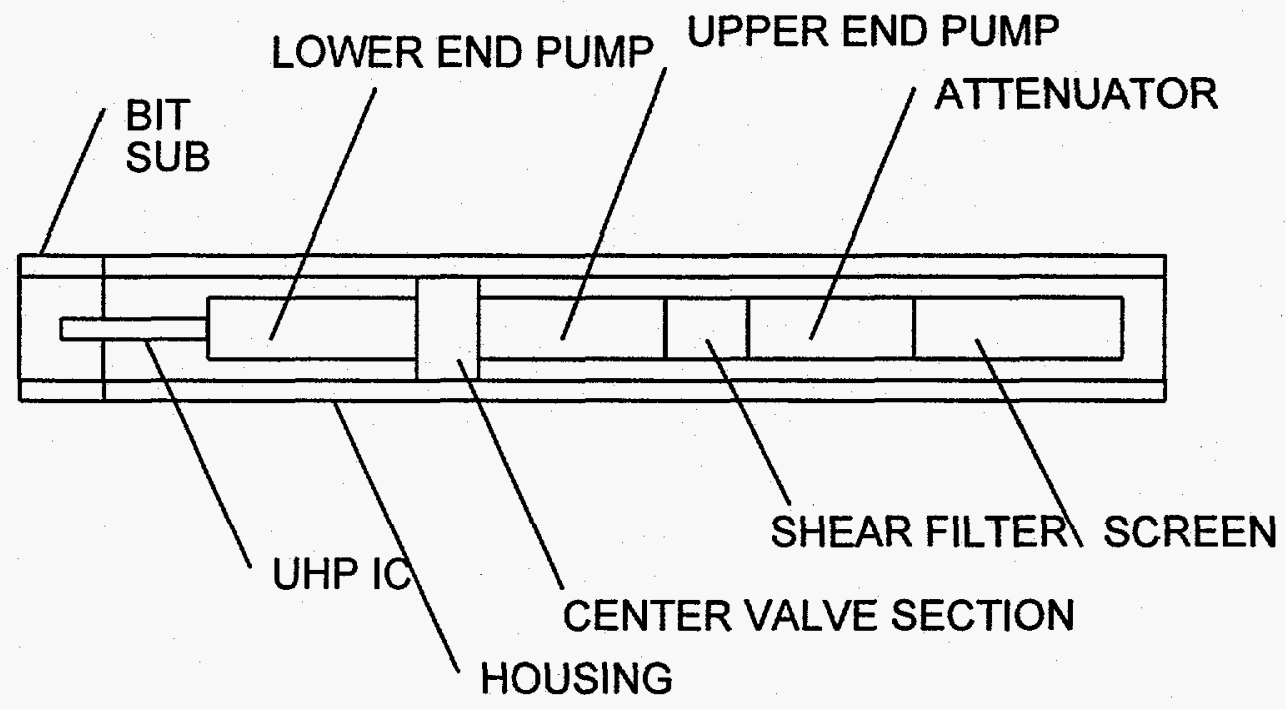

General Arrangement of DHP

Parts for the 6-3/4 inch DHP were fabricated and assembled for testing in the laboratory. The objective of the initial test was to establish that the DHP functioned, to confirm theoretical design performance and to begin to identify engineering design oversights and weaknesses. The initial test run was 12 hours after which the pump was disassembled, inspected and evaluated.

During part of the test run, pressure signals were monitored and recorded via the laboratory data acquisition system. The differential pressure signal was typical of hydraulically driven intensifier type high pressure pumps and matched the theoretically calculated differential pressure across the pump very well. The UHP output pressure was not constant, but varied over time, fluctuating between a minimum of $27,450 \mathrm{psi}$ and a maximum of $29,660 \mathrm{psi}$. The character of the recorded signal was slightly different than would be expected from the theoretical design performance calculations in that it was much smoother. 
During the design phase, the average efficiency had been estimated during the test to be 72 percent at $120 \mathrm{gpm}$ with $9.5 \mathrm{ppg}$ mud. With the pressure data obtained during the laboratory test run, an experimentally determined estimate of average DHP efficiency was calculated as 77 percent. When this estimate was adjusted to $120 \mathrm{spm}$ and $9.5 \mathrm{ppg}$ mud weight per design specifications, the efficiency was determined to be 75 percent. Consequently, flow losses through the pump were less than expected and the DHP efficiency was slightly better than originally anticipated. All measured and calculated performance parameters were within 2 to 4 percent of design performance specifications.

The design concepts appear to be valid and hold the promise of being able to achieve desired pump life with modifications in the details of the design of various components. As a result of the first laboratory test, problems with the detailed design of several components were identified and proposed actions were identified. It is anticipated that with further design and laboratory test iterations, additional design improvements required to achieve an acceptable DHP life will be identified, evaluated and addressed. Once acceptable performance and reliability is established through laboratory testing and design modification, the DHP should be tested down hole in the field. It is anticipated that four to six down hole field experiments would be required to properly evaluate the developmental status and potential of the DHP for jet-assist drilling.

It is recommended that the iterative approach of laboratory test, design modification, and field experimentation be followed. It is recommended that this project continue into Phase II - Laboratory Testing, Design Modifications, and Field Testing. 


\section{Introduction}

The goal of jet-assist drilling is to increase the rate of penetration (ROP) in deeper gas and oil wells, where the rocks become harder and more difficult to drill. Increasing the ROP can result in fewer drilling days, and therefore, less drilling cost. In late 1993, FlowDril and the Gas Research Institute (GRI) began an aggressive three-year development program of a down hole pump (DHP ${ }^{\mathrm{TM}}$ ) capable of producing $30,000 \mathrm{psi}$ out pressure. This program was based on UHP mud pumping and sealing technology previously developed by FlowDril. The U.S. Department of Energy (DOE) through its Morgantown, WV (DOE-Morgantown) field office, joined with GRI and FlowDril to develop and test a second prototype designed for drilling in 7-7/8 inch holes.

This project, "Development and Testing of a High-Pressure Down Hole Pump for JetAssist Drilling," was planned in two phases. Phase I included an update of a market analysis, a design, fabrication, and an initial laboratory test of the second prototype. Phase II is continued iterative laboratory and field developmental testing. This report summarizes the results of Phase I.

The project was originally proposed to extend the DHP and jet-assist drilling technology to drilling slimholes. Results of the market analysis for DHP jet-assisted slimhole drilling indicated that the slimhole market would be small (about 1/20th) compared to $7-7 / 8$ inch hole size, the largest market segment. As a consequence of the market size and a desire to promote earlier commercialization of the DHP jet-assisted drilling technology, this project was re-directed from slimhole applications to development of a second prototype DHP for 7-7/8 inch hole size.

\subsection{Jet-Assist Drilling Background}

In the early 1970 s the potential advantages of applying high-pressure $(15,000 \mathrm{psi})$ jet technology to increase rates of penetration (ROP) were demonstrated by Maurer et al (1973) and by Fair (1981). They were able to demonstrate ROP enhancements between 1.2 and 2.9 times conventional rates in tests conducted in Florida and Texas. Both Maurer and Fair required that the entire fluid stream be pressurized. This resulted in extremely high power requirements (2,800 and 11,200 hydraulic horsepower), reliability problems, and safety concerns.

During the late 1980 s and early 1990 s, FlowDril ${ }^{\circledR}$ developed a system for ultra-high pressure, 34,000 psi, jet-assist drilling. The system was described by Butler, et al (1990), by Cure and Fontana (1991) and by Veenhuizen et al (1993). About $40 \mathrm{gpm}$ of the down hole mud stream was pressurized with pumps at the surface, 600 hydraulic horsepower, and conducted to the drill bit through a special dual-conduit drill string. This allowed a high-velocity jet of drilling mud at the bit to be directed at the bottom of the hole to assist the mechanical action of the bit. The system required separate high pressure surface piping, standpipe, and kelly hoses, a dual swivel, and a dual conduit kelly. Twenty-two field projects, 11 in West Texas and 11 in East Texas, totaling about 90,000 feet drilled, 
were conducted through Grace/FlowDril, a joint venture with Grace Drilling Company. Although technical capability and mechanical reliability were demonstrated, the high capital cost of this system restricted commercial implementation.

\subsection{The Down Hole Pump Approach}

In the downhole pump approach, conventional drill pipe and drill collars are used, with the DHP as the last component of the bottom hole assembly next to the bit, as shown in Figure 1. The DHP is about the same size as and is handled like a conventional drill collar. The power required to drive the DHP is obtained from increasing the operating pressure of the surface pumps and delivered downhole via the conventional mud stream. It is expected that surface pump pressures necessary to drive the DHP will be approximately 3,500 to $3,700 \mathrm{psi}$, pressure well within the working pressure range of rotary drilling equipment.

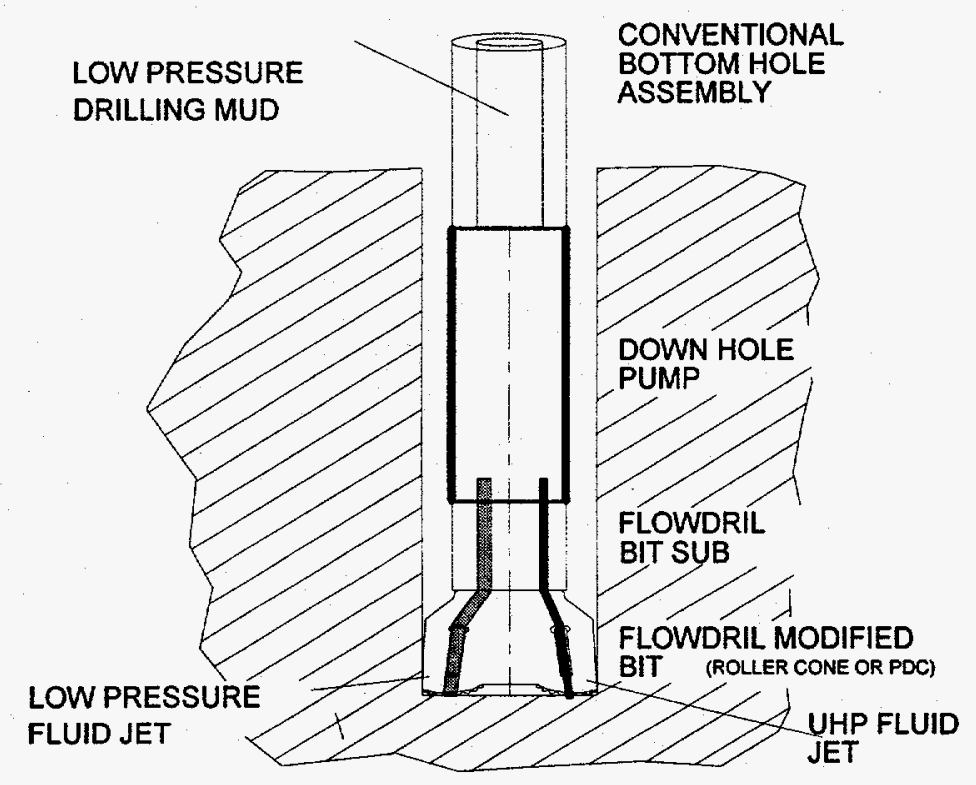

Figure 1. Down Hole Pump Approach to Jet-Assist Drilling

Within the DHP, the fluid stream is divided. Approximately seven percent of the stream is pressurized to $30,000 \mathrm{psi}$ and directed through a high pressure nozzle on the drill bit to produce the high speed jet. The remainder of the fluid stream passes through the bit nozzles at conventional bit nozzle pressures. 


\subsection{Intensifier Type Pump}

The FlowDril DHP is a reciprocating, intensifier type ultra-high pressure pump. Flow International, a sister company to FlowDril, has manufactured and marketed this type of ultra-high pressure pump commercially for water-jet cutting applications since 1974. It is a fluid driven pump where the drive fluid is hydraulic oil. The output high pressure fluid is a non abrasive fluid, generally filtered water. A schematic of an intensifier pump is shown in Figure 2. The drive fluid is a higher volume, lower pressure fluid that drives a large diameter low pressure piston. Connected to the large diameter piston is a smaller diameter plunger rod that when driven into the high pressure cylinder, pressurizes a smaller volume of fluid in the cylinder to higher pressure (up to $55,000 \mathrm{psi}$ ) and pumps it out through an outlet check valve. The ratio of the area of the larger diameter piston to the area of the smaller diameter plunger rod approximately determines the ratio of the output pressure to the drive flow pressure, and the ratio of drive flow rate to the output flow rate.

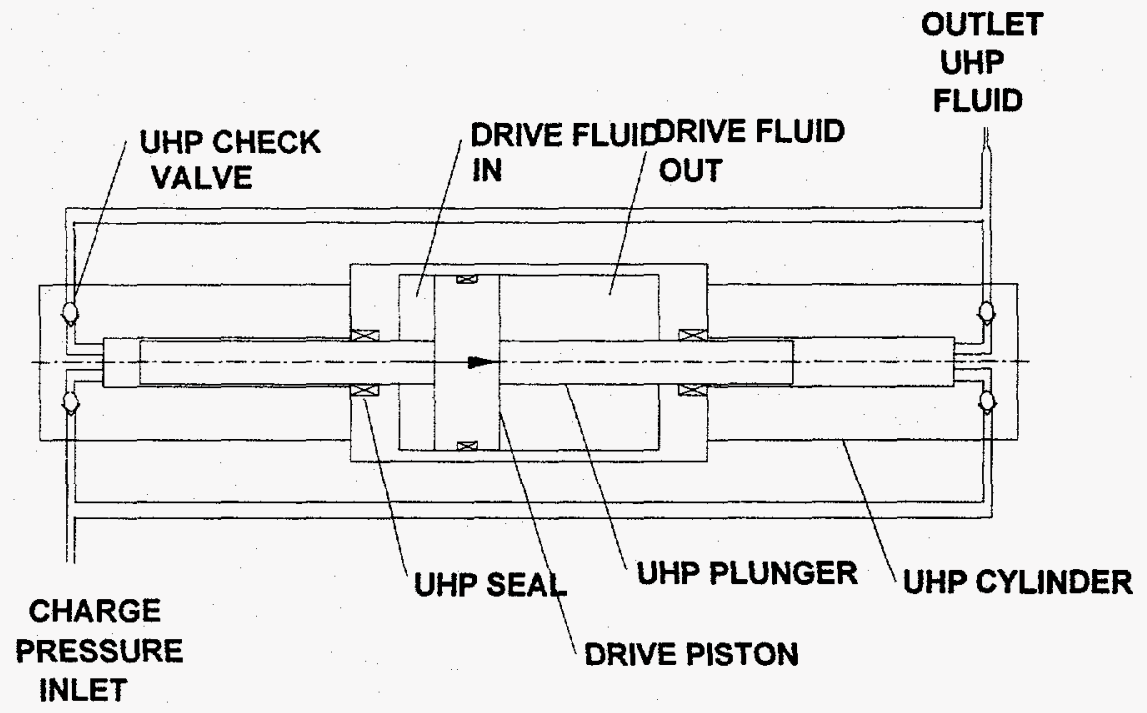

Figure 2. Intensifier Pump Principle

As the low pressure piston is driven to the end of its stroke, a pilot valve is mechanically activated, which in turn shuttles a four-way directional main control valve (not shown in Figure 1). The main control valve, when shuttled, reverses the direction of low pressure flow within the intensifier, driving the low pressure piston in the opposite direction. When operating, the low pressure piston-ultra-high pressure plunger assembly reciprocates back and forth. Output ultra-high pressure flow is produced in both directions. Because it is driven hydraulically, it is possible to achieve power conversion efficiencies between input hydraulic horsepower and output hydraulic horsepower of over 70 percent. 


\subsection{GRI Development Program}

Both the first prototype, and the second prototype described in later sections of this report, are a reciprocating double ended, intensifier style positive displacement, high pressure pump with the same operating principle as shown in Figure 2. A schematic of a down hole pump using this principle is shown in Figure 3. In the case of the down hole intensifier pump, the drive fluid and the high pressure output fluid are both derived from the same source, the abrasive drilling mud pumped down hole through the drill string.

Because of space limitations within the envelope of a drill collar, the down hole intensifier employs multiple low pressure drive pistons and fluid porting through the shaft connecting the drive pistons. Also shown in Figure 3 are the main control valve that directs the drive fluid to either chambers "A" or "B", and the pilot valve (also called trigger valve) that hydraulically shifts the main control valve. Other elements shown that are required for a practical down hole pump are a by-pass valve, an ultra-high pressure (UHP) accumulator and a filter on the inlet to the UHP portion of the fluid circuit. The by-pass valve allows for circulation in the hole without the DHP operating, particularly in the event the DHP stalls. The attenuator maintains UHP flow during the non pumping period at the end of stroke when the intensifier style pump shifts direction. The filter reduces the size of particles allowed through the components in the UHP portion of the fluid circuit, minimizing the opportunity for plugging and reducing wear.

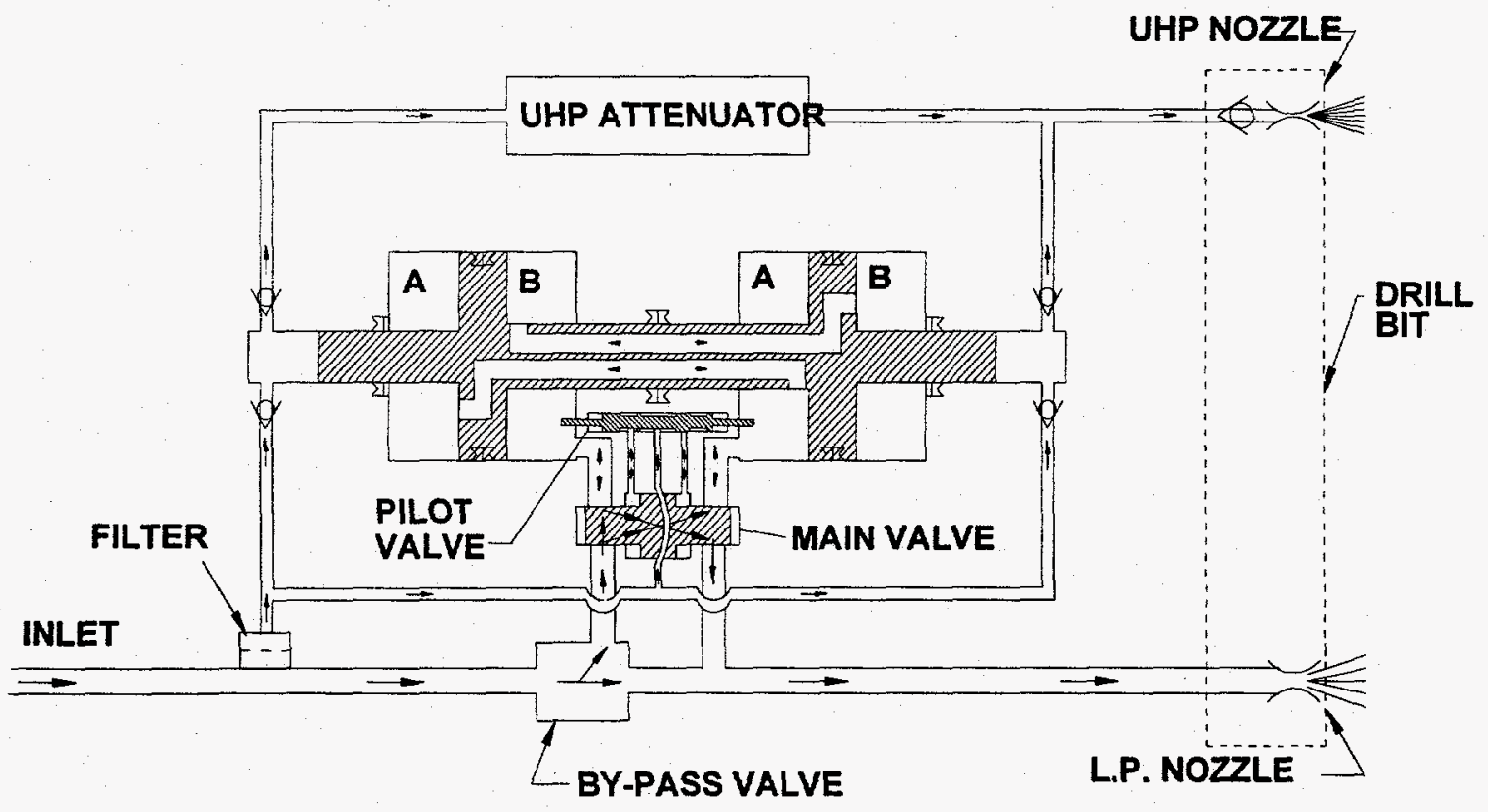

Figure 3. Schematic of Down Hole Pump

Under the GRI project, a prototype 7-5/8 Inch DHP for drilling 8-1/2 or 8-3/4 inch diameter holes was designed, fabricated, and a breadboard version tested in the 
laboratory. Subsequently, five field experiments were conducted with the 7-5/8 inch prototype during which seven down hole pump trials were conducted. Results of the field experiments with the 7-5/8 inch prototype have been presented by Veenhuizen, et al (1996). The down hole configuration of the 7-5/8 inch DHP for the field experiments is shown in Figure 4.

The assembly consisted of the bit, a bit sub, the DHP section, the attenuator collar and attenuator hanger sub, a float sub, and a screen sub. The hanger sub supports the UHP attenuator within the outer housing of the assembly. Connection to the drill collars above the pump assembly was usually with a crossover sub.

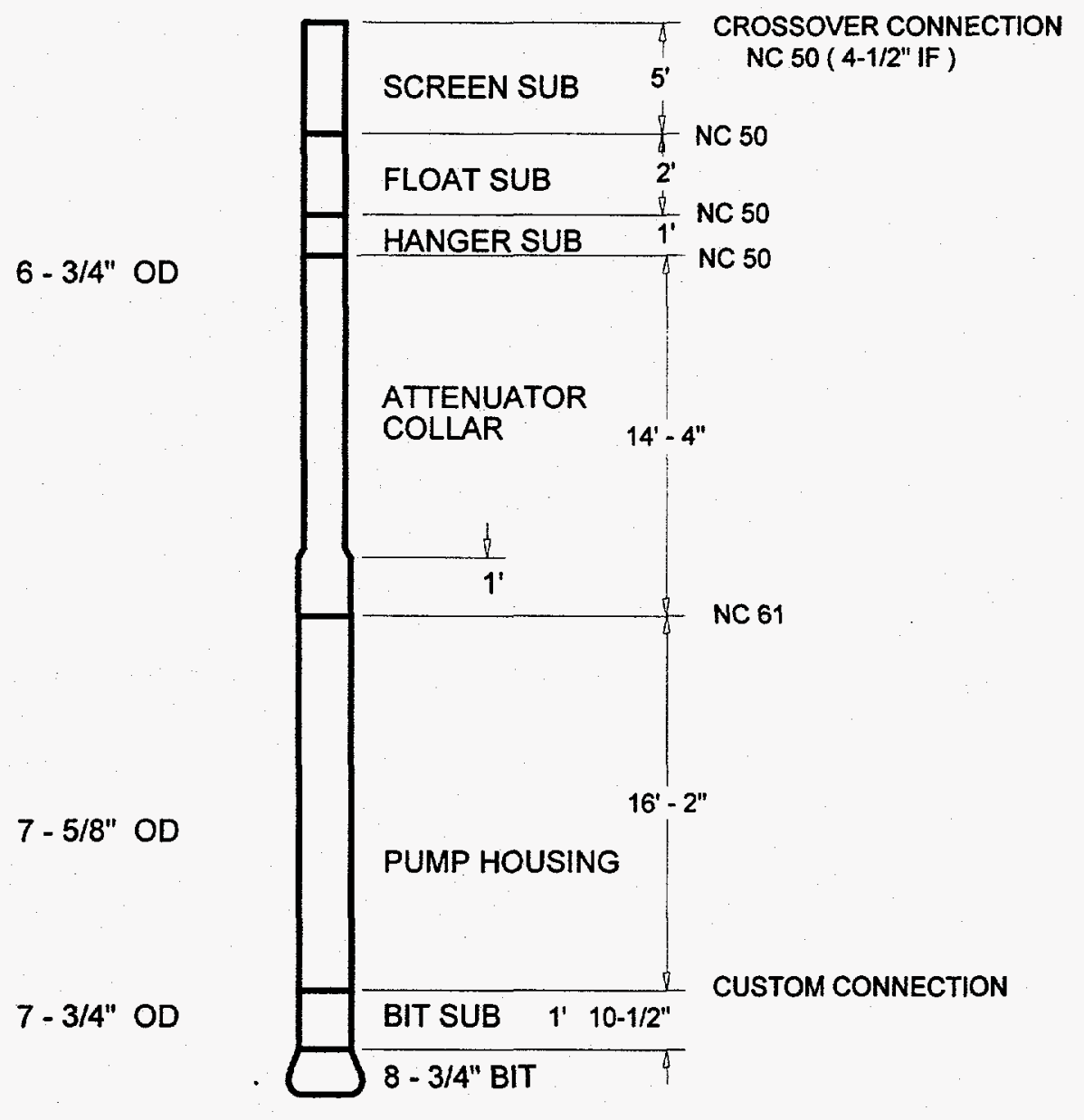

Figure 4. GRI 7-5/8 Inch DHP Field Experiment Configuration

The length of the assembly, not including the drill bit, was 40 feet 4-1/2 inches. The bit sub was the largest in diameter at 7-3/4 inches. The next largest in diameter was the DHP section at 7-5/8 inches. The top of the attenuator collar, the hanger sub, the float sub, and the screen sub were all 6-3/4 inches in diameter and could be fished with a full strength 
overshot. The top of the DHP section, however, was too large and would have required a custom slimhole overshot, or a spear to be fished. Had it been required, the entire assembly could have been washed over with a custom slimhole style washover pipe. All of the connections between sub sections of the assembly were standard API connections, except for the custom connection between the bit sub and the pump housing. This was a custom connection similar to that used in down hole mud motors.

A photograph of the 7-5/8 inch DHP is shown in Figure 5. It is from the first field experiment that was conducted at Amoco's Catoosa Drilling Test Facility in Oklahoma. Visible in the photograph is the 8-3/4 inch bit, the bit sub, and most of the lower portion of DHP section. The UHP extended nozzle is also visible on the bit.

A close up of the UHP jet-assist drill bit is shown in Figure 6. It was a commercially available 8-3/4 inch Smith International F3 tungsten carbide insert bit to which the UHP extended nozzle tower and nozzle were added by FlowDril. The UHP nozzle tower extended from a UHP outlet in the bit sub and out through an existing mud nozzle port on the bit. The nozzle used was a 0.064 inch diameter proprietary nozzle developed by FlowDril. 


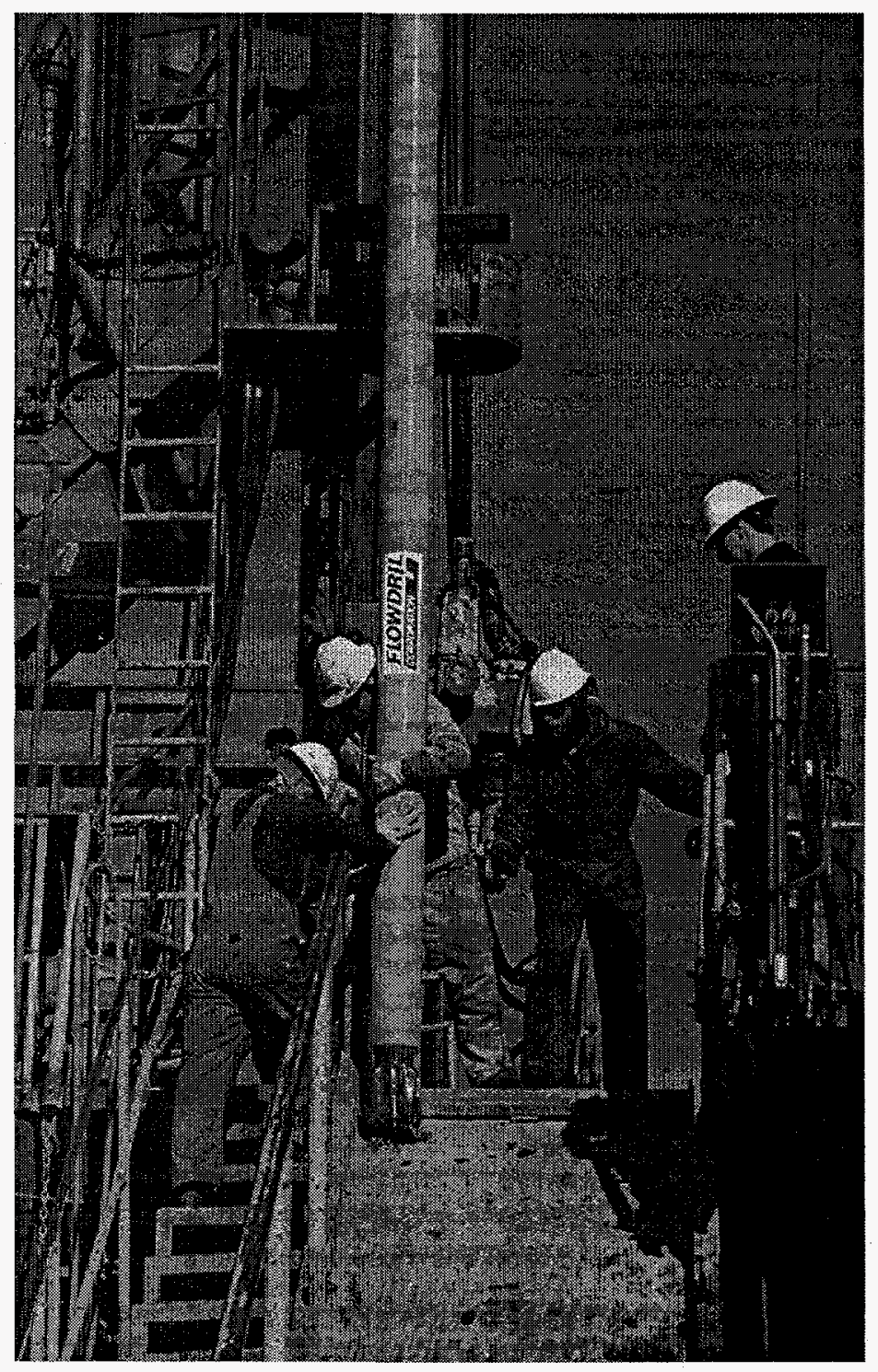

Figure 5. Photograph of First Prototype, 7-5/8 Inch, High Pressure Down Hole Pump during First Field Experiment under GRI Program 


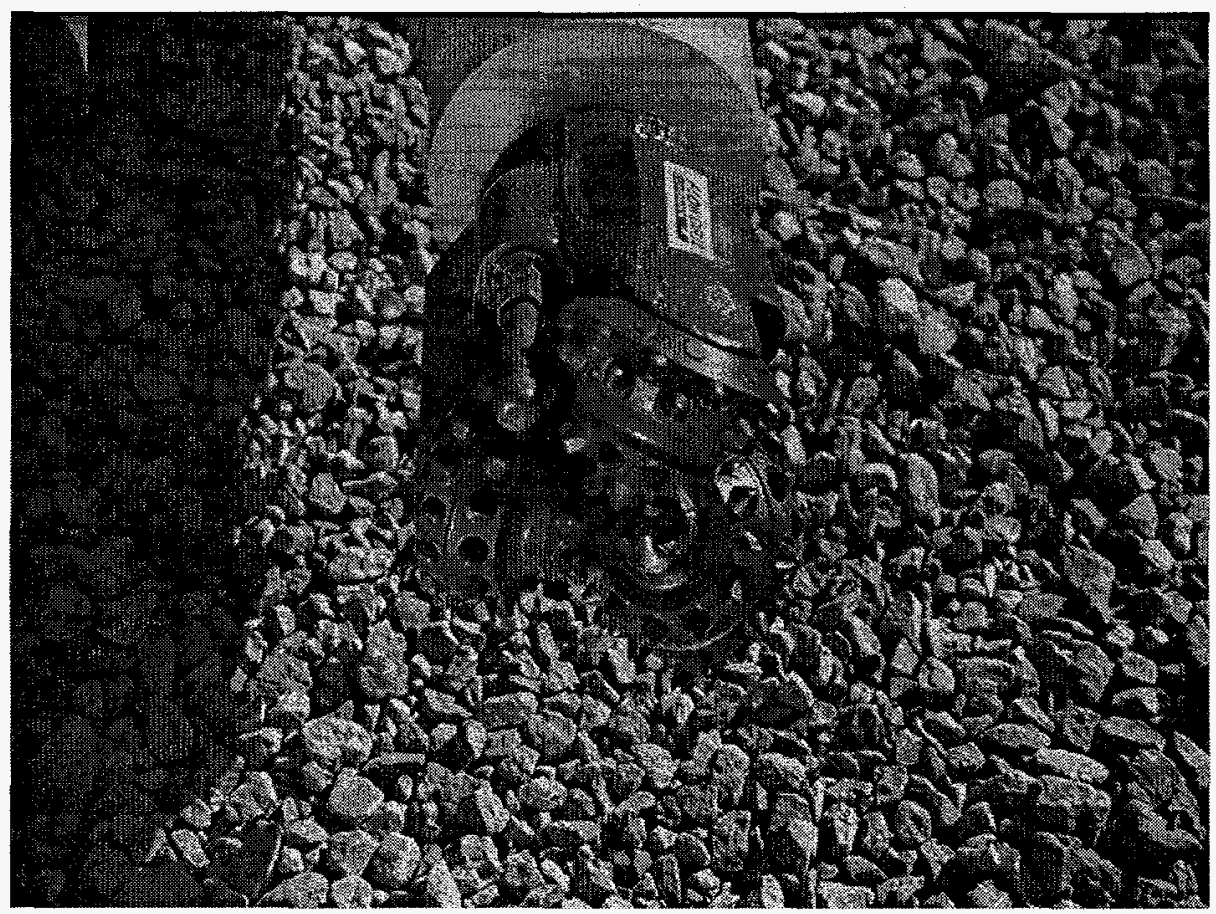

Figure 6. Smith F2 8-3/4 Inch Drill Bit with Extended UHP Nozzle used during First Field Experiment under GRI Program 


\section{DHP Market Analysis Summary}

As originally proposed, this DOE project was aimed at development of DHP technology for slimhole drilling. The first task of the project was to assess the potential slimhole market size and include it with the previous market analysis conducted under the GRI program. Bit sizes considered to be slimhole sizes were those 6-1/4 inches or smaller in diameter, with an emphasis on 4-3/4 inch. The analysis of a potential slimhole market indicated that it was relatively small compared to DHP market segments in larger hole sizes. The GRI market analysis and the slimhole market analysis are both summarized in this section.

\subsection{GRI Market Analysis}

Under the GRI program, the U.S. land, vertical rotary drilling market, particularly gas drilling, was analyzed to evaluate the potential market for jet-assist drilling with a high pressure DHP. The results of this analysis are contained in the GRI topical report Market Analysis: Downhole Pump for Jet-Assisted Drilling (Veenhuizen and O'Connor, 1994). The analysis specifically addressed the following issues:

- Drilling Market Outlook - Continued existence of a U.S. land drilling market.

- DHP Market Size - Revenue potential to a DHP service supplier.

- Expected Market Locations - Geographic locations of probable DHP operations.

- Expected Bit Sizes - Market size opportunity for various DHP sizes.

- Expected Operating Well Depth - Operational depths most common for the DHP.

- Industry Savings from DHP Use - Economic savings (incentive for use) derived by end users of the DHP technology.

- DHP Technical Requirements - Technical requirements that a DHP must meet to be responsive to a commercial market.

From a review of historical U.S. land drilling activity for 1992, the most recent data available at the time, ten of the more active drilling regions emphasizing deeper gas drilling, well total depths of 7,500 feet or more, were selected as the basis of analysis. The data used for this selection were from the Joint Association Survey on 1992 Drilling Costs, for U.S. land drilling, both all drilling (gas, oil, dry) and gas drilling, at 2,500-foot total well depth intervals. The ten drilling regions selected are listed in Table 1. 
Table 1. Ten Regions Included in Market Analysis

\begin{tabular}{|c|c|c|c|}
\hline Region & Gas & Oil & Dry \\
\hline Colorado & $\frac{\text { Well }}{318}$ & $\frac{\text { Well }}{28}$ & $\frac{\text { Hole }}{15}$ \\
\hline Texas Railroad & 316 & 45 & 34 \\
\hline District 6 & & & \\
\hline $\begin{array}{l}\text { Texas Railroad } \\
\text { District } 4\end{array}$ & 304 & 9 & 122 \\
\hline Oklahoma & 281 & 114 & 111 \\
\hline Wyoming & 55 & 55 & 96 \\
\hline $\begin{array}{l}\text { Texas Railroad } \\
\text { District } 3\end{array}$ & 95 & 469 & 156 \\
\hline South Louisiana & 89 & 86 & 166 \\
\hline North Louisiana & 57 & 16 & 32 \\
\hline $\begin{array}{l}\text { Texas Railroad } \\
\text { District } 5\end{array}$ & 43 & 15 & 20 \\
\hline Eastern New Mexico & 33 & 180 & 23 \\
\hline
\end{tabular}

These ten regions are also shown in Figure 7. They represent about 90 percent of the gas wells over 7,500 feet in total depth that were drilled in 1992.

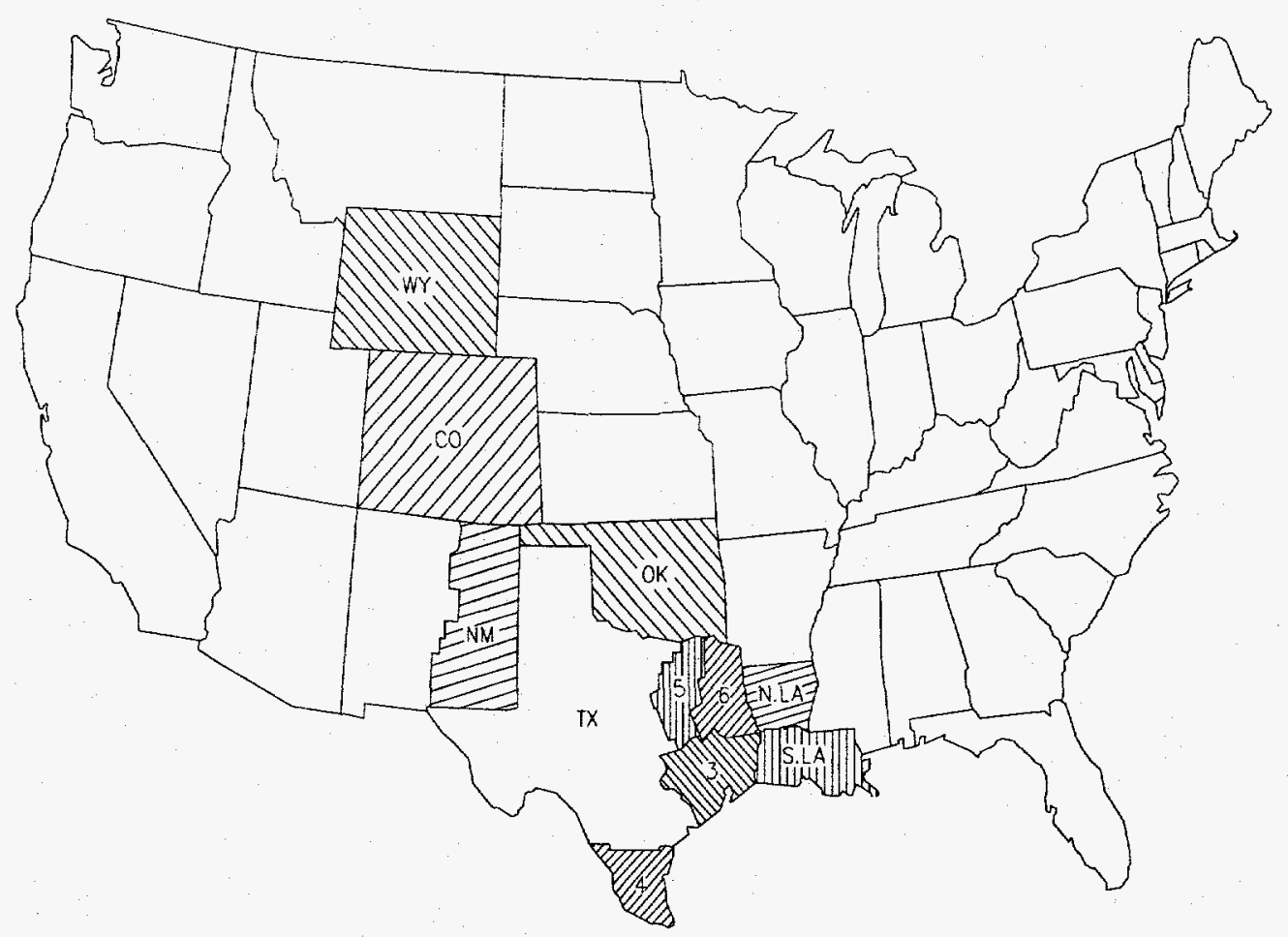

Figure 7. Ten Regions Included in Market Analysis 
The overall cost reduction to justify use of the DHP technology must be sufficient to offset the additional cost of use of the technology (DHP revenue) and to provide some benefit (savings) to drilling contractors or operators (incentive for use of the technology). Drilling faster reduces the number of days spent drilling a well, reducing the accumulation of those drilling costs that are "time-sensitive." Time-sensitive costs included in the analysis were rig cost per day, geological services (mud logging), liquids and solids disposal, drilling mud and chemicals, overhead, field supervision, fuel and utilities, rentals, closed system equipment, drill pipe inspection, BHA inspection and repair, directional services, and miscellaneous.

The wells were divided into four 2,500-foot depth ranges between 7,500 feet and 15,000+ feet. Representative bit records were obtained from Hughes Christensen and Smith International for each of the selected depth ranges for each of the ten regions. Using the bit records, representative time sensitive costs by well depth and by bit size that would be affected by the DHP were estimated by two consultants from the drilling industry. DHP market revenue and savings to the industry were then estimated, assuming a range of costs for DHP use and a range of jet-assist ROP improvement ratios.

Based on the time-sensitive cost estimates, FlowDril examined the potential effect that the DHP might have had, had it been available. For this portion of the analysis, certain drilling intervals were excluded, somewhat arbitrarily, as not being compatible with the DHP. Those sections of hole excluded were intervals with the following:

- Minimum and maximum bit sizes of 6.00 to 12.25 inches; drilling intervals on wells outside the minimum/maximum bit size range were excluded.

- Mud weights greater than 16.0 pounds per gallon; drilling intervals using greater than 16.0 pounds per gallon of mud were excluded. All oil base mud and air intervals were excluded.

- Conventional ROPs greater than $50 \mathrm{ft} / \mathrm{hr}$; drilling intervals achieving conventional ROPs of $50+\mathrm{ft} / \mathrm{hr}$ were excluded.

- Less than three conventional drilling days; drilling intervals of three days or less were excluded.

- Percentage rotating time less than $30+$ percent; drilling intervals operating at less than 30 percent rotating time were excluded.

Tables 2 and 3 set forth the aggregate DHP market size across all regions in terms of revenue for all drilling and gas drilling, respectively, in millions of dollars. The market sizes are presented as a function two variables as follows:

- Cost per DHP Pumping Hour (Cost/DHP-hour) - A range from \$100/DHP-hour to \$350/DHP-hour, in increments of \$50/DHP-hour, was assumed. The Cost/DHP-hour is defined as an all-inclusive cost that would include (a) the DHP supplier's effective 
charge rate/DHP-hour; (b) incremental rig fuel; (c) rig pump liners; (d) incremental rig mud pump maintenance; and (e) required jet-assist bit modification costs.

- ROP Improvement Ratio - The improved rate of penetration derived from use of the DHP versus the conventional ROP; a range of ROP ratios was utilized from 1.25 to 2.50 times, in increments of $0.25 \mathrm{ROP}$ improvement.

Table 2. DHP Market Sizes - All Drilling

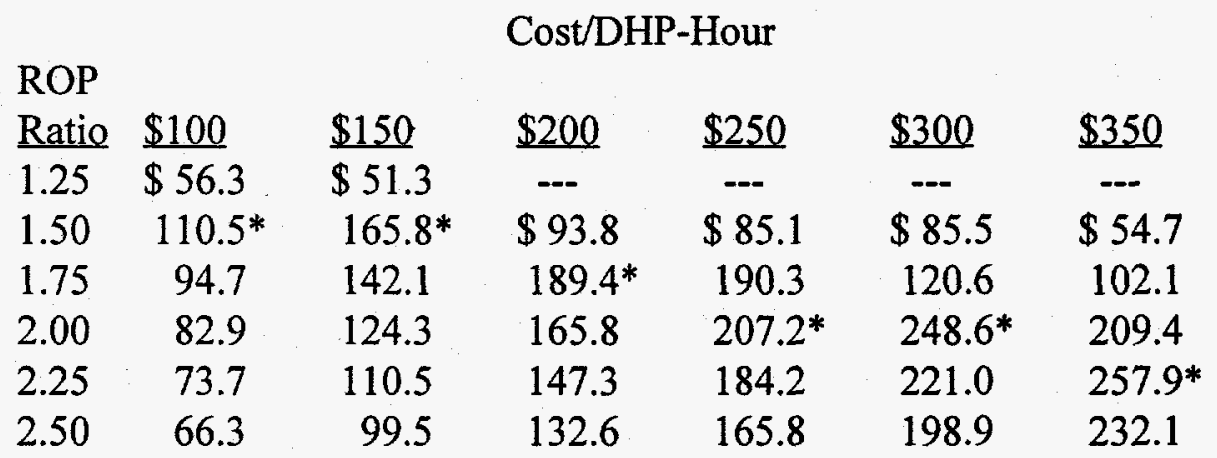

Table entries in millions of dollars.

* DHP market size is dependent upon the number of DHP pumping hours, which declines after 100 percent saturation as the ROP ratio increases due to the fixed number of conventional rotating hours that can be affected.

Table 3. DHP Market Size - Gas Drilling

\begin{tabular}{|c|c|c|c|c|c|c|}
\hline & & & & & & \\
\hline Ratio & $\$ 100$ & $\$ 150$ & $\$ 200$ & $\$ 250$ & $\$ 300$ & $\$ 350$ \\
\hline 1.25 & $\$ 12.6$ & $\$ 4.5$ & --- & --- & --- & -.. \\
\hline 1.50 & $39.5^{*}$ & $59.2^{*}$ & $\$ 20.9$ & $\$ 9.5$ & $\$ 7.5$ & $\$ 5.2$ \\
\hline 1.75 & 33.9 & 50.8 & $67.7^{*}$ & 70.6 & 26.9 & 11.4 \\
\hline 2.00 & 29.6 & 44.4 & 59.2 & $74.1^{*}$ & $88.9^{*}$ & 75.7 \\
\hline 2.25 & 26.3 & 39.5 & 52.7 & 65.8 & 79.0 & $92.2^{*}$ \\
\hline 2.50 & 23.7 & 35.5 & 47.4 & 59.2 & 71.1 & 82.9 \\
\hline
\end{tabular}

Table entries in millions of dollars.

* DHP market size is dependent upon the number of DHP pumping hours, which declines after 100 percent saturation as the ROP ratio increases due to the fixed number of conventional rotating hours that can be affected. 
Market sizes, in terms of revenue, range from no revenue to a maximum of $\$ 257.9$ million for all drilling. For gas drilling, the range is from no revenue to $\$ 92.2$ million. These estimates are thought to be conservative because the base year, 1992, was the lowest level of drilling activity in 26 years and because of the additional constraints required by the filtering process to qualify as "DHP-affected" rotating hours. Assuming a cost of \$250/DHP-hour and an ROP ratio of 2.0 (about mid-range of DHP costs per hour and ROP improvement ratio), the all drilling annual aggregate market size can be stated as $\$ 207$ million based on 1992 drilling activity. The gas drilling annual aggregate market size is then $\$ 74$ million.

Industry savings were calculated as the difference between the estimated cost of conventionally drilling the well and the projected cost if the DHP had been used for jetassisted drilling. The results for all drilling and for gas drilling are shown in Tables 4 and 5 , respectively. As might be intuitively expected, savings increase with decreasing DHP costs and increase with increasing ROP performance. The savings range from no savings to a high of $\$ 389.7$ million for all drilling and a high of $\$ 116$ million for gas drilling. Again, assuming a cost of \$250/DHP-hour and an ROP ratio of 2.0, industry savings were estimated to be $\$ 173$ million and $\$ 42$ million for all drilling and for gas drilling, respectively.

Table 4. Industry Savings from DHP Use - All Drilling

\begin{tabular}{|c|c|c|c|c|c|c|}
\hline \multirow{3}{*}{ ROP } & & \multicolumn{5}{|c|}{ Cost/DHP-Hour } \\
\hline & & & & & & \\
\hline & $\$ 100$ & $\$ 150$ & $\$ 200$ & $\$ 250$ & $\$ 300$ & $\$ 350$ \\
\hline 1.25 & $\$ 29.5$ & $\$ 8.9$ & $\cdots$ & --- & --- & -- \\
\hline 1.50 & 142.8 & 87.6 & $\$ 49.2$ & $\$ 29.2$ & $\$ 14.9$ & $\$ 3.3$ \\
\hline 1.75 & 231.0 & 183.7 & 136.3 & 90.4 & 63.3 & 45.8 \\
\hline 2.00 & 297.2 & 255.7 & 214.3 & 172.8 & 131.4 & 95.0 \\
\hline 2.25 & 348.6 & 311.8 & 274.9 & 238.1 & 201.2 & 164.4 \\
\hline 2.50 & 389.7 & 356.6 & 323.4 & 290.3 & 257.1 & 224.0 \\
\hline
\end{tabular}


Table 5. Industry Savings from DHP Use - Gas Drilling.

ROP

\begin{tabular}{|c|c|c|c|c|c|c|}
\hline Ratio & $\$ 100$ & $\$ 150$ & $\$ 200$ & $\$ 250$ & $\$ 300$ & $\$ 350$ \\
\hline 1.25 & $\$ 3.4$ & $\$ 0.8$ & -- & -- & -- & -.. \\
\hline 1.50 & 38.1 & 18.4 & $\$ 5.7$ & $\$ 2.6$ & $\$ 1.3$ & $\$ 0.3$ \\
\hline 1.75 & 66.0 & 49.0 & 32.1 & 15.7 & 7.4 & 4.2 \\
\hline 2.00 & 86.8 & 72.0 & 57.2 & 42.4 & 27.6 & 14.5 \\
\hline 2.25 & 103.0 & 89.9 & 76.7 & 63.6 & 50.4 & 37.2 \\
\hline 2.50 & 116.0 & 104.2 & 92.3 & 80.5 & 68.6 & 56.8 \\
\hline
\end{tabular}

\subsection{Slimhole Market Analysis}

The slimhole market analysis was to address small diameter vertical rotary, vertical with motors, horizontal re-entry, and coiled tubing drilling of vertical or horizontal re-entry holes. Particular interest was slim-hole re-entry horizontal drilling out of 5-1/2 inch and 4-1/2 inch casing, either with conventional slim-hole or with coiled tubing. The corresponding hole/bit sizes are either 4-3/4 inch or 4-1/2 inch for the 5-1/2 inch casing, and 3-7/8 inch for the 4-1/2 inch casing.

An upper bound on the market size for small hole diameter drilling can be estimated from bit record data from Smith International, Inc. and Hughes Christensen. The bit footage and bit hours by bit size were provided by Smith for 1991 and 1992, and by Hughes Christensen for 1993 and 1994 for all U.S. land drilling and all bit types. Total footage represented is 66.6 million feet in '91 and 60.8 million feet in '92 from Smith; and 68.5 million feet in ' 93 and 67.7 million feet in ' 94 from Hughes, a sampling about 50 percent of drilling activity in each of the years. Bit hours for bit sizes from 3-3/4 through 6-3/4 inch are shown in Figure 1. Bit sizes are given in terms of Smith's nomenclature where $3.6=3-6 / 8=3-3 / 4,4.4=4-4 / 8=4-1 / 2$, etc. 


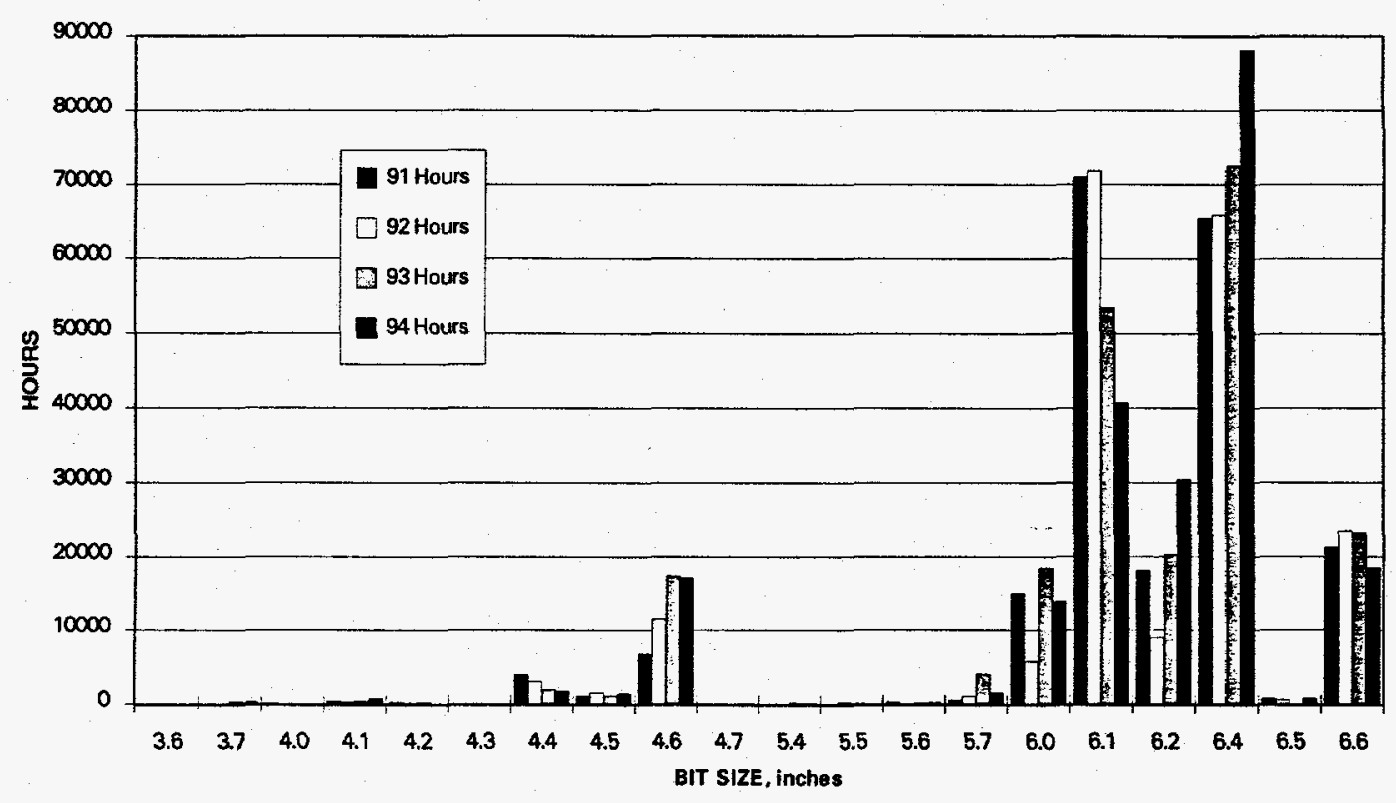

Figure 8. Bit Hours by Bit Size: 3-3/4"(3.6) through 6-3/4"(6.6)

As can be seen in Figure 8, drilling hours was the largest for 6-1/2 (6.4) inch and for 6-1/8 (6.1) inch bits. The number of bit hours for 4-3/4 inch bits is less than half that for 6-1/8 inch bits in 1994. Between 1991 and 1993, the number of hours for 4-3/4 inch bits increased almost 50\% per year, but leveled off between 1993 and 1994. The number of bit hours for bits smaller than 4-3/4 is negligible, even compared to those for 4-3/4 inch bits.

An estimate of the current, maximum market size was obtained as follows. Given that the total number of bit hours from the bit record data base for 4-3/4 inch bits is about 17,000 hours (Hughes, '94), and assuming this is half the number of hours for all drilling, further assuming all these hours are hours that could be affected by the DHP, then the total number of hours is 34,000 . Assuming an ROP increase of 2.0 times conventional rates, and a DHP net service charge of \$250/DHP-Hour, the maximum possible size of the DHP market for 4-3/4 inch holes in 1994 was $\$ 4.25$ million $(34,000 \mathrm{hr} \times 1 / 2 \mathrm{x}$ $\$ 250 / \mathrm{hr}$ ). Doing the same exercise for 6-1/8 inch and 6-1/4 inch hole sizes combined together (about 71,000 hours) leads to a maximum possible DHP market for 6-1/8 inch and 6-1/4 inch holes of $\$ 17.8$ million.

An estimate was made of the potential maximum market size in the future, out to the year 2000. Resource Marketing International (RMI) projected the world-wide market, excluding the CIS (previously the Soviet Union) and China, for slim-hole drilling. The projections were for "slim-holes" - 4-3/4 inch and smaller - and for "Special" holes above 4-3/4 inch to 6-1/8 inch. Their projections were made in 1993 based on 1992 data 
from oil company and service company representatives engaged in slim-hole drilling. The RMI world-wide projection for "slim-holes" was very aggressive and is shown in Figure 2. The projection is based on 165 slim-holes drilled by the companies represented in the RMI study. RMI did not separate the U.S. market from the World market. The projection for the number of slim-holes drilled in the U.S. shown in Figure 2 is FlowDril's estimate using RMI's projection and adjusting it in accordance with the bit data from Smith and Hughes Christensen. With the assumption that about seventy percent of the hours for 4-3/4 inch bits reported in the bit record data base was for holes drilled as true "slim-holes", the number of U.S. slim-holes drilled in the U.S. in 1992 was estimated at 186. Using the same assumption, the number of slim-holes drilled in 1993 and 1994 were estimated as 240 each year. For 1995 to 2000, the growth rate indicated by RMI for the increase in the world market was adopted to project the number of holes drilled "slim-hole" out to 2000 .

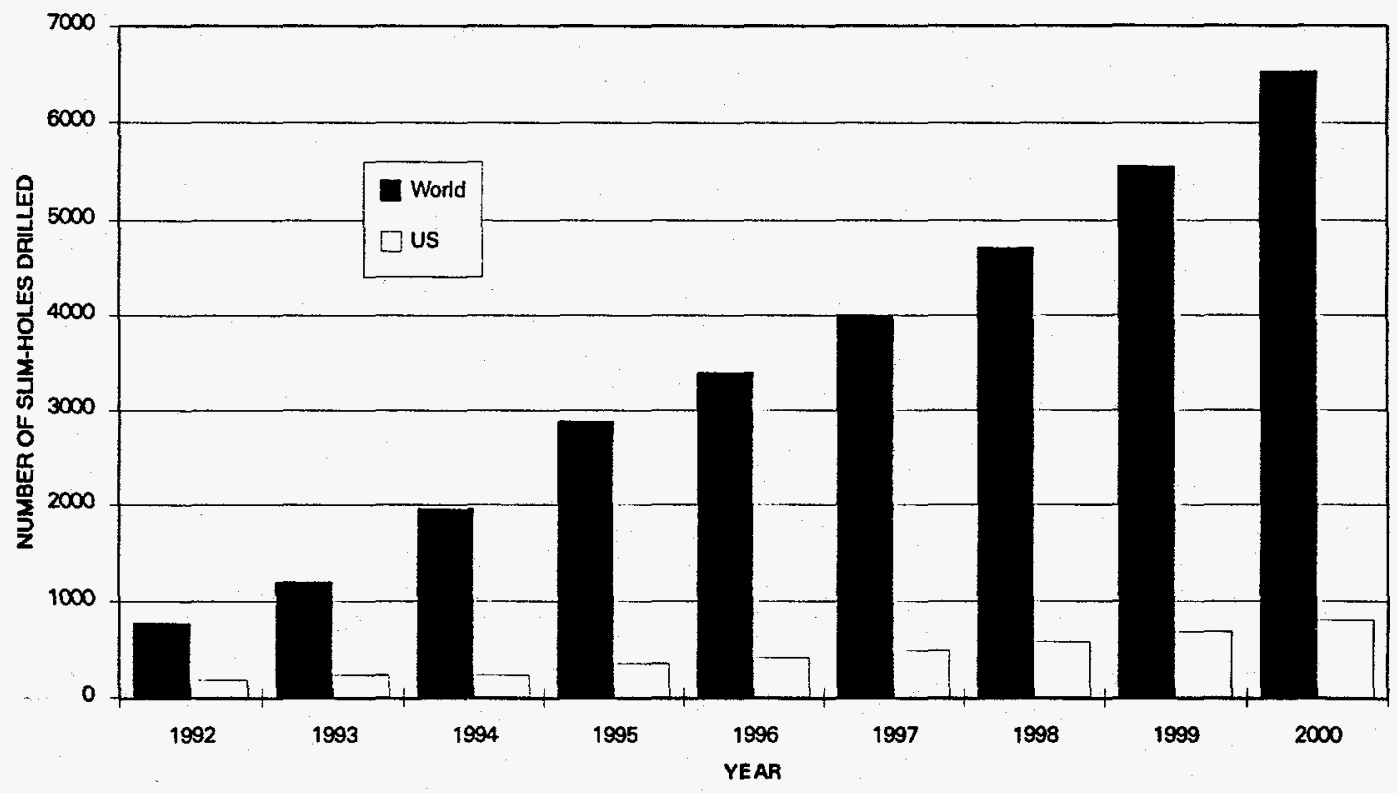

Figure 9. RMI Projections of Number of "Slim-Holes" Drilled World-Wide. FlowDril's Estimate for Number of "Slim-Holes" in US based on RMI projections and Bit Hours from Smith and Hughes Christensen Bit Record Database

Shook, et al (1995) conducted a study for GRI on slim-hole drilling and completion barriers for gas wells. Shook, et al used the number of gas well completions as a measure of slim-hole activity. A slim-hole completion was defined as "production casing less than or equal to $4 \mathrm{inch}$, even though the hole drilled may have been larger than required for a 4-inch production casing. Unfortunately, the number of holes actually drilled annually as "slim-holes" is not available from the completion data. 
The number of slim-hole completions for both gas and oil has averaged about 980 per year over the five-year period 1989 through 1993. It peaked in 1990 at about 1100 . It has steadily decreased during the last three years of this period. Shook, et al projected the number of slim-hole completions into the future utilizing three growth rate scenarios. Their highest growth rate scenario, "Slim Completion-Hi", doubled the percentage of total wells completed as slim-hole completions between 1994 and 1999 to 7 percent of the total gas and oil completions. This highest growth rate projection applied by Shook, et al was used to project total gas and oil slim-hole completions as shown in Figure 10.

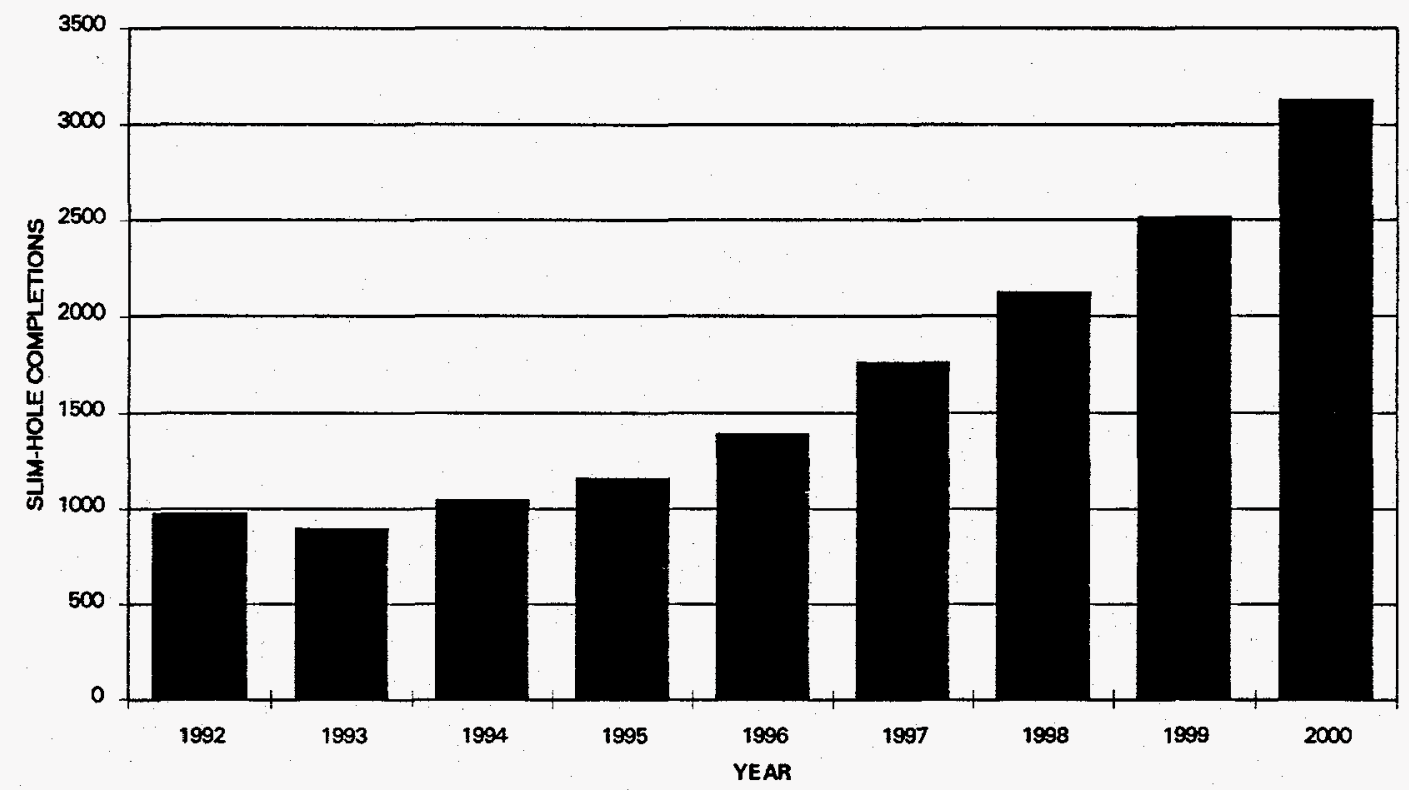

Figure 10. Projected Number of "Slim-Hole" Completions, based on Shook, et al

Another assumption by Shook, et al is that the number of holes drilled as "slim-holes" was about 5 percent of the number of slim-hole completions in 1994. To project the number of holes drilled as slim-holes, they again used three growth rate scenarios. The highest growth rate scenario assumed that the number of holes drilled as slim-holes would increase from 5 percent to 25 percent of the number of slim-hole completions in the year 2000. This amount of growth was characterized by Shook, et al as being aggressive. Utilizing the projected total number of slim-completions shown in Figure 10 and Shook, et al's highest growth rate scenario, we projected the total number of holes drilled as slim-holes out to the year 2000. This projection is shown in Figure 11. Also shown in Figure 11 is the estimate based on RMI for the U.S. that was shown in Figure 9. 


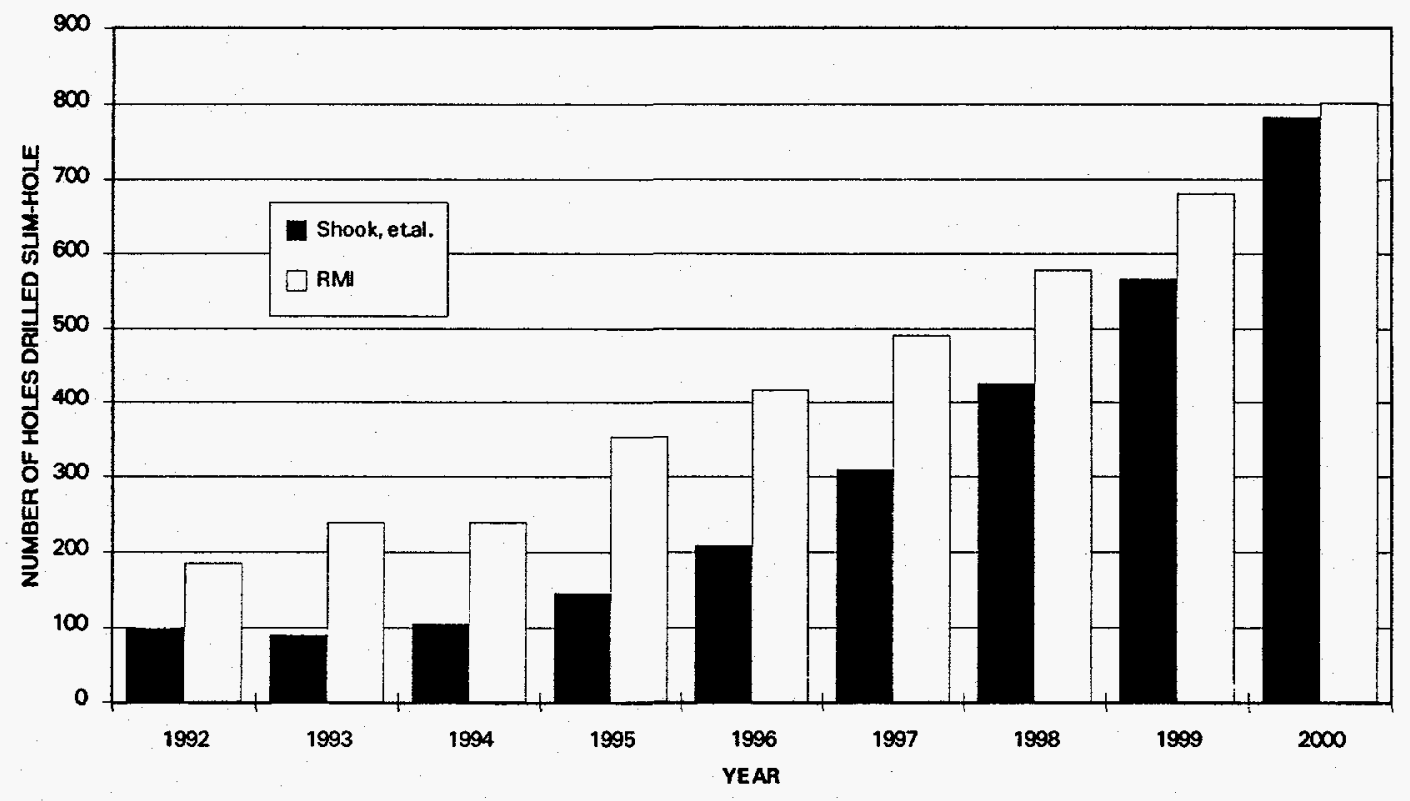

Figure 11. Projections of Number of Holes Drilled as Slim-Holes

From the projection of the number of wells drilled slim-hole, an estimate of the number of DHP slim-hole drilling hours was made. It was assumed that the average footage per well drilled slim-hole, including vertical rotary, vertical with motors, horizontal re-entry, and coiled tubing drilling of vertical or horizontal re-entry holes was 1,500 feet per well. From the 1994 bit record information, the average rate of penetration for 4-3/4 inch bits was 12 feet per hour. It was assumed that with the DHP jet-assisted drilling technology, the rate of penetration would double. With these assumptions and the data shown in Figure 11, the slim-hole drilling hours with the DHP were estimated as shown in Figure 12. 


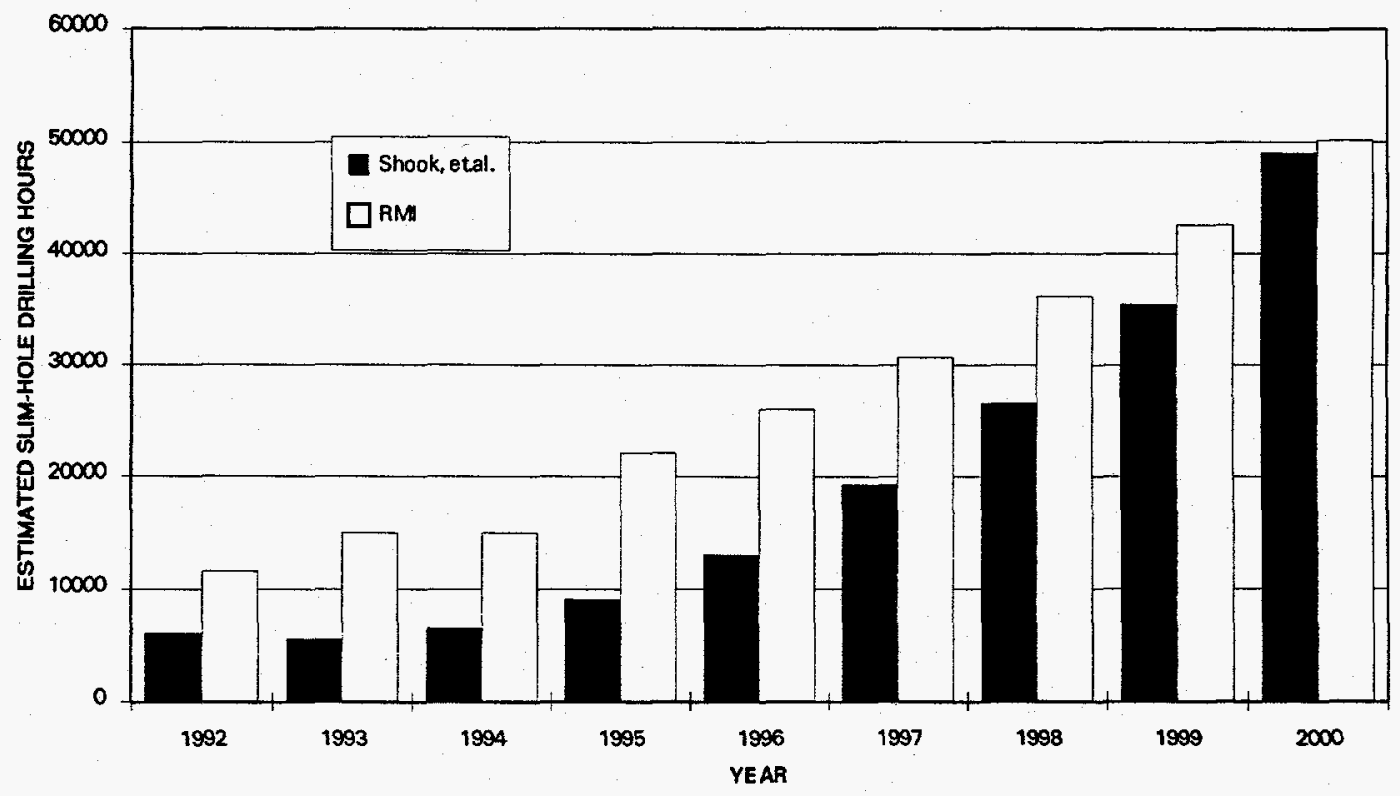

Figure 12. Estimated DHPTM Slim-Hole Drilling Hours

With the estimated total number of DHP slim-hole drilling hours, assuming a pricing for use of the DHP as \$250/DHP Hour, a maximum possible market size was estimated for a slim-hole DHP sized for 4-3/4 inch holes. These estimates projected out to the year 2000 are tabulated in Table 6. Table 6. Maximum Projected DHP Market Size (Revenue) for Slim-Hole
Operation

\begin{tabular}{|c|c|c|}
\hline & Estimate on & $\begin{array}{c}\text { Estimate on } \\
\text { RMI }\end{array}$ \\
\hline Year & Shook, et al & RMI \\
\hline 1992 & $\$ 1.5$ million & $\$ 2.9$ million \\
\hline 1993 & $\$ 1.4$ million & $\$ 3.8$ million \\
\hline 1994 & $\$ 1.6$ million & $\$ 3.8$ million \\
\hline 1995 & $\$ 2.3$ million & $\$ 5.5$ million \\
\hline 1996 & $\$ 3.3$ million & $\$ 6.5$ million \\
\hline 1997 & $\$ 4.8$ million & $\$ 7.7$ million \\
\hline 1998 & $\$ 6.6$ million & $\$ 9.0$ million \\
\hline 1999 & $\$ 8.9$ million & $\$ 10.6$ \\
\hline 2000 & $\$ 12.2$ million & $\$ 12.5$ million \\
\hline
\end{tabular}


Previously from the bit record information, the maximum possible DHP market size was estimated to be about $\$ 4.25$ million for 1994. The maximum possible estimated market size shown in Table 6 for 1994 is $\$ 3.8$ million. This is consistent with the assumption that about seventy percent of the hours for 4-3/4 inch bits reported in the bit record data base was for holes drilled as true "slim-holes."

Included in the maximum market estimate for slim-hole drilling is the "niche" market for coiled tubing drilling (CTD). According to Dowell-Schlumberger, the first CTD was performed in 1991. The number of CTD jobs that have been performed world-wide (as of 1st quarter of 1994) are summarized by year in Table 7. The total world-wide is about 240 CTD wells that includes horizontal re-entry, vertical re-entry deepening, and shallow new wells.

\section{Table 7. Slim-Hole Drilling with Coiled Tubing}

\begin{tabular}{cc} 
Year & CTD Wells \\
\hline 1991 & 3 \\
1992 & 13 \\
1993 & 23 \\
1994 & $70-200$
\end{tabular}

Less than about twenty CTD wells through 1994 have occurred in the U.S. These have occurred in Texas, Alaska, and California. At the present time, Cudd Pressure Control, Sperry-Sun, and Schlumberger indicated that CTD technology is generally not cost competitive with conventional slim-hole drilling in the U.S. outside shallow wells in California and some re-entry remedial drilling in wells in Alaska.

In summary, the maximum DHP market (revenue) for slim-hole drilling, 4-3/4 inch and smaller holes sizes, as given in Table 6 , is estimated to be between $\$ 2.3$ million and $\$ 5.5$ million for 1995, but is expected to grow to about $\$ 12$ million in the year 2000. Savings to the drilling industry would be expected to be in proportion. The maximum possible DHP market size for 6-1/8 inch and 6-1/4 inch hole sizes combined together (about 71,000 hours) is about $\$ 17.8$ million annually. Coiled Tubing Drilling (CTD) in the U.S. is not yet commercially competitive with conventional slim-hole drilling.

The maximum possible DHP slim-hole drilling market, at $\$ 2.3$ to $\$ 5.5$ million, is still considerably less than that expected for conventional hole sizes as determined in the GRI market analysis for the DHP. By conventional hole size, with a DHP target increase in ROP of 2.0 and a simple DHP service fee of $\$ 250$ per DHP hour, the market sizes were as shown in Table 4. The 7-7/8 inch and 8-1/2" - 8-3/4 inch hole sizes are the two largest market segments at 76.6 million per year and $\$ 58$ million per year respectively. 
Table 8. U.S. DHP Market Size

\begin{tabular}{lrl} 
Hole Size & DHP Hours & Market Size(Revenue) \\
\hline $12-1 / 4 "$ & $49,600 \mathrm{hrs}$. & $\$ 12.4$ million/yr. \\
$9-1 / 2 "-9-7 / 8^{\prime \prime}$ & $190,400 \mathrm{hrs}$. & $\$ 47.6$ million/yr. \\
$8-1 / 2 "-8-3 / 4^{\prime \prime}$ & $232,000 \mathrm{hrs}$. & $\$ 58.0$ million/yr. \\
$7-7 / 8 "$ & $306,400 \mathrm{hrs}$. & $\$ 76.6$ million/yr. \\
$6 "-6-3 / 4 "$ & $45,600 \mathrm{hrs}$. & $\$ 11.4$ million/yr.
\end{tabular}

\subsection{DHP Market Analysis Conclusions}

The conclusions of this marketing analysis are summarized below:

- Drilling Market Outlook - Although the market analysis base year, 1992, had the lowest level of drilling activity in a quarter century, according to all industry analysts, the trend is for an improving U.S. land drilling market. This is particularly true for gas drilling.

- DHP Market Size - Estimated for all drilling to be $\$ 207$ million annually, and for gas drilling to be $\$ 74$ million annually, assuming a DHP cost of $\$ 250 / \mathrm{DHP}$-hour and an ROP improvement ratio of 2.0 .

- Industry Savings from DHP Use - Estimated for all drilling (oil, gas, and dry) as $\$ 173$ million annually, and for gas drilling as $\$ 42$ million annually. This represents approximately a 5.5 percent savings in the cost of all drilling, or 10.9 percent of the time variable cost of all drilling whether or not affected by the DHP, for wells drilled over 7,500 feet in depth. For gas drilling, the corresponding savings percentages are about 3.5 percent, and 7 percent for deeper gas wells.

- Market Locations - Of the ten regions examined for U.S. land, vertical rotary drilling, the three regions with the largest total market potential in terms of revenue for all drilling, assuming a cost of \$250/DHP-hour and an ROP ratio of 2.0, are Texas Railroad District 3 ( $\$ 39.2$ million), Oklahoma ( $\$ 31.7$ million), and Texas Railroad District 6 (\$23.3 million). For gas drilling, the largest market potential is Texas Railroad District 6 ( $\$ 18.2$ million), Oklahoma (\$18.1 million), and Wyoming ( $\$ 13.5$ million).

- DHP Sizes - The most significant market is 7-7/8 inch, followed by 8-1/2 to 8-3/4 inch, and then 9-1/2 to $9-7 / 8$ inch hole diameters. Approximately 90 percent of the DHP market, either all drilling or gas drilling, occurs in these three size ranges. The predominant size for both all drilling and gas drilling is 7-7/8 inch hole size.

- Well Depth Range - Sixty-four percent of the market occurs for wells between 7,500 and 12,500 in depth. Forty percent is for wells in the range of 10,000 to 12,500 feet in depth. Only three percent of the DHP market occurs for wells deeper than 15,000 feet.

- Slim-Hole Drilling - No immediate DHP market impact is foreseen from horizontal, slimhole, re-entry, or coiled tubing drilling technologies. The slim-hole drilling 
market for the DHP, in sizes 6-inch and smaller, is less than ten percent of the market share for 7-7/8 inch, and is not a significant market for the DHP in the near future. 


\section{Specifications for Down Hole Pump}

For jet-assisted drilling with a DHP to perform successfully in the marketplace, it must satisfy certain technical requirements. Several of those requirements are outlined in this section. At the conclusion of this section, the technical specifications for design of the DHP are summarized.

\subsection{Rated Output Pressure}

For jet-assisted drilling to be most effective, the DHP will have to develop sufficient pressure for the jet(s) to kerf (cut a slot in) the rock being drilled. The action of the jet in assisting a mechanical bit is believed to be threefold. At lower pressures, where kerfing does not occur, the jet "supercleans" the bottom of the hole and results in ROP ratios of 1.1 to 1.3. At pressures near optimum, the jet kerfs the rock and weakens the rock across the bottom of the borehole, resulting in less work for the mechanical action of the bit. This results in ROP ratios of 1.3 to 2.25 , depending on jet pressure. If the pressure is sufficiently high, the jet removes a significant amount of rock on its own (erosion drilling), and ROP increases over 3.0 have been observed.

Rocks drilled for oil and gas wells are generally sedimentary rocks: shales, limestones, and sandstones. High-pressure jets are most effective for kerfing sandstones because of their higher porosity and permeability, and least effective for kerfing shales because of their lower porosity and permeability. The effect of jet-assist will vary depending on the rock type encountered and pressure applied. Optimum kerfing occurs when the operating pressure is 2 to 3 times the threshold pressure (the pressure at which the jet begins to kerf rock) of the rock (Veenhuizen and Cheung, 1978). Shown in Table 9 are threshold pressures for several rock types measured by FlowDril. The first six are laboratory rocks that have been used for drill bit testing experiments. The last six are from core samples obtained from portions of wells in West Texas (similar to Eastern New Mexico) and from East Texas Railroad Districts 5 and 6. Based on this information, it is estimated that the DHP should be capable of generating at least $25,000 \mathrm{psi}$, and possibly $30,000 \mathrm{psi}$, to be commercially successful across the broadest market. 
Table 9. Measured Threshold Pressure for Several Rocks

$\begin{array}{lc}\text { Rock Type } & \text { Threshold Pressure, psi* } \\ \text { Mancos Shale } & 25,000 \\ \text { Indiana Limestone } & 8,000 \\ \text { Burlington Limestone } & 16,000 \\ \text { Bonne Terre Dolomite } & 16,000 \\ \text { Berea Sandstone } & 4,000 \\ \text { Colton Sandstone } & 9,000 \\ \text { West Texas Anhydrite } & 15,000 \\ \text { West Texas Dolomite } & 12,000 \\ \text { West Texas Sandstone } & 4,500 \\ \text { West Texas Limestone } & 25,000 \\ \text { East Texas Sandstone-1 } & 10,000 \\ \text { East Texas Sandstone-2 } & 15,000 \\ & \\ \text { *All obtained at } 1000 \text { psi ambient pressure. } & \end{array}$

\subsection{Rated Mud Weight}

Mud weight affects hydraulic pressure losses and the fluid speed at which materials erode. A sample set of bit records was sorted for each bit size range identified within the market analysis to ascertain the maximum expected mud weights with which a DHP would have to operate. The results are shown in Table 10. Most of the market is waterbase drilling muds. The exceptions are Texas Railroad District 4 and Southeastern Oklahoma, where oil-base muds are used, and Eastern New Mexico, where brine-water and salt-water-base muds are used. 


\section{Table 10. Maximum Reported Mud Weights, ppg}

\begin{tabular}{|c|c|c|c|c|c|c|}
\hline & & & Bit Siz & inches & & \\
\hline Region & $\begin{array}{c}6- \\
6-3 / 4 \\
\end{array}$ & $7-7 / 8$ & $8-1 / 2$ & $8-3 / 4$ & $\begin{array}{c}9-1 / 2- \\
2-7 / 8\end{array}$ & $12-1 / 4$ \\
\hline Colorado & & 10.0 & 9.5 & & & 9.3 \\
\hline N Louisiana & & 12.5 & & & 12.5 & 9.5 \\
\hline S Louisiana & 17.5 & 9.5 & 12.5 & 12.5 & & 12.5 \\
\hline $\begin{array}{l}\text { E New } \\
\text { Mexico*** }\end{array}$ & 12.5 & 10.2 & 14.0 & 10.1 & & 10.1 \\
\hline Oklahoma** & 16.5 & 10.0 & & & 10.5 & 10.5 \\
\hline TXRR3 & 17.2 & 9.8 & 16.5 & 11.2 & 10.0 & 12.0 \\
\hline TXRR4* & 15.0 & & 17.0 & 10.2 & & 12.5 \\
\hline TXRR5 & & 11.0 & & 10.5 & 11.0 & 9.2 \\
\hline TXRR6 & & 11.0 & & 11.8 & & 9.3 \\
\hline Wyoming & & 10.8 & & 13.8 & & 10.0 \\
\hline Average & 15.7 & 10.5 & 13.9 & 11.4 & 11.0 & 10.5 \\
\hline $\begin{array}{l}* \text { Oil-base } \\
\text { time. } \\
* * \text { In south } \\
\text { used. } \\
* * * \text { Brine an } \\
\text { used }\end{array}$ & $\begin{array}{l}\text { used } \\
\text { n reg } \\
\text {-wate }\end{array}$ & $\begin{array}{l}\text { ut } 30 \\
\text { air- a } \\
\text { dds ar ar }\end{array}$ & nt & nuds & & \\
\hline
\end{tabular}

The heaviest mud weights are generally used at the deepest depths with the smallest bits to balance formation pore pressures. A maximum mud weight of $16 \mathrm{ppg}$ (pounds per gallon) excludes most of the 6-1/2 inch bit size in all regions, except Texas Railroad District 4, and 8-1/2 inch bits in Texas Railroad Districts 3 and 4. For 7-7/8 inch bits, the maximum mud weight within the bit record sample was $12.5 \mathrm{ppg}$ in North Louisiana. The range in mud weight for 7-7/8 inch bits was 9.5 to $12.5 \mathrm{ppg}$.

\subsection{Rated Flow Rate}

The optimum way to deliver the required horsepower down hole to operate the DHP is through increased pressure at the surface. A conventional pressure and horsepower versus flow rate relationship at the bit is shown in Figure 13. The minimum amount of flow required to circulate out cuttings places a lower bound on the hole circulating flow rate. Above this flow rate, pressure available at the bit decreases, although horsepower may increase slightly. An attempt to significantly increase the flow rate results in less delivered pressure to the bit or the DHP, and less delivered horsepower, as transmission losses overwhelm any gain at the bit or DHP. Increasing pressure at the surface while maintaining a minimum flow rate significantly increases both the pressure and horsepower delivered to the bit or DHP. 


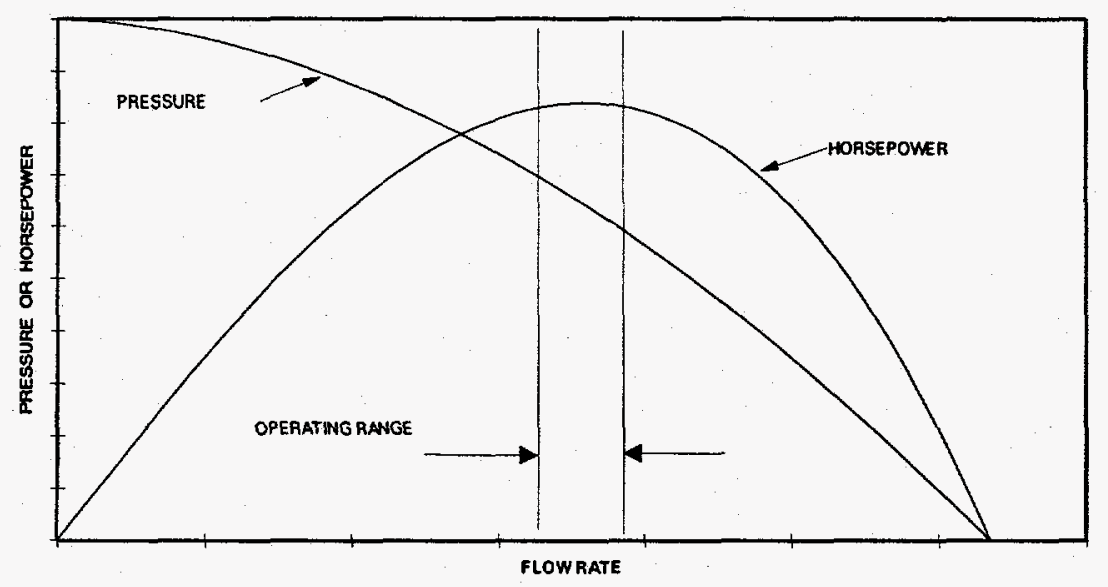

Figure 13. Pressure, Horsepower versus Flow Rate Relationship Downhole

The circulating flow rates down hole should be between the minimum annular velocity past the drill pipe required to transport rock cuttings to the surface and the maximum annular velocity past the larger diameter drill collars such that formation erosion (washouts) is minimized. Optimum annular fluid velocities for normal ranges of holes sizes were developed by Hal B. Fullerton, Jr. as reported by Allen (1975). The simple relationship is

$$
A V=\frac{11,800}{\rho D}
$$

where AV is annular velocity in feet per minute, $\rho$ is mud weight in ppg, and $D$ is hole diameter in inches. This relationship is shown in Figure 14 along with the corresponding flow rate in gallons per minute for 4-1/2 inch diameter drill pipe in a 7-7/8 inch hole size. Optimum annular velocity increases with smaller hole diameter and with lighter mud weights. Two curves are shown for annular velocity and for flow rate in Figure 14. Those labeled " $\mathrm{FN}=1$ " are the actual Fullerton relationship, those labeled $\mathrm{FN}=1.1$ are for values 10 percent higher than for $\mathrm{FN}=1$. 


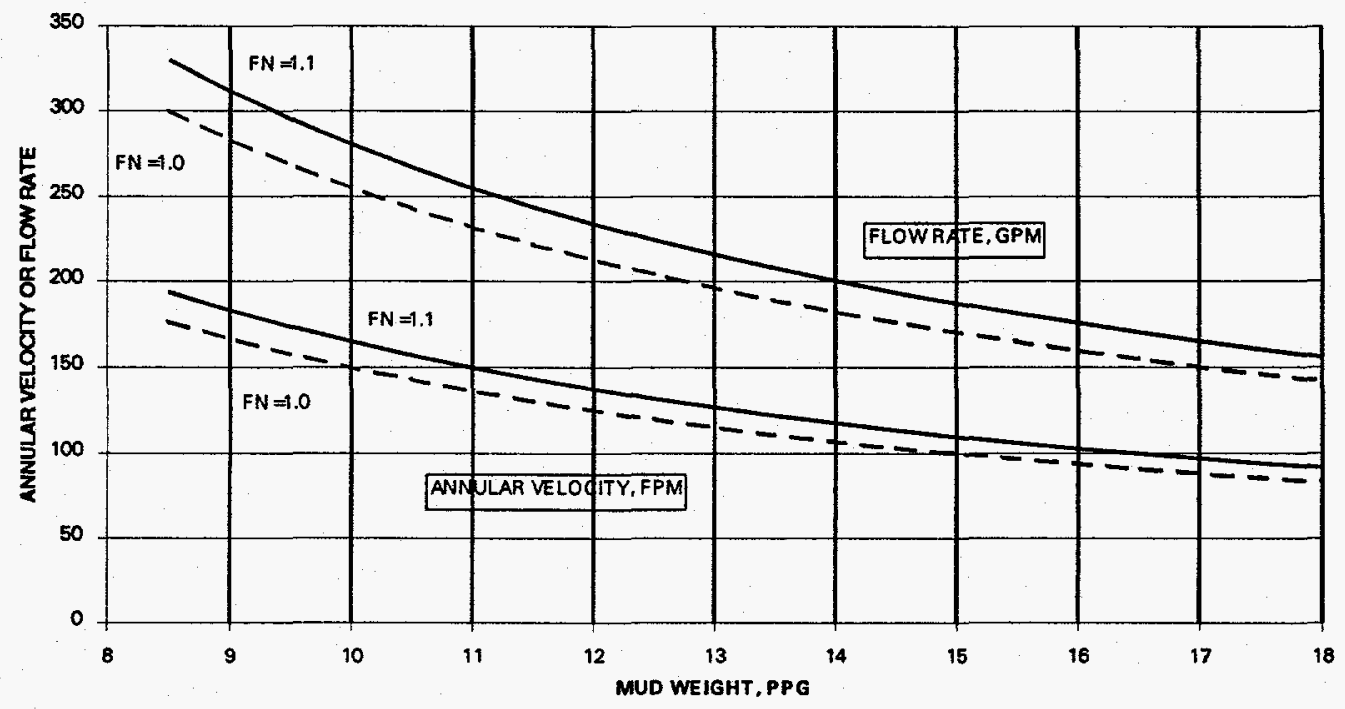

Figure 14. Fullerton Relationship for 7-7/8 inch Hole Size using 4.5 inch Drill Pipe

From Figure 14 the optimum annular velocity and flow rate in a 7-7/8 inch diameter hole (FN=1) for a mud weight of $10 \mathrm{ppg}$ is $150 \mathrm{fpm}$ and $255 \mathrm{gpm}$. A number of bit records were examined to identify common practice. Generally, 10 to 15 percent higher flow rates than the optimum defined by Fullerton are used in practice. This is to maintain optimum annular velocities through sections of hole where a larger diameter hole may occur due to erosion. As a specification for the DHP, a flow rate of $295 \mathrm{gpm}$ ( $\mathrm{FN}=1.1$ ) with an annular velocity of $174 \mathrm{fpm}$ for a $9.5 \mathrm{ppg}$ mud weight was adopted. The higher flow rate determines the maximum stroke rate and the maximum pressure losses through the DHP.

\subsection{Rig Pump Capacity}

Increasing operating pressures will result in increased operating costs for the surface pumps. Surface pump pressures, based on sample bit records average 2,050 psi. Some rigs in the sample operated as high as 4,500 psi. For 7-7/8 inch bit runs, the average was 1,700 psi. To deliver maximum horsepower downhole for the DHP, surface pressures as high as 3,500 to 3,700 psi may be required. Surface mud pump operating costs as a function of pressure were estimated from data solicited from consultants, drilling contractors, and a pump manufacturer. The estimated costs are shown plotted in Figure 15. The cost increases with pressure exponentially, as suggested by Miller (1993). The increased costs that will be experienced to operate the DHP are within reason to support the enhancements in ROP anticipated with jet-assisted drilling. These costs were included in the "Cost per5 DHP Pumping Hour" in Section 3.1. They are not expected to have a significant impact on DHP market size or implementation of the technology. 


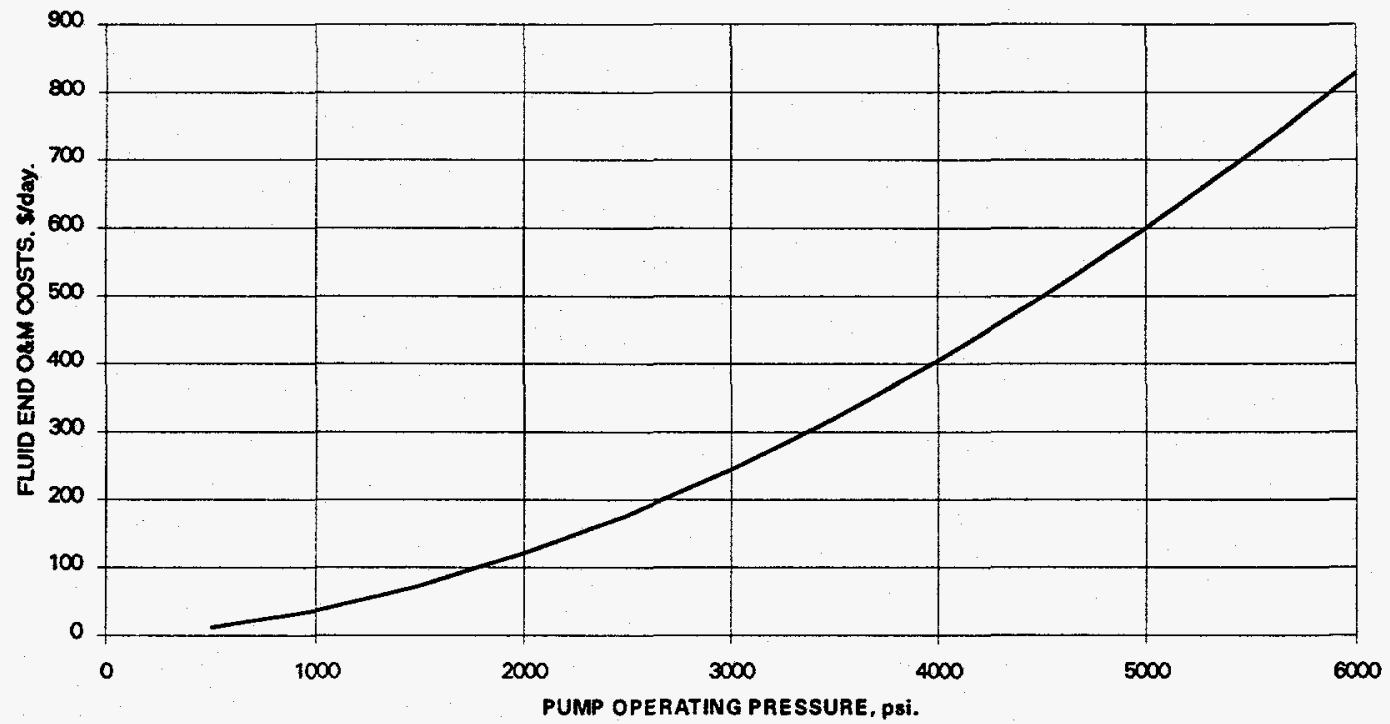

Figure 15. Surface Mud Pump Costs versus Operating Pressure

The rig surface mud pumps must be capable of developing the increased horsepower to operate the DHP. For a 7-7/8 inch diameter hole, 580 to 650 total hydraulic horsepower will be required of the surface pumps to operate the DHP, to overcome drill string pressure losses, and to provide for pressure drop across the conventional bit nozzles. The Rig Locator supplement to Petroleum Engineer International lists rigs and their pumping horsepower by region. Shown in Table 11 are the number of rigs from the Rig Locator supplement for 1992 that have total installed surface mud pump horsepower capable of operating the DHP. In general, the values given are for two surface mud pumps of equal horsepower. For rigs with smaller pumps, both pumps may be run together, as suggested by Miller (1993). 
Table 11. Drill Rigs with Sufficient Pumping Horsepower to Operate DHP

\begin{tabular}{|c|c|c|c|c|c|c|}
\hline \multirow[b]{2}{*}{ Region } & \multirow[b]{2}{*}{$\frac{\text { Total }}{\text { Rigs }}$} & \multicolumn{2}{|l|}{ Pump } & \multicolumn{3}{|c|}{ Rated Depth Capacity* $\geq$} \\
\hline & & Horsepowerz & 7,500 & 10.000 & 12.500 & 15,000 \\
\hline \multirow[t]{2}{*}{ U.S. Land** } & $\overline{1102}$ & 1000 & 698 & 648 & 522 & 396 \\
\hline & & 2000 & 299 & 299 & 293 & 261 \\
\hline \multirow[t]{2}{*}{ Colorado } & 41 & 1000 & 10 & 9 & 6 & 4 \\
\hline & & 2000 & 2 & 2 & 2 & 2 \\
\hline \multirow{2}{*}{ N Louisiana } & 12 & 1000 & 9 & 9 & 9 & 8 \\
\hline & & 2000 & 3 & 3 & 3 & 3 \\
\hline \multirow[t]{2}{*}{ S Louisiana } & 56 & 1000 & 43 & 40 & 36 & 34 \\
\hline & & 2000 & 31 & 31 & 31 & 29 \\
\hline \multirow{2}{*}{$\begin{array}{l}\text { E New } \\
\text { Mexico }\end{array}$} & 50 & 1000 & 42 & 36 & 24 & 15 \\
\hline & & 2000 & 6 & 6 & 6 & 5 \\
\hline \multirow[t]{2}{*}{ Oklahoma } & 230 & 1000 & 180 & 178 & 155 & 121 \\
\hline & & 2000 & 83 & 83 & 81 & 73 \\
\hline \multirow[t]{2}{*}{ TXRR3 } & 70 & 1000 & 64 & 64 & 56 & 44 \\
\hline & & 2000 & 39 & 39 & 39 & 33 \\
\hline \multirow[t]{2}{*}{ TXRR4 } & 35 & 1000 & 32 & 31 & 22 & 15 \\
\hline & & 2000 & 16 & 16 & 16 & 14 \\
\hline \multirow[t]{2}{*}{ TXRR5 } & 13 & 1000 & 8 & 8 & 6 & 4 \\
\hline & & 2000 & 3 & 3 & 2 & 1 \\
\hline \multirow[t]{2}{*}{ TXRR6 } & 74 & 1000 & 52 & 50 & 37 & 22 \\
\hline & & 2000 & 21 & 21 & 20 & 17 \\
\hline \multirow[t]{2}{*}{ Wyoming } & 87 & 1000 & 68 & 63 & 42 & 30 \\
\hline & & 2000 & 13 & 13 & 13 & 12 \\
\hline TOTAL FOR & 668 & 1000 & 508 & 488 & 393 & 297 \\
\hline 10 REGIONS & & 2000 & 217 & 217 & 213 & 189 \\
\hline
\end{tabular}


The rig pumps and rig equipment must also be capable of developing the required surface pressures to operate the DHP. This is estimated as between 3,500 and 3,700 psi. and is shown later under design performance projections. All most all rig triplex mud pumps of the 500 to 1000 , or larger horsepower have rated pressure capability in excess of the required surface pressure for the DHP when equipped with the appropriate size liners. Duplex pumps do not have the rated pressure capability and are generally associated with rigs with shallow depth ratings less than 7,500 feet. Shown in Table 12 are triplex pump manufacturers, input horsepower, and pressure ratings for liner sizes 4 inch through 6 inch, as given in the Hydraulics Manual by the Security division of Dresser Industries. These liner sizes are readily available from either the manufacturer or various suppliers. When smaller horsepower pumps are used, the flow requirements for a 7-7/8 inch hole may require operating two pumps simultaneously to develop sufficient horsepower to operate the DHP, similar to what is commonly done to drill larger diameter surface hole requiring flow rates in excess of a single pump capacity. During field experiments with the 7-5/8 inch fiirst prototype DHP developed with GRI, the rigs were equipped with 1000 horsepower mud pumps: a Skytop Brewster B1100T, Gardner Denver PZ-9, or a National 9-P-100, usually equipped with 5.5 inch liners. Surface standpipe pressures used were between 3,200 and 3,400 psi.

\section{Table 12. Rig Triplex Mud Pump Pressure Ratings}

\begin{tabular}{|c|c|c|c|c|c|c|c|}
\hline \multirow[b]{2}{*}{ Manufacturer } & \multicolumn{3}{|c|}{ Input } & \multicolumn{3}{|c|}{ Liner Size(Inches) } & \multirow[b]{2}{*}{6} \\
\hline & Model & H.P. & 4 & 4.5 & 5 & 5.5 & \\
\hline \multirow[t]{3}{*}{ Continental Emsco } & F-500 & 500 & 3818 & 3025 & 2440 & 2024 & 1699 \\
\hline & F-800 & 800 & 5585 & 4415 & 3590 & 2965 & 2490 \\
\hline & $F-1000$ & 1000 & - & 5340 & 4330 & 3575 & 3010 \\
\hline Ellis Williams & $W-1000$ & 1000 & - & - & 4716 & 3898 & 3275 \\
\hline \multirow{3}{*}{ Gardner Denver } & PZ-7 & 550 & - & 4048 & 3279 & 2710 & 2277 \\
\hline & PZ-8 & 750 & 5000 & 4830 & 3912 & 3233 & 2717 \\
\hline & PZ-9 & 1000 & - & 5000 & 5000 & 4274 & 3592 \\
\hline \multirow[t]{3}{*}{ IDECO } & $\mathrm{T}-500$ & 500 & 3588 & 2826 & 2289 & 1895 & 1591 \\
\hline & $\mathrm{T}-800$ & 800 & - & 4424 & 3588 & 2960 & 2488 \\
\hline & $\mathrm{T}-1000$ & 1000 & - & 5339 & 4322 & 3580 & 3002 \\
\hline \multirow[t]{3}{*}{ National Supply } & 7-P-50 & 500 & 3695 & 2920 & 2365 & 1955 & 1645 \\
\hline & 8-P-80 & 800 & - & 4395 & 3560 & 2940 & 2470 \\
\hline & $9-P-100$ & 1000 & - & 5385 & 4360 & 3505 & 3030 \\
\hline \multirow[t]{2}{*}{ Oilwell } & 850-PT & 850 & 5000 & 4400 & 3565 & 2946 & 2476 \\
\hline & $1100-\mathrm{PT}$ & 1100 & - & 5000 & 4482 & 3704 & 3112 \\
\hline \multirow[t]{2}{*}{ Syktop Brewster } & $\mathrm{B} 1000 \mathrm{~T}$ & 1000 & 5000 & 5000 & 4660 & 3846 & 3233 \\
\hline & B1100T & 1100 & 5000 & 5000 & 4753 & 3928 & 3300 \\
\hline
\end{tabular}

The other rotary drilling components, surface piping, standpipe, kelly hose, swivel, kelly and drill string are all generally rated at a working pressure of 5,000 psi with burst pressures double the working pressure. This is a generally accepted practice, or standard within the industry for U.S. land drilling equipment. For example, both Cardwell 
International and OTEC rate their surface plumbing components and standpipes at 5,000 psi working pressure. Almost all swivels with rated working loads of 400 or more tons are rated at 5,000 psi working pressure. Kelly hoses, API Specification 7 (1985), have rated working pressures of either 5,000 or 7,500 psi, depending on which grade is in use.

The internal pressure rating for new grade E, 4.5 inch, $16.6 \mathrm{lb} / \mathrm{ft}$ drill pipe given in API RP 7G (1984) is 9,830 psi at minimum yield strength. This is generally the lightest drill pipe used in deeper wells. With a factor of safety of 2 , the working pressure is $4,615 \mathrm{psi}$. Used drill pipe is designated by class and color code. Class I used pipe is normally called premium and coded "single white band." Class II is more worn pipe than Class I and coded "double white band" used pipe. Class III is the most worn pipe coded "yellow band." Yellow band pipe is not used in rotary drilling in deeper wells because of the low tensile strength. Class II pipe (double white band), 4.5 inch grade $\mathrm{E}$, has a rated pressure at minimum yield of $7,300 \mathrm{psi}$ or a working pressure of $3,650 \mathrm{psi}$ with a factor of safety of 2. Consequently, used drill pipe in use on those rigs with the deeper well capability would be adequate for safely operating the DHP at surface pressures up to $3,650 \mathrm{psi}$.

The larger capacity rigs, with larger installed pumping horsepower and better condition equipment, are generally located where deeper drilling occurs, i.e., where the DHP market is perceived to be. Over 63 percent of the rigs in the U.S. have a depth capacity of 7,500 feet or greater and installed pump horsepower of $1,000 \mathrm{hp}$ or greater, which should be adequate to support operation of the downhole pump using both surface mud pumps. About 27 percent of the rigs over the U.S. have depth capacity of 7,500 feet or greater and sufficient pump horsepower to support operation using only a single pump. For rigs located within the ten study regions, over 75 percent have a depth capacity of 7,500 feet or greater and installed pump horsepower of $1,000 \mathrm{hp}$ or greater. Within the potential DHP market locations for either all drilling or gas drilling (Texas Railroad Districts 3 and 6, Oklahoma, and Wyoming), almost 80 percent (364 out of 461 rigs) have a depth capacity of 7,500 feet or greater and installed pump horsepower of $1000 \mathrm{hp}$ or greater. Sufficient rigs with sufficient capacity and capability for operation of the DHP should be available and should not have a significant impact on the DHP market.

\subsection{Rated Temperature}

The downhole temperatures expected for each market region are given in Table 13. Geothermal gradient data were taken from Nathenson and Guffanti (1988). Texas Railroad District 6 has the highest geothermal gradient and therefore the highest downhole temperatures. A surface temperature of $70^{\circ} \mathrm{F}$ was assumed for southern regions, and $60^{\circ} \mathrm{F}$ was assumed for higher-altitude northern regions. Temperatures given for 10,000-foot depths are "soak" temperatures. When operating or circulating, downhole temperatures are 20 to $30^{\circ} \mathrm{F}$ lower than soak temperatures. To match the market areas, a specified downhole operating temperature for the DHP at a depth of 10,000 feet is a maximum of $250^{\circ} \mathrm{F}$. 


\section{Table 13. Downhole Temperatures}

$\begin{array}{lcc}\text { Region } & \begin{array}{c}\text { Geothermal } \\ \text { Gradients } \circ \mathrm{F} / 100\end{array} & \begin{array}{c}\text { Temperature at } \\ \text { 10,000 feet }(\circ \mathrm{F})\end{array} \\ \text { Colorado } & 1.9 & \\ \text { N Louisiana } & 2.0 & 250 \\ \text { S Louisiana } & 1.7 & 270 \\ \text { E New Mexico } & 1.4 & 240 \\ \text { Oklahoma } & 1.9 & 210 \\ \text { TXRR3 } & 1.6 & 260 \\ \text { TXRR4 } & 1.4 & 230 \\ \text { TXRR5 } & 2.0 & 210 \\ \text { TXRR6 } & 2.1 & 270 \\ \text { Wyoming } & 1.4 & 280 \\ \text { fyom } & 1.4 & 200\end{array}$

Although no specific information was obtained on hydrogen sulfide $\left(\mathrm{H}_{2} \mathrm{~S}\right)$ or chloride concentrations, it is noted that $\mathrm{H}_{2} \mathrm{~S}$ (sour gas) commonly occurs uphole in Eastern New Mexico and sometimes below 10,000 feet in Texas Railroad District 6. The presence of $\mathrm{H}_{2} \mathrm{~S}$ can lead to component structural failure due to hydrogen embrittlement. High concentrations of chlorides occur in Eastern New Mexico, where saturated brine-water and salt-water drilling muds are used. For highly stressed components where chlorides are present, stress corrosion cracking can occur. Both of these phenomena can lead to catastrophic failure of highly stressed high-pressure components and present a formidable technical design problem. The largest markets identified for the DHP, however, do not occur where either $\mathrm{H}_{2} \mathrm{~S}$ or high chloride concentrations will present a challenge.

\subsection{Performance and Design Specifications}

Performance specifications for the 6-3/4 inch DHP are shown in Table 14. It was specified at a rated UHP output pressure of 30,000 psi at a rated flow rate of $20 \mathrm{gpm}$ with an input low pressure drive flow of $295 \mathrm{gpm}$ at $9.5 \mathrm{ppg}$. Desired pressure losses through the pump were specified as no larger than $400 \mathrm{psi}$ at these flow rates to achieve a hydraulic efficiency of the DHP of over 70 percent. Pressure losses through the DHP also affect the required rig pump operating pressure. Maximum stroke rate was specified at 120 to keep the plunger speeds through the UHP seals consistent with the 7-5/8 inch DHP.

Table 14. DHP Design Point Performance Specifications

$\begin{array}{lr}\text { UHP Pressure } & 30,000 \mathrm{psi} \\ \text { UHP Flow } & 20 \mathrm{gpm} \\ \text { Drive Flow } & 295 \mathrm{gpm}\end{array}$




$\begin{array}{lc}\text { Pressure Loss } & 400 \mathrm{psi} \\ \text { Max. Stroke Rate } & 120 \mathrm{spm} \\ \text { Mud Weight } & 9.5 \mathrm{ppg} \\ \text { Efficiency } & 70 \%\end{array}$

Additional design specifications are listed in Table 15. The maximum design UHP was set above the design performance point at 35,000 psi. The maximum outer diameter was specified as 6-3/4 inches to allow as much interior space as possible and still allow a commercial washover pipe to be used in a 7-7/8 inch hole. To make the tool more compact, it was decided to include the coarse filter, dump sub, float sub, UHP attenuator, and pump section (see Figure 4) together in a single housing about the length of a standard drill collar (31 feet), or shorter if possible. It was also specified to include a fishing neck on the upper end of the housing to accommodate an overshot. The design was also specified to accommodate mud weights up to $12.5 \mathrm{ppg}$ and mud inlet operating temperatures up to $250^{\circ} \mathrm{F}$.

Table 15. DHP Additional Design Specifications

$\begin{array}{lc}\text { Max. UHP Pressure } & 35,000 \mathrm{psi} \\ \text { Tool Max. OD } & 6-3 / 4 \mathrm{in} . \\ \text { Tool Length, 1 Piece } & 28 \mathrm{ft} . \\ \text { Fishing Neck } & 5 \mathrm{ft} . \\ \text { Mud Weights } & \text { up to } 12.5 \mathrm{ppg} \\ \text { Temperature } & \text { up to } 250^{\circ} \mathrm{F}\end{array}$




\section{DHP Design Description}

For the 6-3/4 inch DHP, the same concept as shown in Figure 3 was continued. During the design phase, attempts were made to improve several components and several aspects of the design over the 7-5/8 inch DHP. These included increasing the stroking rate of the pump such that it could be operated at full stroke rate, improving the overall efficiency by reducing hydraulic losses, making it shorter as well as smaller in diameter, and improving the fishability of the tool. In particular, the mechanical design of the center connecting drive tube and connections through the drive pistons was changed significantly.

\subsection{DOE/FlowDril DHP Basic Arrangement}

The basic arrangement of the components outlined in the concept shown in Figure 3, are shown in Figure 16 as they occur in the 6-3/4 inch DHP design. At the lower end of the DHP, the fluid outlet end, is the bit sub (to which the drill bit is attached). In the bit sub and extending into the DHP is the UHP inner conduit (IC) that carries UHP fluid from the DHP to the drill bit. Above the bit sub is the pumping section of the DHP within the DHP housing. The pumping section consists of a lower and an upper end. The lower end of the pump, generally consists of the lower UHP cylinder and two lower end low pressure drive chambers. Between the lower and upper drive chambers is the center valve (manifold) section where the by-pass valve and the DHP shifting control valves (pilot valve and main valve) are located. The upper end of the pump, as does the lower end, generally consists of the two upper drive chambers and the upper UHP cylinder. Above the pumping section and still within the housing are the shear filter, the UHP accumulator (also called an attenuator as in Figure 3), and a coarse inlet screen.

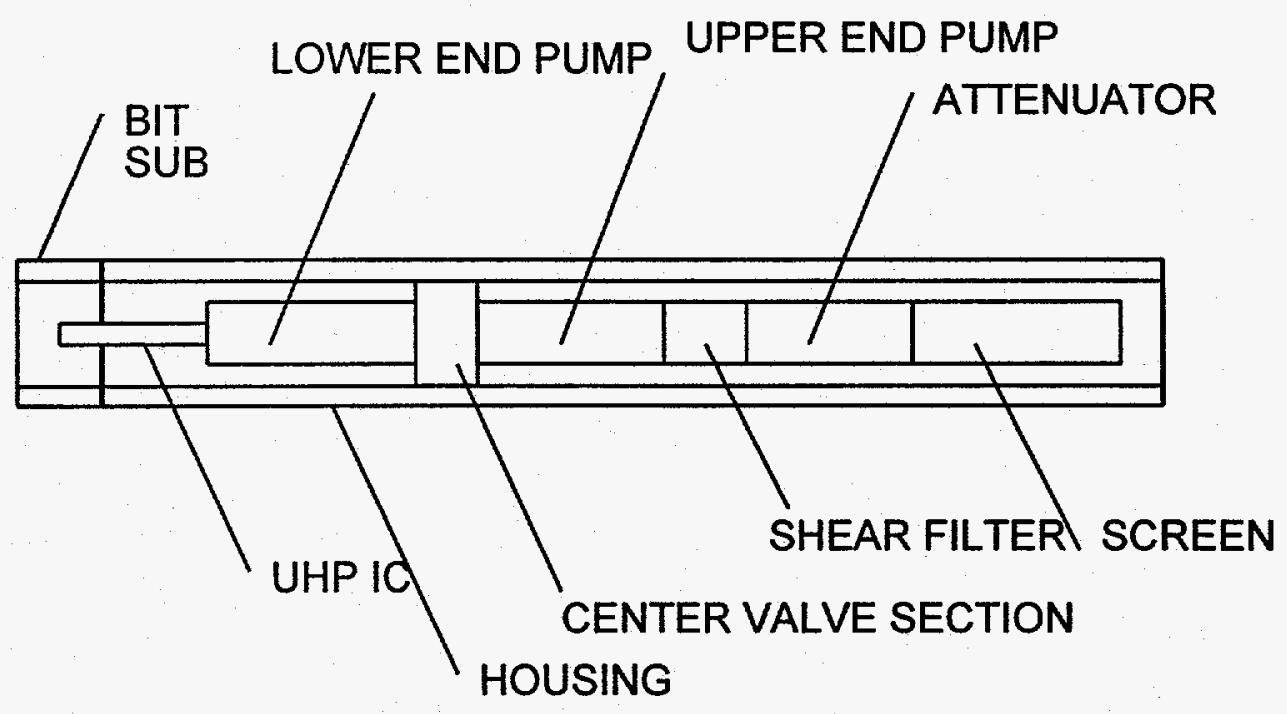

Figure 16. General Arrangement of DHP 
During assembly, the UHP inner conduit, pumping section, shear filter, and UHP attenuator all slide into the housing from the bit sub end as a single assembled unit. This assembly is stabilized within the housing with three longitudinal, strip centralizers located at equal spaces around the circumference of the assembly. The bit sub retains this assembly with a seat at the upper end of the attenuator against a shoulder within the housing. The coarse screen is inserted into the DHP housing from the upper end.

A schematic of the pumping section, consisting of the lower end of the pump, the center valve (manifold) section, and upper end of the pump is shown in Figure 17. The pumping section is arranged symmetrically about the center valve section. As indicated in the figure, there are four drive pistons, each in a separate drive cylinder. The four drive pistons are connected together with the connecting tube. The connecting tube also conveys fluid between drive cylinders and the main shifting valve as indicated conceptually in the sketch in Figure 3. Outboard of the drive pistons are the UHP plungers, one on either end of the pump section. The UHP plungers run in the UHP cylinders through the UHP dynamic seals. At the outlet end of the UHP cylinders are the UHP inlet and outlet check valves. The four drive pistons operate hydraulically in parallel to generate the force conveyed through the connecting tubes to the UHP plungers to pressurize the UHP fluid in the UHP cylinders.

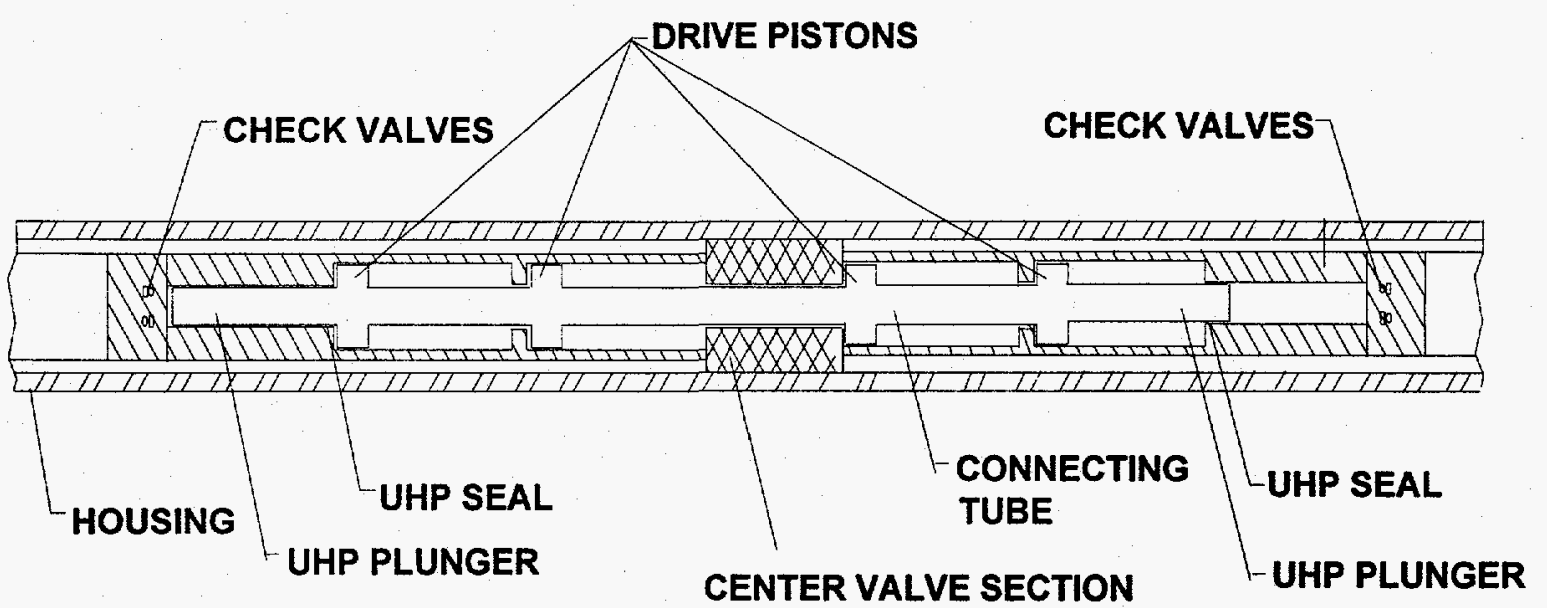

Figure 17. Pumping Section of the DOE/FlowDril DHP

The lower pressure drive fluid pumped down the drill string from the surface enters the DHP from the upper end and encounters the coarse screen first. It then flows over the UHP attenuator, over the shear filter, over the upper end of the pumping section, and into the main control valve. The main control valve directs the flow within the pumping section to drive the pistons either upward or downward. Fluid downstream of the drive pistons is exhausted through the main control valve downstream of the center valve section into the lower end of the pumping section. It then flows over the lower end of the pump, through the bit sub to the drill bit, and out the conventional nozzles of the drill bit. 
The inlet drive fluid is isolated from the lower pressure outlet fluid by seals between the center valve manifold section and the housing. The inlet to the main control valve is upstream of these seals, and the outlet of the main control valve is below these seals.

As entering drive fluid flows over the shear filter, a small portion is drawn through the filter to supply the UHP fluid and the fluid used to hydraulically shift the main control valve. The UHP inner conduit, lower UHP cylinder outlet, upper UHP cylinder outlet, and UHP attenuator are connected by two UHP outer conduits passing through the annual region between the inner pumping section assembly and the outer housing and through the center valve section. A similar arrangement provides lower pressure fluid from the shear filter to the center valve section for shifting the main control valve and to the inlet to the lower end UHP cylinder.

\subsection{Connecting Tubes}

Running through the center of the pumping section of the DHP are the connecting tubes. They conduct drive fluid between the four drive cylinders and the main control valve. They also transmit the force to drive the UHP plungers into the UHP cylinders. There are three of the them in the DHP design; two outboard connecting tubes and one center connecting tube. The center connecting tube is longer than the outboard ones and passes through the center valve section.

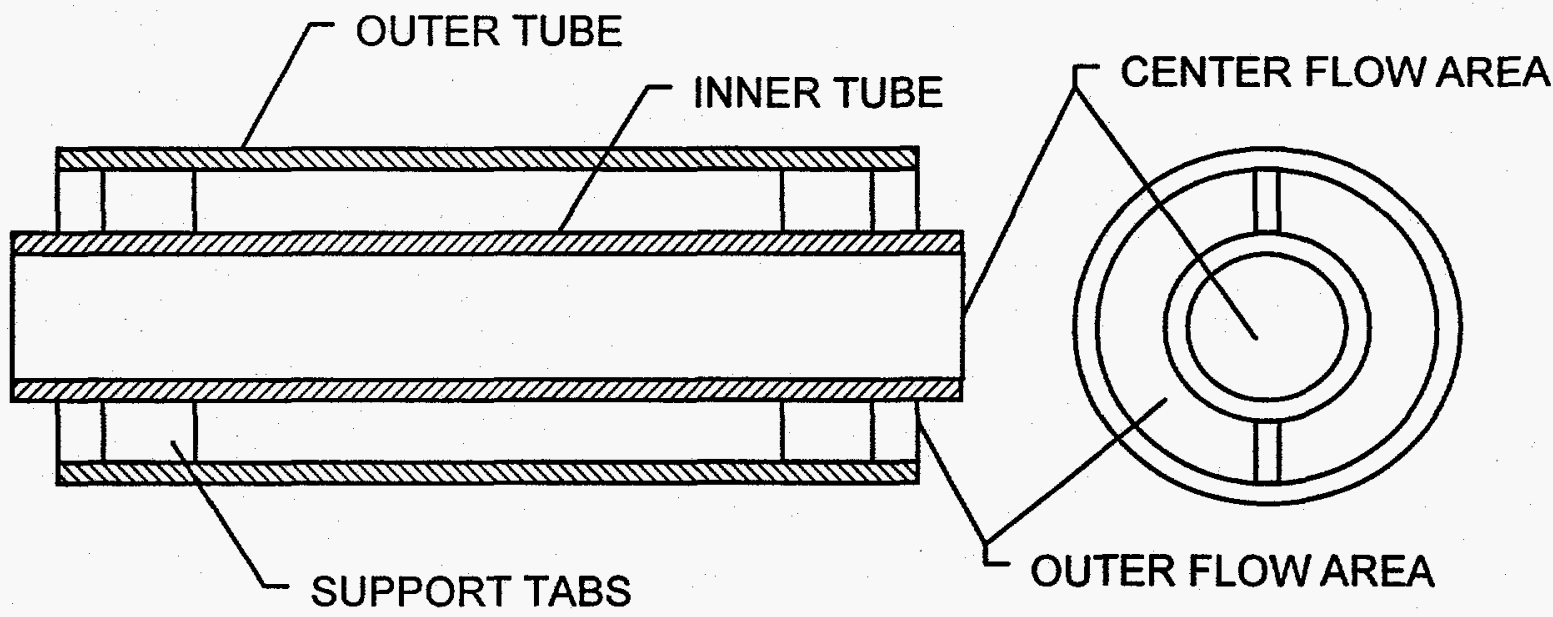

Figure 18. Connecting Tubes

They consist of two concentric tubes, welded together at the ends with support tabs as shown in Figure 18. The bore of the inner tube is the center flow area for the passage that connects to the lower side of each drive piston and drive chamber to the main control valve. The annular region between the inner and outer tubes, the outer flow area, is the 
fluid passage that connects the upper side of each drive piston and drive cylinder to the main control valve. In each passage, fluid flows in either direction, depending on whether the pump is stroking upward, or stroking downward. The fluid flow direction in the outer flow area, however, is always in the opposite direction to the flow direction in the center flow area. The pressure, as does the fluid flow direction, alternates in each flow passage between drive pressure and outlet (exhaust) pressure. Relative diameters of the two concentric tubes were determined by attempting to equalize hydraulic flow losses between the outer flow area and the inner flow area.

The outer tube transmits the force to drive the UHP plunger. The outboard connecting tubes carry the largest load, as it is accumulated for the pressure generated by three drive pistons, however, the longer center connecting is more critical for buckling under load.

\subsection{Low pressure Drive Cylinders/Pistons/Seals}

Attached to each end of the each connecting tube weldment is a low pressure drive piston. These drive pistons run in the low pressure liners, or cylinders. The arrangement is shown in Figure 19. The low pressure liners/pistons comprise the fluid drive cylinders that hydraulically drive the connecting tube - drive piston - UHP plunger assembly up and down (or back and forth) in the DHP.

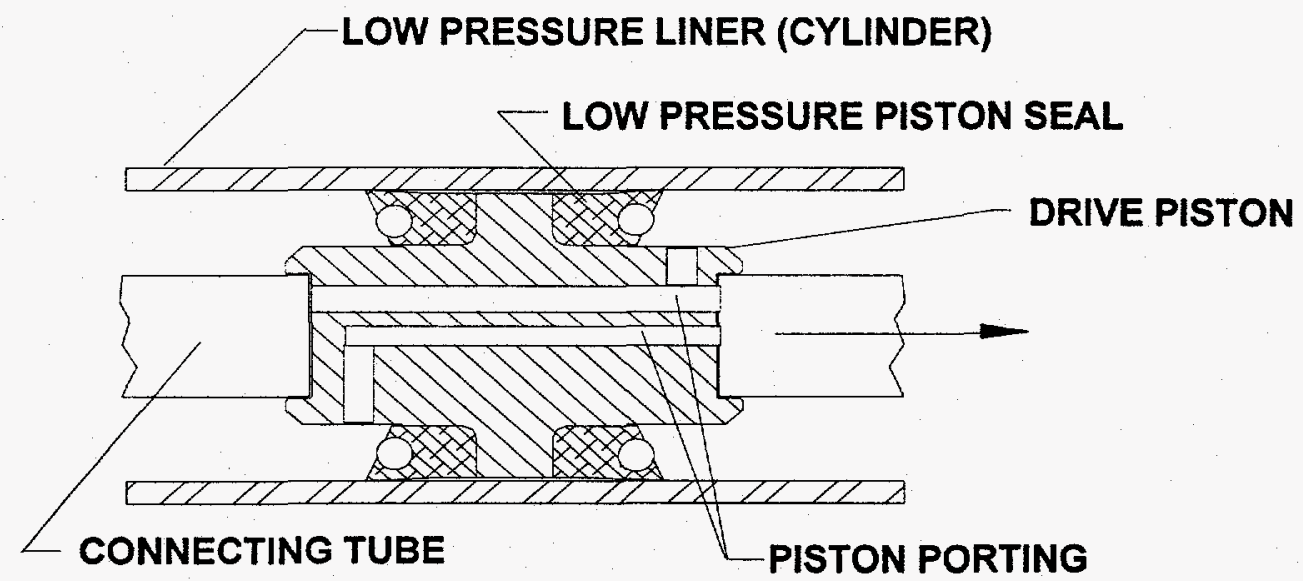

Figure 19. Low Pressure Cylinder/Piston/Seals

When fluid at drive pressure is on the upper side of each piston, the lower side of each piston is at outlet (exhaust) pressure. To seal these pressures from each other, seals mounted on the pistons are used. These dynamic piston seals run on the interior surface of the liners. Fluid passages are ported through the pistons to connect all the upper sides of the pistons together, and all of the lower side of the pistons together. Porting in the end pistons is slightly different as they connect to the UHP plungers. The pistons are connected to the connecting tubes using split ring clips held against the piston with a 
retainer ring bolted to the face of the piston (not shown). Between the two low pressure drive cylinders on both the lower pump end and upper pump end are liner separators with rod seals (not shown) through which the connecting tube travels. These liner separators support and align the ends of the low pressure cylinder liners.

\subsection{UHP Cylinders/Plunger/Seals}

Outboard of the two end drive pistons are the UHP plungers. The end of the low pressure drive piston, the UHP plunger, and UHP cylinder arrangement are shown in Figure 20. The UHP plunger is retained in the drive piston with a threaded in tie rod through the hollow UHP plunger.

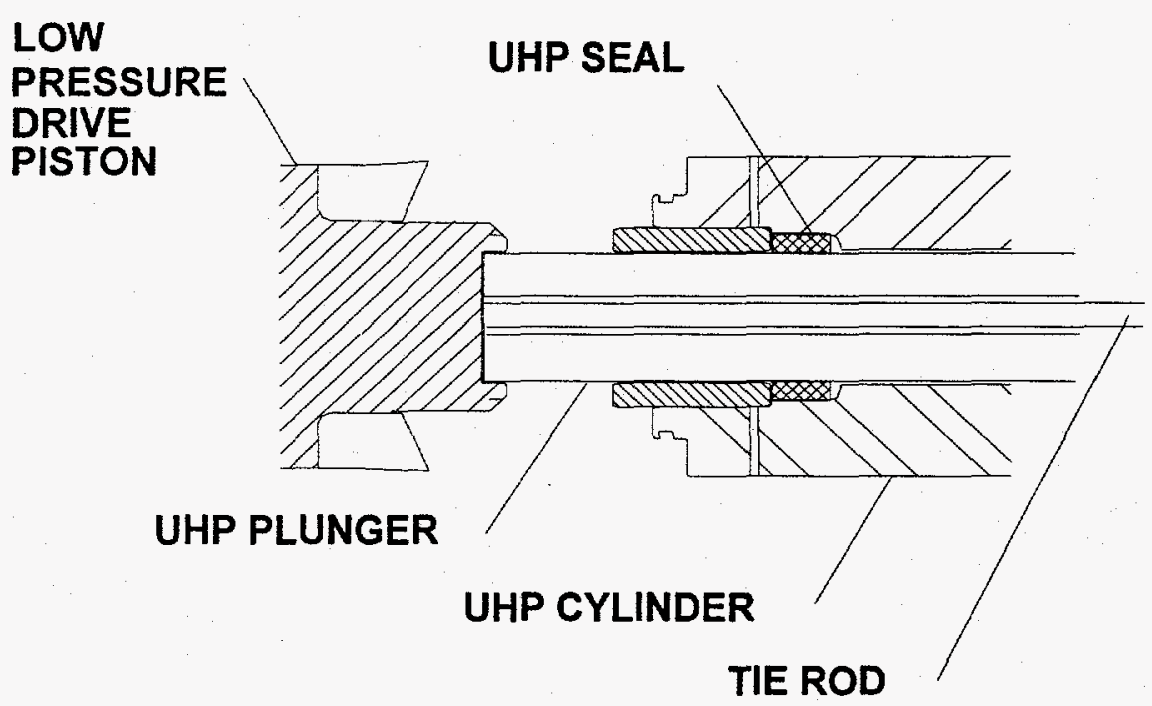

Figure 20. UHP Cylinder/Plunger/Seal

Where the UHP plunger enters the UHP cylinder is where the UHP dynamic seals are located. Between the two outboard drive cylinders and the UHP cylinder is an end bell (not shown) through which the UHP plunger travels and which supports the UHP cylinder and the low pressure cylinder liner.

Design of the UHP cylinder is based on resistance the high cycle fatigue. Pressure from inside to outside the UHP cylinders varies each pump stroke from the drive pressure of $2,100 \mathrm{psi}$ during the charging return stroke to $30,000 \mathrm{psi}$ on the pumping stroke.

\subsection{UHP Check Valves}

At the outboard end of each UHP cylinder is the UHP inlet/outlet check valve assembly. This is shown in Figure 21 with the outlet check valve open and the inlet check valve 
closed. The type of check valves used are ball and seat without springs. Both the ball and the seats are of very hard materials. The seal is made by a narrow band of contact of the round ball in the cone shaped seat. The check valve housing is again a highly stressed component subject to the same pressure cycling as the UHP cylinders.

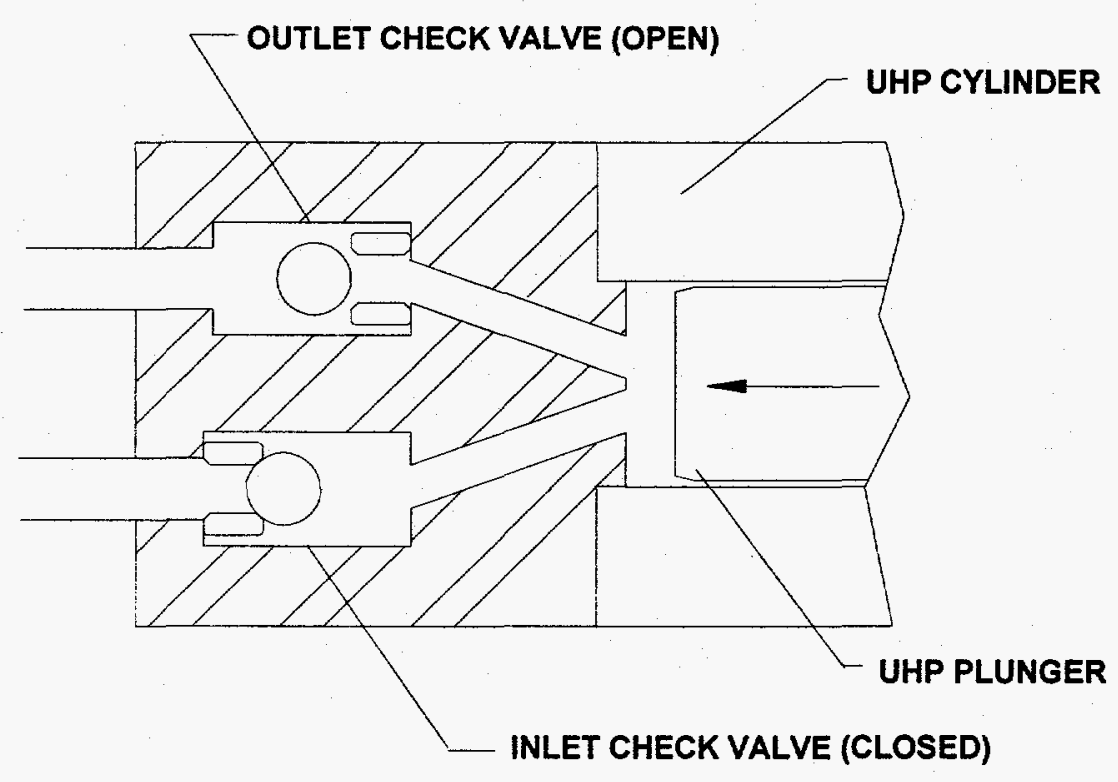

Figure 21. UHP Check Valves

\subsection{Center Valve Manifold Section}

Separating the lower end of the pump from the upper end of the pump is the center valve manifold section (see Figures 16 and 17). The center valve manifold section has three pieces; a lower manifold section, a middle manifold section, and an upper manifold section. The middle valve manifold has straight through bores for the main control valve, pilot (trigger) valve, and by-pass valve as shown in Figure 22.

Around the outside circumference of the middle manifold are the seals between the center valve section and the housing of the pump that separate the inlet drive flow from the lower pressure outlet flow (exhaust) of the pump. It is across these seals that the pressure to drive the DHP is maintained.

The lower and upper valve manifolds have circumferential internal porting to connect the " $\mathrm{A}$ " and " $\mathrm{B}$ " main valve ports to the lower and upper low pressure drive cylinders. To fit the valve pieces and provide the porting in the center valve manifold sections required a design compromise between physically fitting the components within the available space, providing enough wall thicknesses to have the structural strength required, and yet provide fluid passages large enough to avoid large pressure losses and fluid erosion. It is 
the fluid passages in the lower and upper valve manifolds that are the most susceptible to fluid erosion.

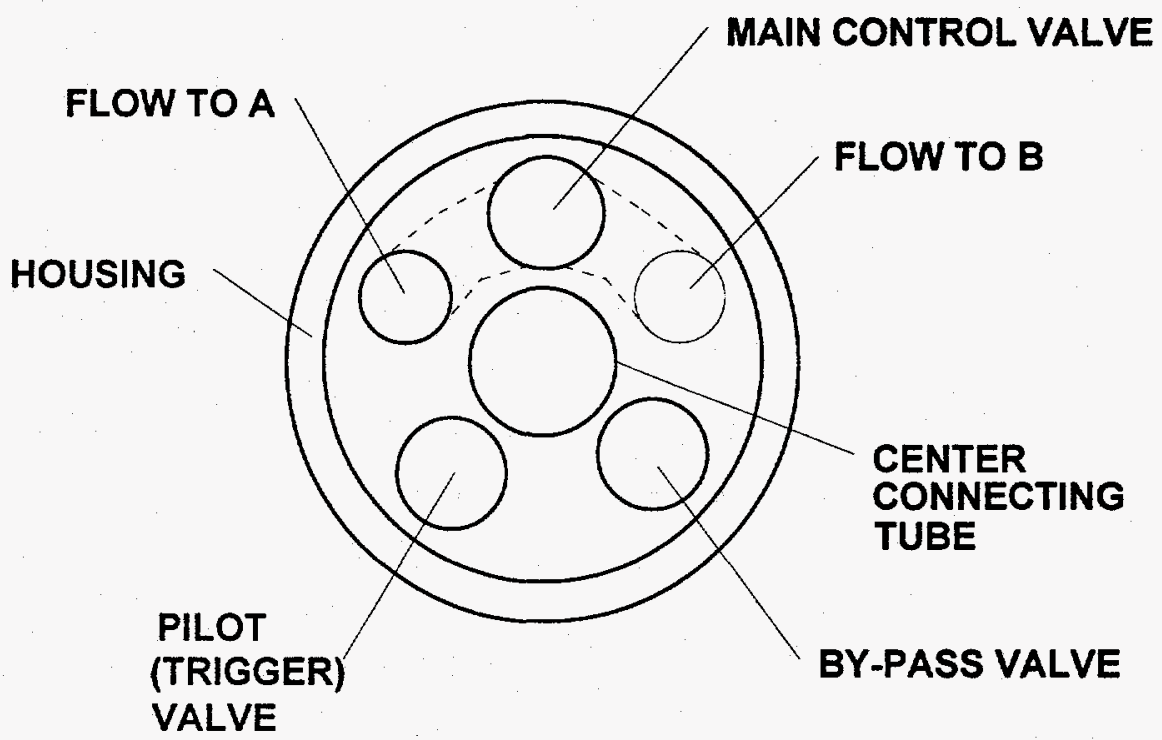

Figure 22. Center Valve Manifold Cross Section

\subsection{Main Valve}

The main control valve controls the direction of the drive fluid within the DHP. It is located in the center valve manifold section. It is a four-way directional control valve that is pilot operated. It is shown in Figure 23 shifted such that the inlet port, the pressure port, is open to " $\mathrm{A}$ " (see Figure 3 for " $\mathrm{A}$ " and " $\mathrm{B}$ " locations in the drive cylinders) and the tank port, or exhaust port, is open to "B". In the DHP the drive pistons within the drive cylinders are between the pressurized "A" port and the "B" port open to tank (exhaust). When in the opposite position, the spools are moved across the pressure and tank ports opening inlet pressure to "B" and tank (exhaust) to " $\mathrm{A}$ " and the fluid flow direction and pump stroking direction are changed to the opposite direction. The effect of the valve is to re-direct the flow within the DHP. When the main valve goes across center, or is in the center position, the spools do not completely close off either the pressure port or the tank port. That is, the flow through the main valve and the pump is never blocked off, or stopped. In this case, the pressure port is momentarily connected directly to the tank port and inlet fluid is lost to the outlet (exhaust) side of the pump. 


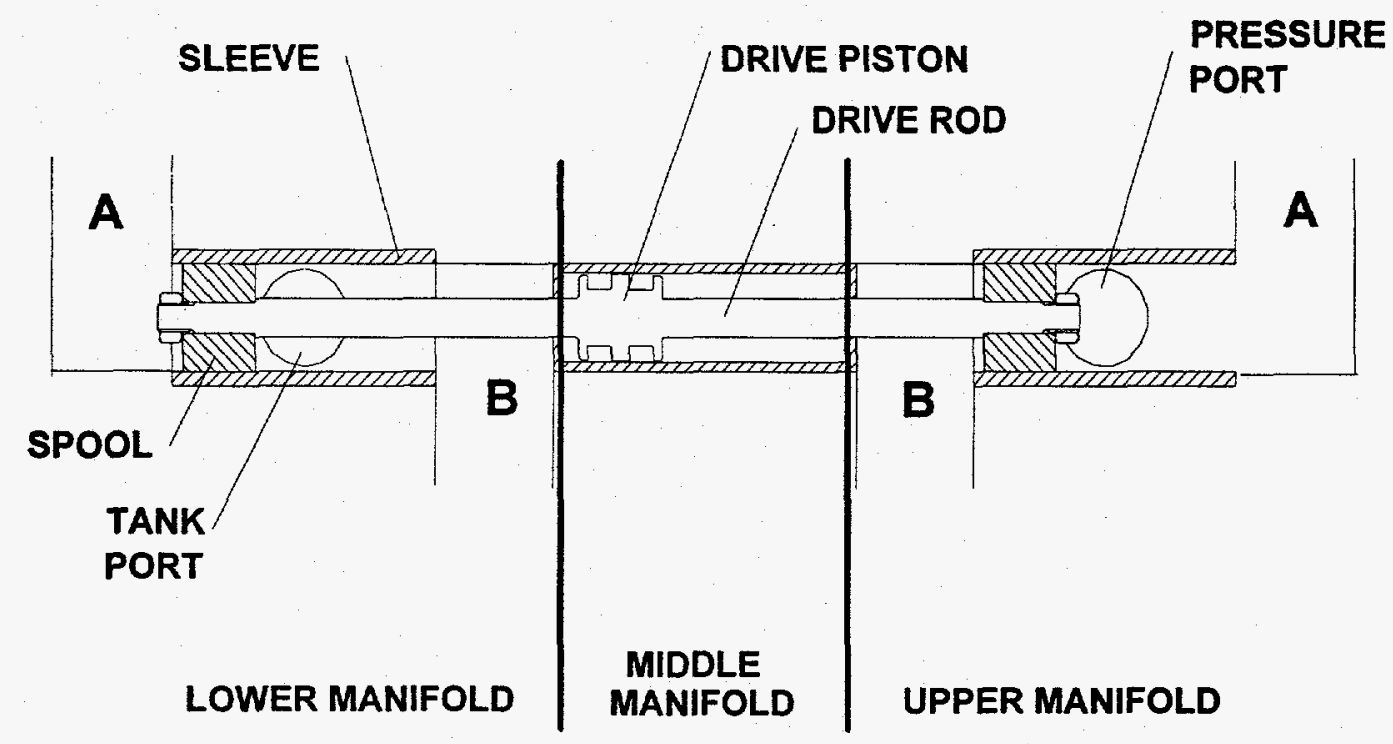

Figure 23. Four-Way Directional Main Control Valve

During DHP operation, the number of main valve position changes is the same as the stroke rate of the DHP. The time required for the main valve to change positions (shifting time) affects the smoothness of the pump operation and the DHP efficiency. The shorter the shift time the more efficient is the DHP. Calculated times for the complete travel of the main valve from pressure to port "A" to port "B" is $25 \mathrm{msec}$. The entire flow through the DHP is re-directed in about $10 \mathrm{msec}$. The main pumping assembly in the DHP hydraulically stops and changes direction in about $15 \mathrm{msec}$. The main valve speed of travel is the highest of any moving component within the DHP. The valve is hydraulically shifted via the main valve drive piston. Fluid used for shifting the main valve is valved through the pilot (trigger) valve and is part of the filtrate from the shear filter.

The valve spools and the sleeves are made of very hard materials to resist abrasion and erosion. The port sizes are of such size that the fluid velocities are high, causing the main valve and the center valve manifolds to account for over 50 percent of the hydraulic pressure losses through the DHP.

As shown in Figure 23, the main valve spans all three sections of the center valve section; the lower manifold, middle manifold, and upper manifold. The valve sleeves are located in the lower and upper manifolds. They are mechanically retained in the bores of the lower and upper manifolds with a spiral lock ring device.

\subsection{Pilot (Trigger) Valve}

The pilot (trigger) valve is also a four way directional control valve. It controls the fluid that hydraulically shifts the main control valve. The pilot valve arrangement is shown in Figure 24. The valve actuation method is a detented, spring loaded, mechanically 
initiated snap action that when triggered, shifts the pilot valve spool between one of two positions; pressure $(\mathrm{P})$ connected to port $A$ and tank $(\mathrm{T})$ connected to port $\mathrm{B}$, or pressure connected $\mathrm{B}$ and tank connected to $\mathrm{A}$. The detents are to ensure that the spool position cannot "wander", thus ensuring the logical position of both the pilot valve and the main valve. In this way it is ensured that the valve positions are bi-stable (either one position or the other) and that the DHP will not "park", but will always start under all conditions.

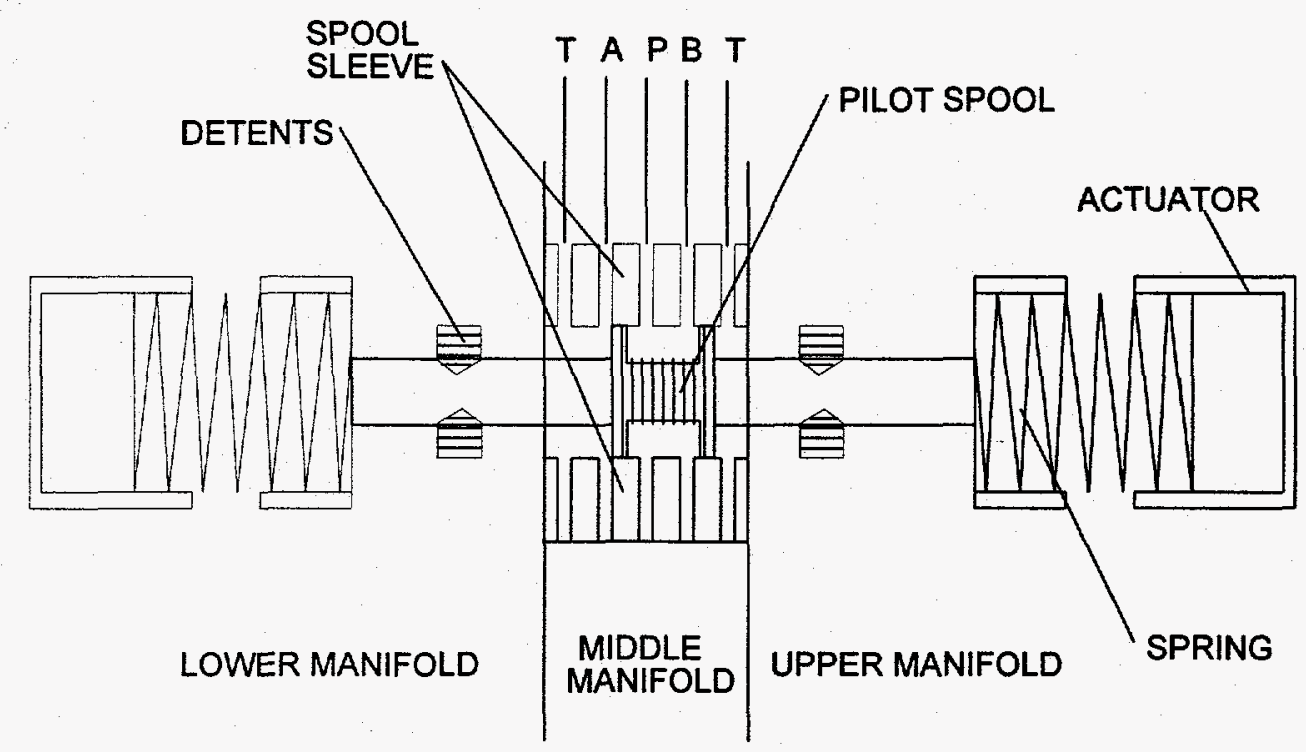

Figure 24. Trigger Valve (P open to B)

The actual valve portion of the pilot valve is located in the middle manifold, with the detents and actuators located in the lower and upper manifolds. During operation, the two interior drive pistons (as shown conceptually in Figure 3) contact the ends of the actuators and depress the springs. When the spring is compressed and the actuator sleeves bottom, the detents are released and the spring forces the spool to travel across, starting the shift of the main valve.

\subsection{By-Pass Valve}

The by-pass valve is also located in the center valve section. When in the open position, as shown in Figure 25, the inlet flow is connected to the outlet, by-passing the pumping section of the DHP. In the open position, flow may also enter the pumping section of the DHP and cause it to slowly stroke. 


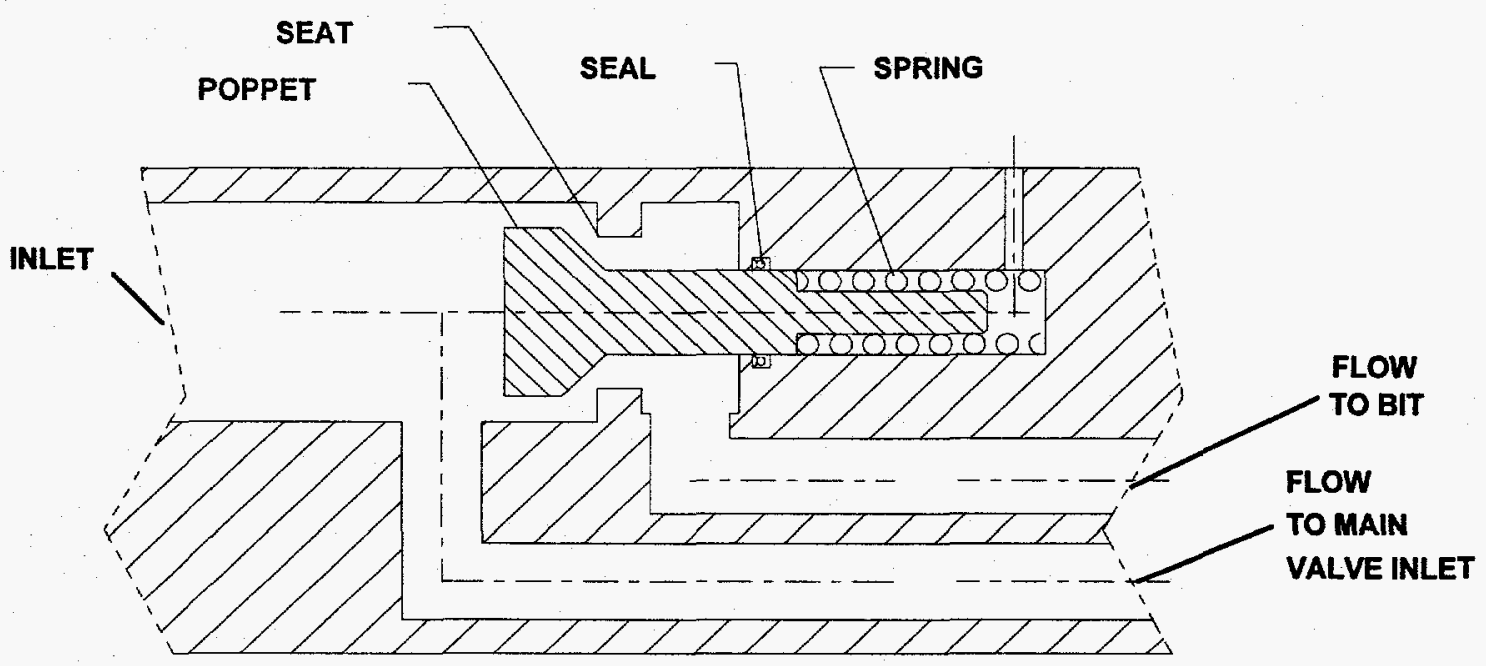

Figure 25. By-Pass Valve (open position)

The by-pass valve is flow activated. Increasing the fluid flow to the DHP about 10 percent increases the fluid drag on the valve poppet, and forces the valve poppet against the spring, allowing the valve poppet to close off against the valve seat When the bypass valve is closed, all the inlet flow to the DHP is diverted into the pumping section at the inlet to the main valve. The design includes adjustable stops to adjust the spring tension, thus allowing adjustment in closing flow rate to be made. This adjustment must be made, however, before final assembly in the DHP housing.

\subsection{Shear Filter}

Above the upper end of the pumping section is the shear filter. A portion of the inlet flow to the DHP is drawn off as filtrate through the shear filter to supply fluid to the pilot (trigger) valve for shifting the main control valve, and to supply the inlet fluid to both UHP cylinders. All the UHP fluid is from the filtrate through the shear filter.

The shear filter itself is a screen tightly stretched over a slotted liner. It is shown schematically in Figure 26. The slots collect the filtrate after passing through the screen. Material screened is removed from the screen surface by the flow passing over the screen. Tests with an 80 mesh screen showed that approximately 9 percent of the inlet flow could be drawn off as filtrate when the inlet flow contained 5 pounds of LCM (lost circulation material) per barrel (42 gallons). 


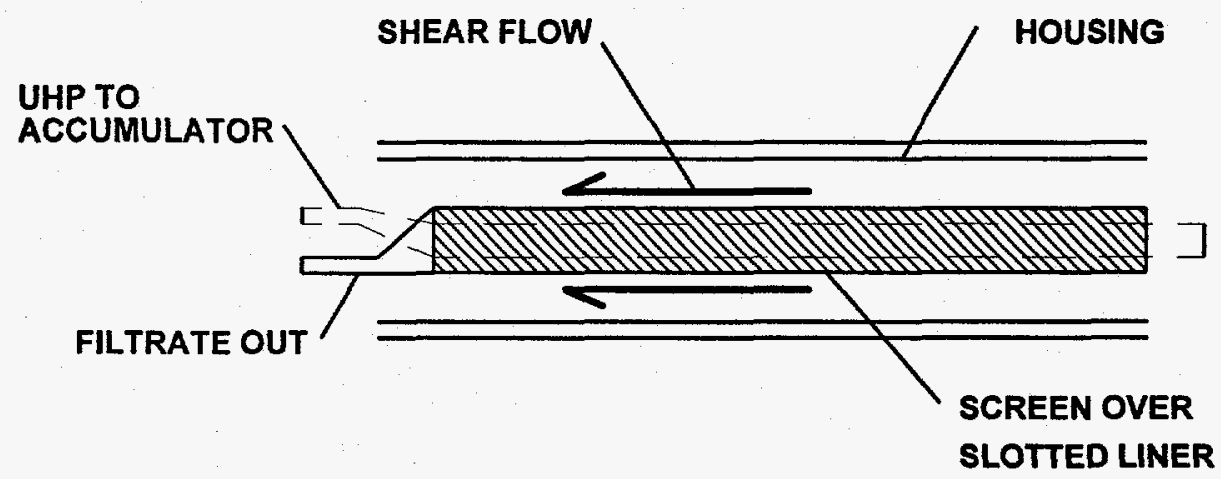

Figure 26. Shear Filter

\subsection{UHP Attenuator}

The UHP attenuator (accumulator) is located upstream of the shear filter and provides flow conditioning for the flow over the shear filter. Its two main purposes are to provide flow to the UHP nozzle when the DHP shifts direction and is not pumping, and to minimize the UHP pressure variation in those components external to the UHP check valves to minimize UHP fatigue problems. It is a dead volume attenuator with an enclosed volume of 2.5 gallons. It provides a volume of UHP fluid large enough that the compression and expansion of the fluid itself provides a sufficient volume of fluid to the UHP jet to maintain the flow of the jet within 10 percent of rated pressure $(30,000 \mathrm{psi})$ during the time when the DHP is not pumping. The upper end of the attenuator shoulders against a shoulder within the pump housing as indicated in Figure 27.

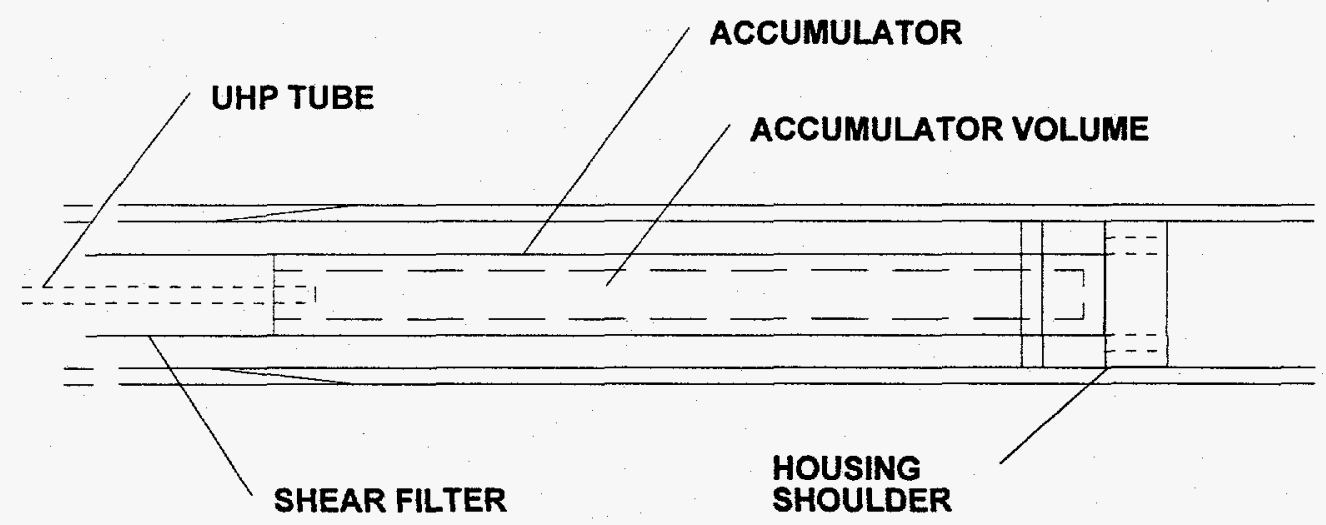

Figure 27. UHP Accumulator

\subsection{DHP Housing}

The UHP inner conduit, pumping section, shear filter, and UHP attenuator all slide into the housing from the bit sub end as a single assembled unit. The housing is shown in 
Figure 28 with the bit and bit sub attached and may be compared to Figure 4 for the 7-5/8 inch DHP.

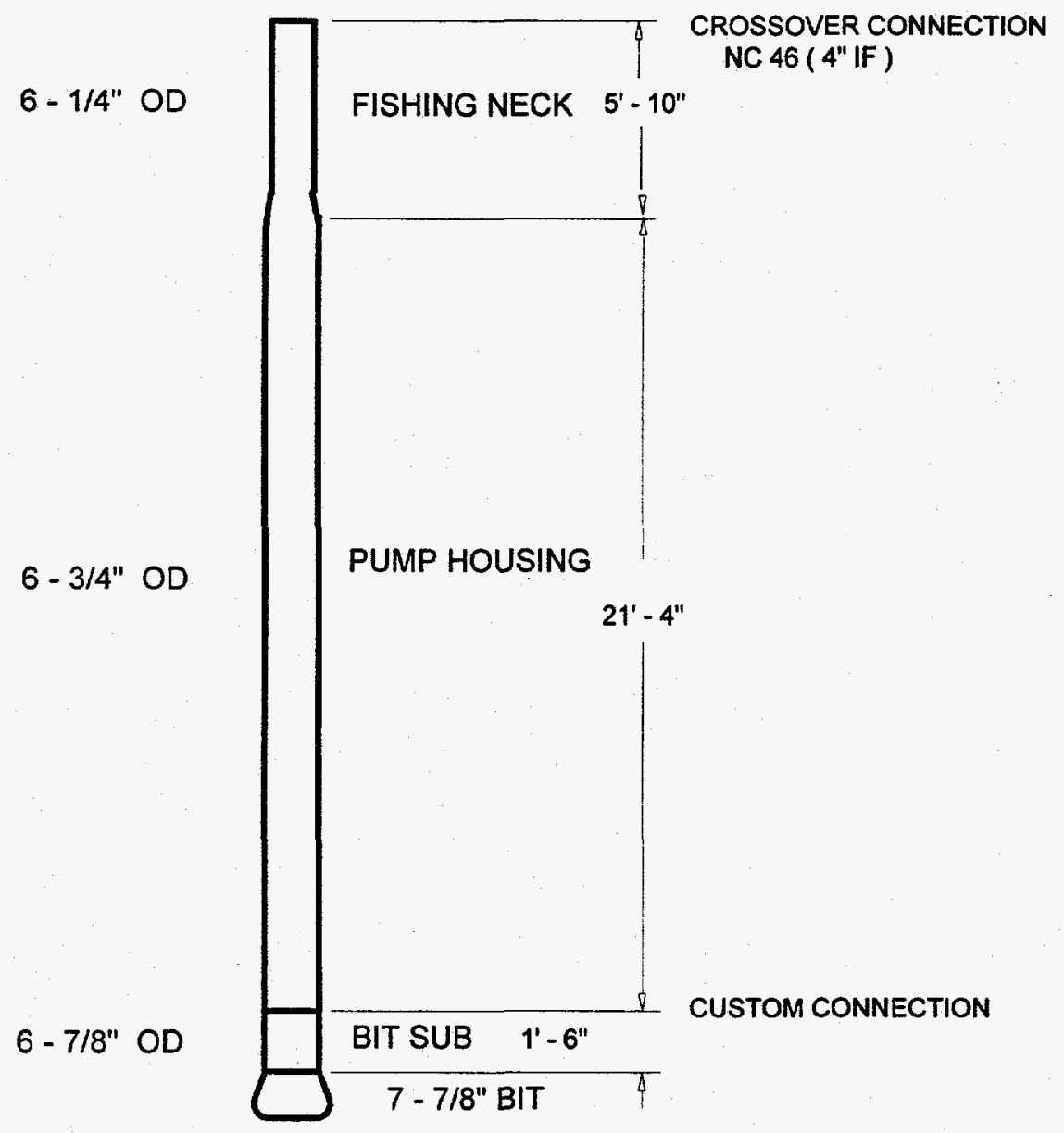

Figure 28. Field Experiment Configuration of 6-3/4" DHP Assembly

The connection for the bit sub is a custom API connection that is stronger and has a higher bending strength ratio than the standard NC46 (4" IF) connection at the upper end. The housing wall thickness is $3 / 4$ inch. Bending stiffness of the housing closely matches a 6-1/4 inch OD standard drill collar. As shown, the 5' - 10" of the housing is a 6-1/4" OD fishing neck to allow use of slimhole or semi full strength overshots in a 7-7/8 inch diameter hole, such as several of the Bowen Overshots - Series 150. For washing over just the DHP, a Tri-State Oil Tool washover pipe, 7-5/8 TSWP would be appropriate.

\subsection{Bit Sub}

The UHP fluid is delivered through the bit sub via the UHP inner conduit (IC) from the lower end of the pumping section. The lower end of the UHP IC is a female stab connection for the UHP tubing normally installed on the drill bit. 
Inside the bit sub is the super bolt arrangement that is used to pre-load the pumping section, the shear filter, and the UHP attenuator in the housing under a compressive load. The housing is then put in tension. It is this pre-load that holds the pumping section, shear filter and UHP attenuator assembly together inside the housing.

\subsection{Design Performance Projections}

Shown in Table 16 are projections of the expected performance of the 6-3/4 inch DHP at a hole depth of 10,000 feet with typical drill pipe and drill collar sizes for drilling 7-7/8 inch diameter holes. There are six conditions shown; three different mud weights, and two flow rates for each mud weight. The second column of projections corresponds to the design point performance specifications as given in Table 14 (Section 3). 


\section{Table 16. 6-3/4 Inch DHP Performance Projections}

DRILL STRING

Hole Diameter

Hole Depth

Pipe O.D.

Pipe I.D.

Collar O.D.

Collar I.D.

Length Collars

Total WOB

\section{SURFACE PUMPING}

Mud Weight

Circulation Rate

Fullerton Multiplier

Ann Velocity DP

Ann Velocity Collars

Ann Velocity DHP

Drill String Losses

Bit Pressure Drop

Surface Pressure

Pump Horsepower

DHP PERFORMANCE

DHP Total Press Diff

DHP Pressure Loss

Net DHP Drive Press

DHP Drive Flow

Net In Horsepower

Area Ratio

LP Output Flow

DHP Rated Flow

DHP Rated Pressure

UHP Horsepower

DHP Stroke Rate

UHP Seal PV

UHP Nozzle Dia.

DHP Efficiency in.

ft.

in.

in.

in.

in.

ft.

lb.

$$
\begin{array}{r}
7.875 \\
10000 \\
4.5 \\
3.83 \\
6.25 \\
2.25 \\
744 \\
47162
\end{array}
$$

\section{ppg}

gpm

FN

fumin

$\mathrm{ft} / \mathrm{min}$

ft/min

psi

psi

psi

hhp

psi

psi

psi

gpm

hhp

-

gpm

gpm

psi

hhp

stk/min

psi-fpm

in.

$\%$

9.5

268

1.00

157

286

399

787

450

3694

578

2457

337

2120

268

389

13.82

251

18.0

30088

288

109

$3.67 \mathrm{E}+06$

0.063

74

7.875
10000
4.5
3.83
6.25
2.25
744
47162

7.875

10000

4.5

3.83

6.25

2.25

744

45899
9.5

295

1.10

173

315

439

935

450

3897

671

2512

400

2112

295

437

13.82

276

20.0

30038

316

120

4.03E+06

0.066

72

11

232

1.00

136

248

346

696

450

3568

483

2421
300

2122

232

332

13.82

217

15.6

30072

249

94

$3.18 E+06$

0.060

75

7.875
10000
4.5
3.83
6.25
2.25
744
45899

11

255

1.10

150

272

380

825

450

3747

558

2472

354

2118

255

372

13.82

239

17.2

30071

273

104

3.49E+06

0.063

74
7.875

10000

4.5

3.83

6.25

2.25

744

44636

7.875

10000

4.5

3.83

6.25

2.25

744

44636

$\begin{array}{rr}12.5 & 12.5 \\ 204 & 225 \\ 1.00 & 1.10 \\ 120 & 132 \\ 218 & 240 \\ 304 & 335 \\ 623 & 743 \\ 450 & 450 \\ 3466 & 3633 \\ 413 & 477\end{array}$

$\begin{array}{rr}2393 & 2439 \\ 269 & 320 \\ 2124 & 2119\end{array}$

$204 \quad 225$

$288 \quad 324$

$13.82 \quad 13.82$

$191 \quad 211$

$13.7 \quad 15.1$

$30071 \quad 30056$

$219 \quad 241$

$83 \quad 91$

2.79E+06 3.08E+06

0.058

76

0.061

74 


\section{DHP Initial Laboratory Test}

Parts for the 6-3/4 inch DHP were fabricated and assembled for testing in the laboratory. The objective of the initial test was to establish that the DHP functioned, to confirm theoretical design performance and to begin to identify engineering design oversights and weaknesses. The initial test run was planned for 12 hours after which it was to be disassembled and inspected. The 12 hour run occurred in two segments, a 5.5 hour run after which the pump was dismounted from the test stand and set aside for four days because of laboratory scheduling, then remounted and run an additional 6.5 hours.

\subsection{Laboratory Test Arrangement}

The test arrangement in the laboratory is shown in Figure 29. The DHP was mounted on the same test bench as used for testing the 7-5/8 inch DHP. Laboratory testing of the DHP is normally conducted with the pump in the horizontal position.

For the first test, a plug was installed in place of the by-pass valve. The laboratory pumping system was started with the system flow by-pass valve (FV) open to tank 2 (T2). The system flow by-pass valve (FV) was then closed directing flow to the DHP. The DHP started without incident and run continuously for the first 5.5 hours. The same procedure was used for the additional 6.5 hours of the test run.

Pressure gages were installed at the inlet (G1), at the outlet (G2) ahead of a back-pressure orifice, and on the UHP output (G3) ahead of the UHP nozzle to monitor performance of the DHP. During part of the run, electronic pressure transducers were installed at these locations to record pressure signals with the laboratory digital data acquisition system. The pressure gages were calibrated with a dead weight calibration apparatus. The electronic pressure transducers were then calibrated against calibrated pressure gages. Flow rate was determined by a stroke counter (G5) on MP1 and an rpm meter (G6) on MP2. Temperature was monitored with a gage (G4) mounted in the laboratory plumbing between mud tank 1 (T1) and the inlet to the mud pumps. The stroking of the DHP is audible and the stroke rate was determined by counting against a stop watch. 


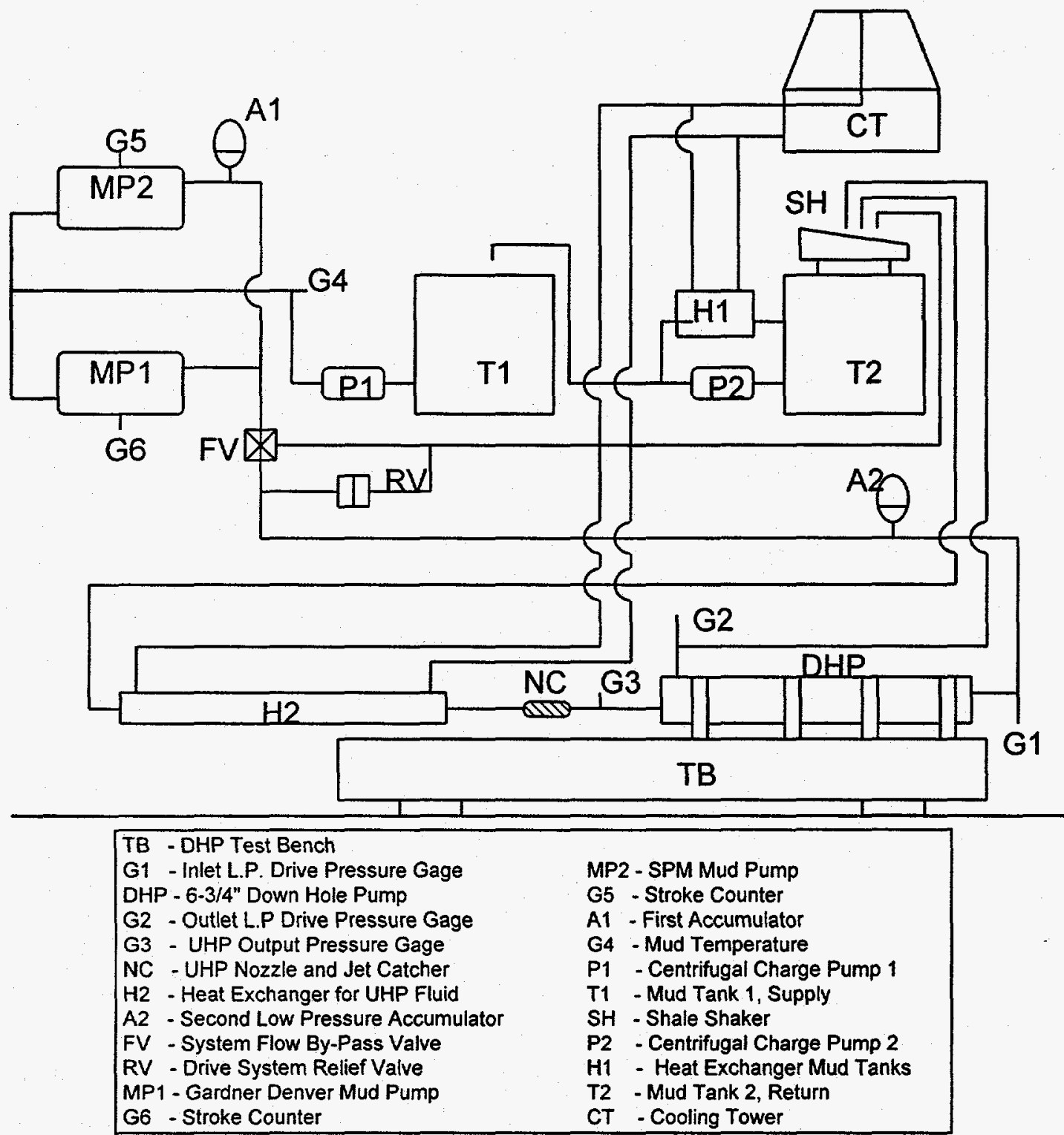

Figure 29. Laboratory Test Arrangement for Testing DHP 


\subsection{Run Parameters}

The run parameters, as determined during the initial test runs of 5.5 and 6.5 hours, are listed in Table 17. The UHP output nozzle was a 0.064 inch diameter FlowDril nozzle.

\section{Table 17. Laboratory First Test Run Parameters}

$\begin{array}{ll}\text { Max. UHP Output Pressure } & 28,000-31,000 \mathrm{psi} \\ \text { Inlet Drive Pressure } & 2870 \mathrm{psi} \\ \text { Outlet Pressure } & 450 \mathrm{psi} \\ \text { Inlet Drive Flow Rate } & 270-275 \mathrm{gpm} \\ \text { Mud Weight } & 8.7 \mathrm{ppg} \\ \text { Mud Temperature } & 120^{\circ} \mathrm{F}\end{array}$

\subsection{Character of Input and Output Pressures}

During part of the test run, pressure signals were monitored and recorded via the laboratory data acquisition system at the DHP low pressure driving flow inlet (G1), at the DHP outlet (G2) just upstream of the back-pressure orifice (exhaust from the pump), and at the UHP outlet just upstream of the UHP nozzle (G3). The pressure transducers had a response time of $1 \mathrm{msec}$. For the pressure signals shown in the following figures, the sample rate per signal was 1,000 samples per second.

A two second long record of the recorded pressure at the inlet is shown in Figure 30. Four shifts of the main valve were captured in the recorded pressure signal.

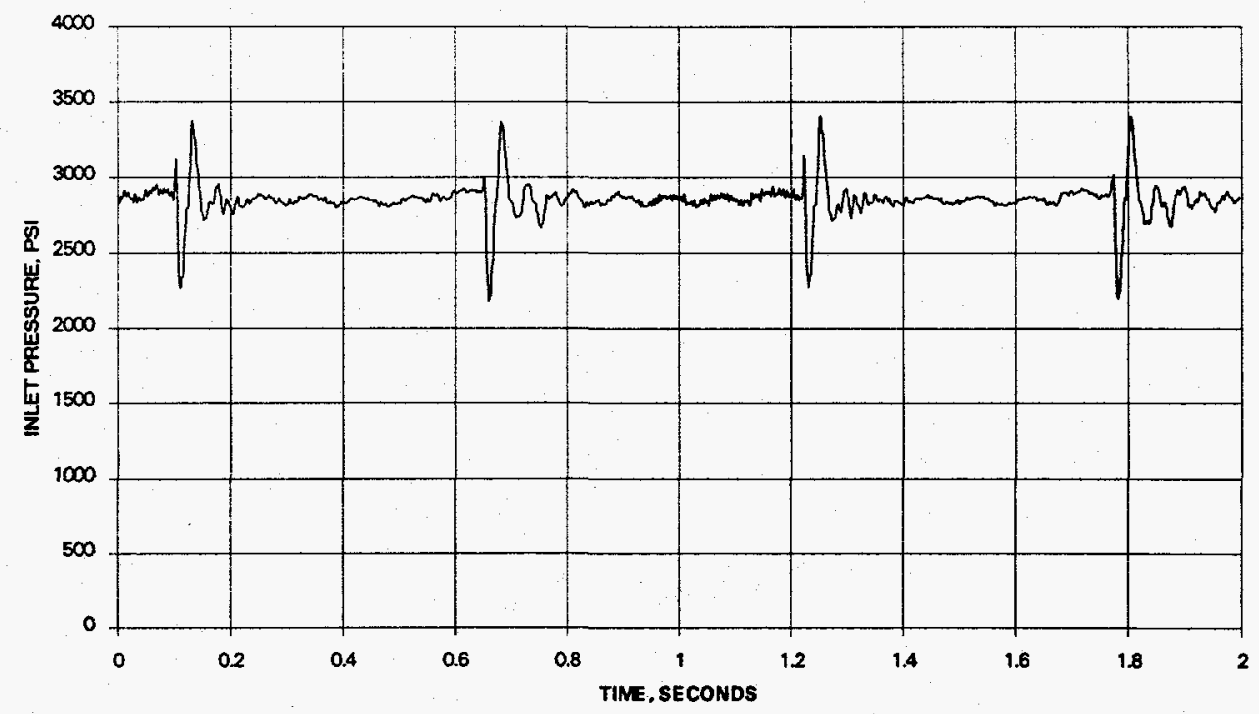

Figure 30. Inlet Low Pressure Flow Pressure Signal 
Each shift of the main valve corresponds to a change in direction of the drive piston/plunger assembly within the DHP. Time between stroke changes shown was approximately $545 \mathrm{msec}$, corresponding to a stroke rate of $110 \mathrm{spm}$. The inlet pressure signal is characterized by an approximate 100 to 200 psi sharp rise, followed by a dip of about $620 \mathrm{psi}$, followed by a rise of about $520 \mathrm{psi}$. This pressure would propagate uphole toward the surface in a down hole configuration. As it would propagate toward the surface, it would be damped by the mud viscosity, but as observed with the 7-5/8 inch DHP, would be evident on the surface.

The low pressure flow pressure signal at the outlet of the DHP, G2, is shown in Figure 31. It was recorded at the same time as the inlet pressure signal shown in Figure 30. In the down hole configuration, this is the pressure signal just before the low pressure nozzles in the drill bit. Corresponding to the pressure dip apparent in the inlet pressure signal, there is a sharp pressure rise of about 1,200 to 1,400 psi in the low pressure flow outlet. This occurs because of the blowdown effect from a large accumulated volume upstream (the supply line) to a smaller volume (in the bit sub) with a fixed outlet orifice as the main valve shifts across center and momentarily connects the inlet directly to the outlet of the DHP through the main shifting valve.

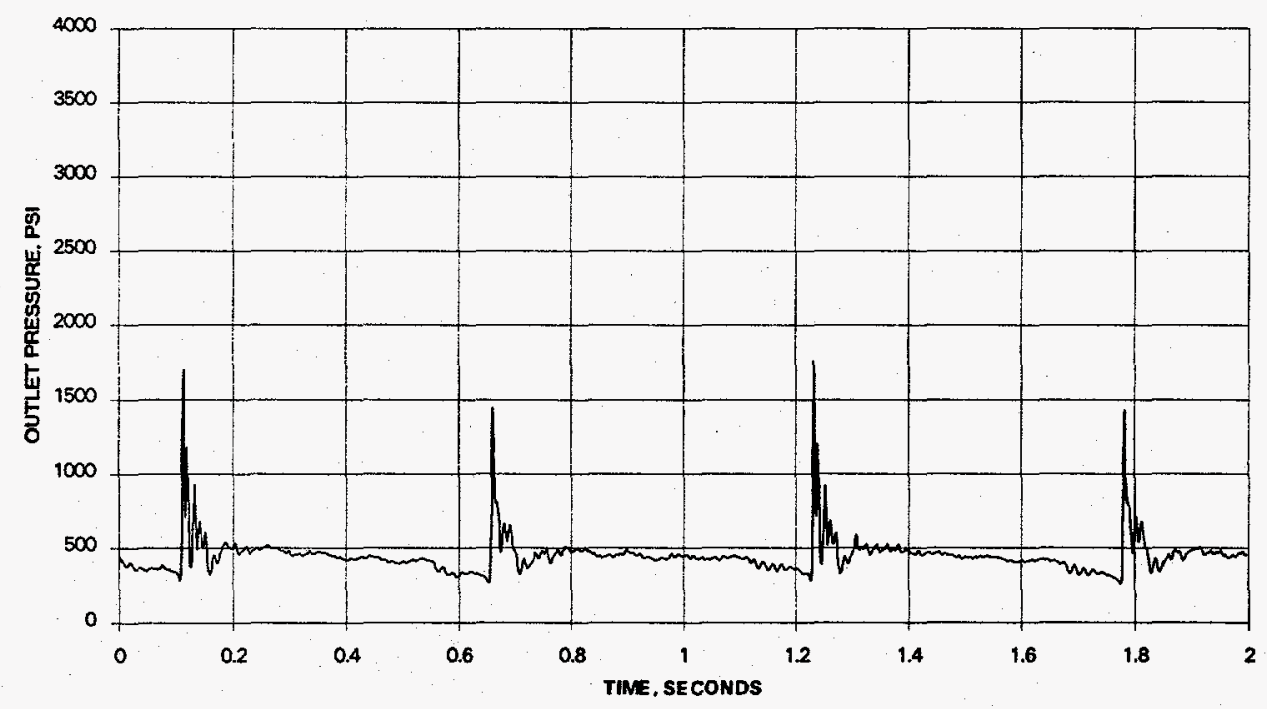

Figure 31. Outlet Pressure Signal

The difference between inlet pressure and outlet (exhaust) pressure is the differential pressure across the DHP that drives it. This pressure signal is shown in Figure 32. Included in this pressure are the net drive pressure across the low pressure drive pistons that drive the UHP plungers and the pressure loss that occurs from the fluid flowing through the valves and flow passages of the pump. With the exception of the rapid rise in pressure from the 1,700 to $2,000 \mathrm{psi}$ dip, the differential pressure signal shown is typical 


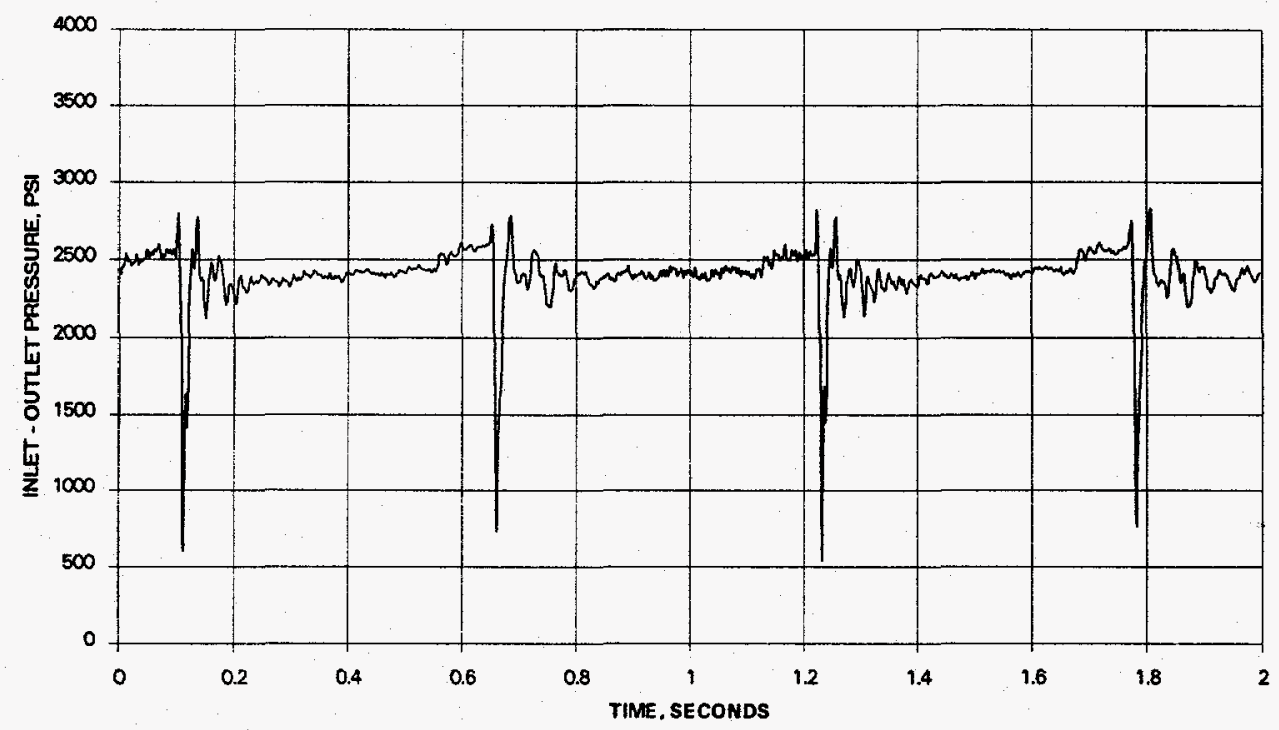

Figure 32. Inlet Minus Outlet Pressure Signal

of hydraulically driven intensifier type high pressure pumps. The large pressure dip is due to the necessity to re-pressurize and re-compress the inlet UHP fluid in the UHP cylinder before it is pumped out of the UHP cylinder through the outlet check valve. With the exception of the rapid pressure rise after the characteristic dip, it matches theoretically calculated differential pressure across the pump very well. Theoretical design calculations had estimated the characteristic pressure dip to be between 1,700 and $1,800 \mathrm{psi}$. The rapid pressure rise after the dip is thought to be a combination of a negative wave reflection of the pressure dip from the accumulator, $\mathrm{A} 2$, in the laboratory supply system. 


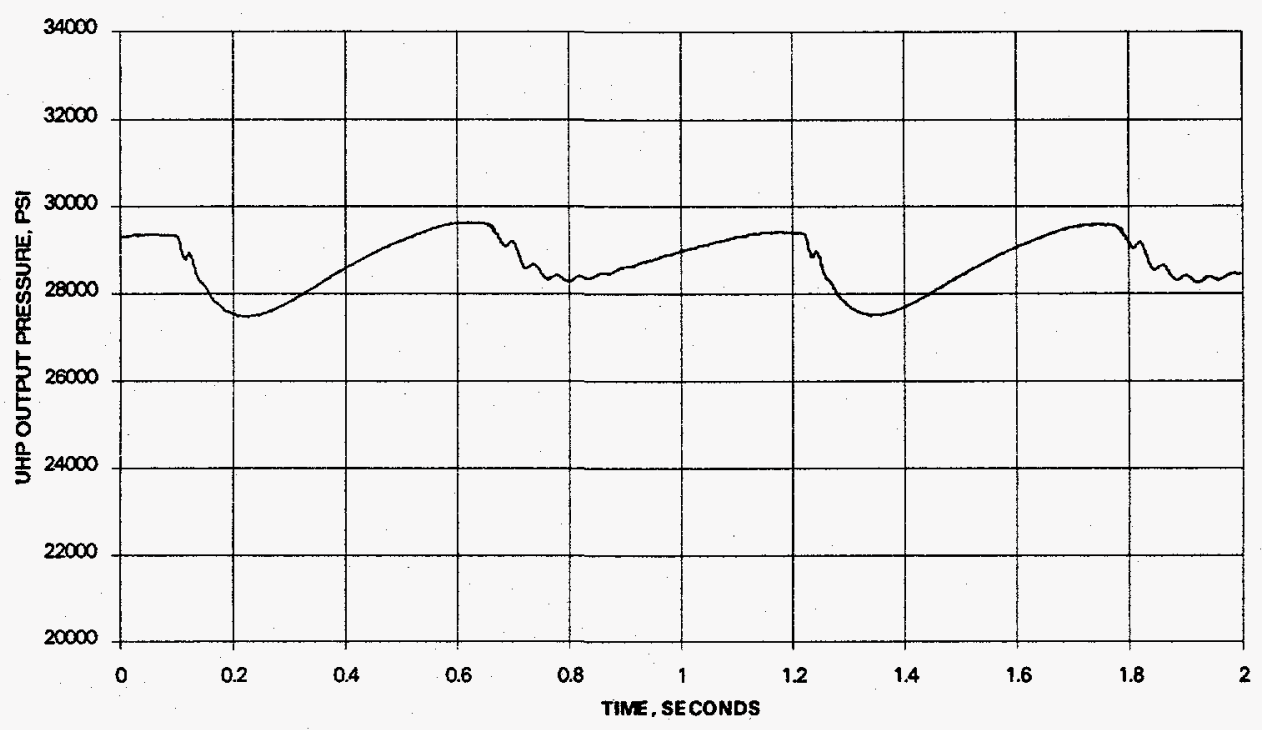

Figure 33. UHP Output Pressure Signal

The corresponding UHP output pressure signal is shown in Figure 33. The peak UHP output pressure shown is 29,660 psi. As can be seen, the UHP output pressure is not constant, but varies over time, fluctuating between a minimum of $27,450 \mathrm{psi}$ and a maximum of 29,660 psi. The character of the recorded signal is slightly different than would be expected from the theoretical design performance calculations in that it is much smoother. It was expected that the UHP pressure signal would exhibit sharper changes in pressure localized at the main valve shift times, similar to the low pressure differential pressure signal shown in Figure 32.

The average UHP output pressure calculated from the recorded pressure signal is 28,720 psi; , or 0.968 of the peak (rated) UHP output pressure. Design of the UHP accumulator at full output flow rate called for the variation between maximum and minimum UHP output pressure at a rated output (maximum value) of 30,000 psi to be no more than 3,000 psi. It may be noted that adjacent peaks are not the same, but every other one is the same. This occurs because the UHP accumulator is located at the upper end of the pump and transmission losses from the upper end are larger than from the lower end where the outlet is located. Consequently, the higher UHP pressure peaks correspond to the pump stroking from the upper end to the lower end and pumping UHP fluid out of the lower end UHP cylinder.

\subsection{Stroke Rate and UHP Output Flow Rate}

During the laboratory run, the stroke rate of the DHP was counted against a stop watch. At an input flow rate of $270 \mathrm{gpm}$, the stroke rate was counted as 110 strokes per minute (spm), or 0.93 of the ideal stroke rate. From the displacement relationship, at this input flow rate, the ideal stroke rate would be $118 \mathrm{spm}$. The difference, $8 \mathrm{spm}$, is 
representative of volume loss as the main valve goes across center and UHP compressibility losses. It also indicates that almost the entire stroke length (displacement) available mechanically within the DHP is being utilized, i.e.; the DHP is not short-stroking.

Rated UHP output flow (maximum achieved during latter part of stroke) was calculated using the measured pressure and known nozzle discharge coefficient as $18.0 \mathrm{gpm}$. As UHP pressure varies in time, so does UHP output flow rate according to flow through a fixed size orifice. The average UHP output flow was $17.3 \mathrm{gpm}$, or 0.98 of the peak flow. At $120 \mathrm{spm}$, the rated UHP output flow was estimated to be $19.6 \mathrm{gpm}$. This agrees with the performance specification at $120 \mathrm{spm}$ within two percent.

\subsection{Efficiency and Flow Losses}

Measured differential pressure was 2,402 from the recorded pressure data. Drive pressure is estimated from calculations to be about $2,100 \mathrm{psi}$ at an inlet flow of $270 \mathrm{gpm}$ and an UHP output pressure of 30,000 psi. Flow losses are then 2,402-2,100, or about 302 psi. When adjusted to a stroke rate of $120 \mathrm{spm}$, and a mud weight of $9.5 \mathrm{ppg}$, the flow losses were estimated to be 384 psi. This is about 4 percent better than the desired 400 psi limit specified under the performance specifications.

During the design phase, the average efficiency had been estimated to be 72 percent. With the pressure data obtained during the laboratory test run, an experimentally determined estimate of average DHP efficiency was calculated as 77 percent. This agrees almost exactly with using average values of pressure and flow rate. Average inlet hydraulic horsepower (hhp) was $450 \mathrm{hhp}$. Average outlet (exhaust) horsepower was 65 hhp. Average net input horsepower to produce the UHP output horsepower was then 385 hhp. Average output UHP horsepower was $296 \mathrm{hhp}$. The average UHP output hhp to the average net input horsepower gives the average DHP efficiency as 77 percent. When this latter estimate is adjusted to $120 \mathrm{spm}$ and $9.5 \mathrm{ppg}$ mud weight, the efficiency is 75 percent.

\subsection{Post Laboratory Test Run Inspection}

After the 12-hour laboratory test run was concluded, the DHP was dismounted from the test stand and stripped down for inspection. During the inspection, all components of the DHP were visually examined in detail. In some cases, measurements to determine wear were performed. Components with potential problems were identified and the observations recorded. Particular attention was focused on the critical components of the main shifting valve; the pilot valve; the new concept connecting tube; the UHP cylinder, plunger and dynamic seals; and all dynamic seals. In each case a recommended course of action was identified. 
Main Valve

The following observations were made regarding the main shifting valve:

- Main valve drive rod: no visible wear.

- Main valve drive rod seals: no measurable wear.

- Main valve spools: $0.0005^{\prime \prime}-0.001$ " wear, but within allowed limit of 0.004 " .

- Main valve sleeves did not show any wear.

Proposed action would be to continue observation over a longer interval.

Pilot (Trigger) Valve

The following observation was made regarding the trigger valve:

- Trigger valve spool and housing: no measurable wear.

- Trigger valve detents: no measurable wear.

- Trigger valve springs: spring ends fatigued and broke on both springs.

This came about because the amount of spring compression was too large, causing too high a stress for the material used for the spring. Proposed action would be to use a spring with a high yield strength.

\section{Connecting Tubes}

Observations regarding the connecting tube design new to this pump include:

- Connecting tube seals: look excellent, no wear, no fretting, both surfaces good.

- Connecting tube retainer clips: look good, no fretting or yielding, easy to assemble/disassemble.

- Connecting tube bolts: all bolts retained pre-load torque.

- Middle connecting tube: longitudinal scratches from center manifold.

The scratches appeared to occur as a result of damaged seals on drive pistons 2 and 4 . Proposed action would be to repair the surface of the connecting tube and monitor this condition to determine if this problem is linked to damaged seals on pistons.

\section{UHP Cylinder/plungers/dynamic seals}

The observations regarding the UHP components were:

- UHP dynamic seals: OD erosion on extrusion hoop, minor ID extrusion, OD and ID erosion on backup ring, both UHP ends.

- UHP Plungers: look good, no spalls or material pickup.

- UHP Cylinders: Erosion due dynamic seal OD leakage.

The damage to the cylinders was the result of a failing UHP dynamic seal. The UHP dynamic seal is a critical component required for a successful DHP and has been, and will continue to be, an area for continual improvement. Several alternative designs are under consideration. Proposed action would be to initiate an alternative design that incorporates a tighter backup ring and a shorter seal to increase the load and contact stress on the extrusion hoop, then re-evaluate. 
Drive Pistons

Observations regarding the new seal arrangement for the drive pistons included:

- Drive pistons 2 and 4: dynamic seal had o-ring's blown out and the seals had blown over retaining lip, and were leaking.

Proposed action would be to change the seal to a deeper polypak seal and modify pistons to have a larger retention lip, then re-evaluate.

Qther

Other observations included

- Centralizers: peeled off on assembly, a result of poor bonding process.

- Upper manifold: galling on either assembly or disassembly, appears results of centralizers peeling off.

Proposed action would be to repair the upper fluid manifold and improve the centralizer bonding process by building a gluing jig, and defining a better procedure for surface preparation.

\subsection{Conclusions after First Laboratory Test Run}

Conclusions as a result of the first 12-hour laboratory test run of the 6-3/4 inch DHP are as follows:

- The 6-3/4 DHP can be fabricated and can be assembled.

- The pump started without incident and ran very well during the 12 hours of test.

- Pressure signals recorded during the test run indicated that the pump behaved and performed as expected based on design and performance calculations.

- Flow losses through the pump were less than expected and the DHP efficiency was slightly better than originally estimated.

- All measured and calculated performance parameters were within 2 to 4 percent of design performance specifications.

- Inspection after the conclusion of the 12-hour test run identified some items that require further action. 


\section{Conclusions and Recommendations}

\subsection{Conclusions}

The conclusions of this marketing analysis are summarized below:

- DHP Market Size - Estimated for all drilling to be $\$ 207$ million annually, and for gas drilling to be $\$ 74$ million annually, assuming a DHP cost of $\$ 250 / \mathrm{DHP}$-hour and an ROP improvement ratio of 2.0 .

- Industry Savings from DHP Use - Estimated for all drilling (oil, gas, and dry) as $\$ 173$ million annually, and for gas drilling as $\$ 42$ million annually. This represents approximately a 5.5 percent savings in the cost of all drilling, or 10.9 percent of the time variable cost of all drilling whether or not affected by the DHP, for wells drilled over 7,500 feet in depth. For gas drilling, the corresponding savings percentages are about 3.5 percent, and 7 percent for deeper gas wells.

- Market Locations - Of the ten regions examined for U.S. land, vertical rotary drilling, the three regions with the largest total market potential in terms of revenue for all drilling, assuming a cost of \$250/DHP-hour and an ROP ratio of 2.0, are Texas Railroad District 3 (\$39.2 million), Oklahoma ( $\$ 31.7$ million), and Texas Railroad District 6 ( $\$ 23.3$ million). For gas drilling, the largest market potential is Texas Railroad District 6 (\$18.2 million), Oklahoma (\$18.1 million), and Wyoming (\$13.5 million).

- DHP Sizes - The most significant market is 7-7/8 inch, followed by $8-1 / 2$ to $8-3 / 4$ inch, and then $9-1 / 2$ to $9-7 / 8$ inch hole diameters. Approximately 90 percent of the DHP market, either all drilling or gas drilling, occurs in these three size ranges. The predominant size for both all drilling and gas drilling is 7-7/8 inch hole size.

- Well Depth Range - Sixty-four percent of the market occurs for wells between 7,500 and 12,500 in depth. Forty percent is for wells in the range of 10,000 to 12,500 feet in depth. Only three percent of the DHP market occurs for wells deeper than 15,000 feet.

- Slim-Hole Drilling - No immediate DHP market impact is foreseen from horizontal, slimhole, re-entry, or coiled tubing drilling technologies. The slim-hole drilling market for the DHP, in sizes 6 inch and smaller, is less than ten percent of the market share for 7-7/8 inch, and is not a significant market for the DHP in the near future. 
Design point specifications to have a successful DHP were concluded to be:

$\begin{array}{lr}\text { UHP Pressure } & 30,000 \mathrm{psi} \\ \text { UHP Flow } & 20 \mathrm{gpm} \\ \text { Drive Flow } & 295 \mathrm{gpm} \\ \text { Pressure Loss } & 400 \mathrm{psi} \\ \text { Max. Stroke Rate } & 120 \mathrm{spm} \\ \text { Mud Weight } & 9.5 \mathrm{ppg} \\ \text { Efficiency } & 70 \%\end{array}$

It was also specified to include a fishing neck on the upper end of the housing to accommodate an overshot.

The detailed design was successfully completed such that the DHP was successfully fabricated, successfully assembled, and successfully started and operated in a 12-hour laboratory test run. Conclusions as a result of the first 12-hour laboratory test run of the 6-3/4 inch DHP were as follows:

- The pump started without incident and ran very well during the 12 hours of test.

- Pressure signals recorded during the test run indicated that the pump behaved and performed as expected based on design and performance calculations.

- Flow losses through the pump were less than expected and the DHP efficiency was slightly better than originally estimated.

- All measured and calculated performance parameters were within 2 to 4 percent of design performance specifications.

- Inspection after the conclusion of the 12-hour test run identified some items that require further action.

As concluded from data obtained from the initial 12-hour laboratory test run, the DHP design was successful in that all the measured and calculated performance parameters were within acceptable range of the specified performance in terms efficiency, input pressure and flow rates, and output pressures and flow rates. It was also apparent that deficiencies in the design of several of the components exist and will require further development to achieve a DHP with acceptable life.

\subsection{Recommendations}

The design concepts appear to be valid and hold the promise of being able to achieve desired pump life with modifications in the details of the design of various components. As a result of the first laboratory test, problems with the detailed design of several components were identified and proposed actions were identified. It is anticipated that with further design and laboratory test iterations, additional design improvements required to achieve an acceptable DHP life will be identified, evaluated and addressed. Once acceptable performance and reliability is established through laboratory testing and 
design modification, the DHP should be tested down hole in the field. It is anticipated that four to six down hole field experiments would be required to properly evaluate the developmental status and potential of the DHP for jet-assist drilling.

It is recommended that the iterative approach of laboratory test, design modification, and field experimentation be followed. It is recommended that this project continue into Phase II - Laboratory Testing, Design Modifications, and Field Testing. 


\section{References}

Allen, J. H., "How to Relate Bit Weight and Rotary Speed to Bit Hydraulic Horsepower," Drilling - DCW, 1975.

API RP 7G, "Drill Stem Design and Operating Limits," American Petroleum Institute, Dallas TX, May 28, 1984.

API Specification 7, "Specification for Rotary Drilling Equipment," American Petroleum Institute, Dallas, TX, May 1, 1985.

Butler, T., Fontana, P. and Otta, R., "A Method for Combined Jet and Mechanical Drilling," 65th Annual Technical Conference and Exhibition, SPE/LADC No. 20460, New Orleans, LA, September 23-26, 1990.

Cure, M. and Fontana, P., "Jet-Assisted Drilling Nears Commercial Use," Oil and Gas Journal, March 11, 1991.

Doremus, D., "Coiled Tubing Drilling: Update '94," 2nd International Conference and Exhibition on Coiled Tubing Technology, World Oil, Houston, Texas, March 2831, 1994.

Fair, J. C., "Development of High-Pressure Abrasive-Jet Drilling," Journal of Petroleum Technology, August, 1981.

JPT, Journal of Petroleum Technology, "Slim Holes, Fat Savings," September, 1993.

Maurer, W. C., Heihecker, J. K., and Love, W. W., "High-Pressure Drilling," Journal of Petroleum Technology, July, 1973.

Miller, J. E., "Modify Mud Pump Operation to Reduce Maintenance," World Oil, July, 1993.

Nathenson, M., and Guffanti, M., "Geothermal Gradients in the Conterminous United States," Journal of Geophysical Research, v. 93, pp. 6437-6450, 1988.

Shook, R. A., Dech, J. A., Maurer, W. C., Matson, R. P., Mueller, D. T., Hopmann, M., Boonen, P., and Reeves, S. R., "Slim-Hole Drilling and Completion Barrier," Topical Report GRI-95/0182, Gas Research Institute, May, 1995.

Veenhuizen, S. D., Butler, T. J., and Kelley, D. P., "Jet-Assisted Mechanical Drilling of Oil and Gas Wells," Proceedings of the 7th American Water Jet Conference, Seattle, Washington, August 28-31, 1993.

Veenhuizen, S. D. and Cheung, J. B., "Waterjet Drilling of Small Diameter Holes," Fourth International Symposium on Jet Cutting Technology, BHRA, Canterbury, England, April 12-14, 1978.

Veenhuizen, S. D. and O'Connor, J. M., "Market Analysis: Downhole Pump for JetAssisted Drilling," Topical Report GRI-94/0176, Gas Research Institute, April, 1995. 